\title{
I. DIE PATRIOTEN
}

\section{Die Anfänge}

Am Nachmittag des 15. Januar 1790 fand sich im Haus des Straßburger Commissaire de Guerre Barbier de Tinan eine Gruppe von gut vierzig Männern ein. Bereits im Vorfeld des Treffens hatten die Versammelten ihre Absicht, eine Gesellschaft nach dem Vorbild der Pariser Société de la Révolution ${ }^{\prime} \mathrm{zu}$ gründen, in einer Acte d'Union festgehalten. Der Gastgeber, ein Jurist und vor der Revolution durch seine Aktivitäten als Freimaurer bekannt ${ }^{2}$, hatte sich auf das Treffen gründlich vorbereitet. Er eröffnete die Versammlung durch eine feierliche Rede, in der er die Revolution als Morgenröte einer neuen Zeit würdigte. Seine Verehrung sprach er insbesondere der Nationalversammlung aus, deren Arbeit an der Verfassung er als Grundstein einer neuen Ordnung darstellte: Nous voyons triompher les nobles efforts de nos Représentants, et s'éléver, malgré les sourdes cabales des ennemis du bien, l'édifice majestueux de la Constitution ${ }^{3}$. Grundlage einer Bürgerbewegung für Revolution, Nationalversammlung und Verfassung solle ein über ganz Frankreich gespanntes Netz von Revolutionsgesellschaften sein. Aufgabe dieser Gesellschaften sei vor allem die Erziehung der Franzosen zu guten Bürgern: Il faut travailler $\grave{a}$ régénérer les mours publiques, seul appui certain des bonnes lois ${ }^{4}$.

Im Anschluß an seine Ansprache legte Barbier de Tinan den Entwurf eines Briefes an die Pariser Revolutionsgesellschaft vor, in dem diese um die $\mathrm{Zu}$ sendung ihrer Statuten und der Bedingungen für die Affiliation, den Anschluß ans Netz der schon bestehenden Clubs, gebeten wurde. Die Versammelten stimmten dem Entwurf zu und wandten sich dann der Ausarbeitung eines provisorischen Reglements für die neugegründete Gesellschaft zu. Sie verabschiedeten zunächst mehrere Artikel, die sich auf die Bildung eines Vorstands bezogen. Par acclamation, durch einmütigen Applaus, wurde Barbier de Tinan zum ersten Präsidenten der Vereinigung bestimmt. Bevor sich die Versammlung trennte, beauftragte sie ihn, sich mit zwei Mitgliedern seiner Wahl zum

${ }^{1}$ Société de la Révolution war der ursprüngliche Name des Pariser Jakobinerclubs. Zur Frühgeschichte der Pariser Jakobiner: Michael REISCH, The Formation of the Paris Jacobins. Principles, Personalities and Politics, Binghampton 1975; AULARD, Société des Jacobins, Bd. 1: 1789, Paris 1889.

${ }^{2}$ Claude BETZINGER, Art. „Jean-Jacques Barbier de Tinan“, in: NDBA, Bd. 1, S. 107.

${ }^{3}$ Clubprotokoll vom 15. Jan. 1790.

${ }^{4}$ Ibid. 
regierenden Ammeister zu begeben, um diesen über die Neugründung zu informieren ${ }^{5}$.

So wurde mit einem wenig spektakulären, unter Ausschluß der Öffentlichkeit stattfindenden Akt einer der ersten Provinzclubs und gleichzeitig diejenige Gesellschaft gegründet, die schon bald eines der Zentren städtischer Politik in Straßburg werden sollte. Das erste Kapitel analysiert die Geschehnisse in den ersten Tagen und Wochen der Clubgeschichte. Es umreißt kurz den lokalhistorischen Kontext der Gründung, um sich dann drei für diese Studie zentralen Aspekten der Frühzeit zuzuwenden: erstens den frühen Versuchen einer Selbstdefinition der „Verfassungsfreunde“, die ein klares Bekenntnis zur Einheit beinhaltete, zweitens das Verhältnis des Provinzclubs zum Zentrum der Revolution, der Nationalversammlung, und drittens der sozialen und politischen Konfliktlage, welche die Gründung eines lokalen Verfassungsclubs befördert haben könnte.

\section{Die munizipale Revolution}

Zu Beginn des Revolutionsjahres wurde Straßburg noch auf der Grundlage des Schwörbriefs von 1482 regiert. Die politische Hierarchie in der Stadt baute auf den zwanzig Zünften der Stadt auf, in denen alle Vollbürger organisiert waren. Einst hatten die Zunftversammlungen Vertreter in den Großen Schöffenrat, den Rat der Dreihundert, gewählt; dieser war jedoch seit dem 17. Jahrhundert nicht mehr einberufen worden. So lag die Macht ausschließlich in den Händen des höchsten städtischen Gremiums, des Magistrats. Dieser bestand aus großem und kleinem Rat, sowie aus mehreren Ausschüssen, den Geheimen Stuben, welche die Arbeit des Gremiums koordinierten. An der Spitze der städtischen Hierarchie stand der Ammeister, der sich mit fünf Kollegen in regelmäBigen Abständen abwechselte ${ }^{6}$.

Alle Sitze im Magistrat wurden auf Lebenszeit vergeben. Wenn ein Amtsträger starb, kam es seinen Kollegen zu, einen Nachfolger zu wählen. Auf die-

${ }^{5} \mathrm{Da}$ dies tatsächlich geschah, belegt ein Zeitungsartikel aus der Straßburgischen Zeitung, in dem über die Gründung berichtet wird. Darin heißt es: Ihre Existenz und ihr Zweck ist beydes kein Geheimnis. Beydes ist dem regierenden Herrn Ammeister, als Haupt der Municipalität, bekannt gemacht worden. (Art. „Straßburg, den 26 Jänner“, in: Straßburgische Zeitung Nr. 12, 27. Jan. 1790).

${ }^{6}$ Zur alten Straßburger Stadtverfassung: Martin ALIOTH, Gruppen an der Macht. Zünfte und Patriziat in Straßburg im 14./15. Jahrhundert. Untersuchungen zu Verfassung, Wirtschaftsgefüge und Sozialstruktur, 2 Bde., Frankfurt a. M. 1988, hier: Bd. 1, S. 117f.; Francis L. FORD, Strasbourg in Transition. 1648-1789, New York 1966, S. 10f.; Peter HERTNER, Stadtwirtschaft zwischen Reich und Frankreich. Wirtschaft und Gesellschaft Straßburgs 1650-1714, Wien 1973, S. 37-51; Hermann G. NAGEL, Die Entstehung der Straßburger Stadtverfassung, Straßburg 1916, S. 79-106; Ingeborg STREITBERGER, Der königliche Prätor von Straßourg 1685-1789. Freie Stadt im aboluten Staat, Wiesbaden 1961, S. $23 \mathrm{f}$. 
se Art und Weise blieben die höchsten Ämter stets in den Händen weniger Familien. Für die Jahre 1600 bis 1680 ist nachgewiesen, daß die Sitze in den Geheimen Stuben von 163 Personen besetzt wurden, die 91 verschiedenen Familien angehörten ${ }^{7}$. Die Gesamtzahl der Familien von Voll- und Schirmbürgern in dieser Zeit lag bei 5000; dies belegt den Tatbestand einer städtischen Oligarchie $^{8}$.

Die Wahlen zu den Generalständen leiteten auch in Straßburg den Anfang vom Ende des Ancien Régime ein ${ }^{9}$. Der Cahier de Doléances des Dritten Standes von Straßburg formulierte den Protest eines Teiles der Bürgerschaft gegen die oligarchische Stadtverfassung ${ }^{10}$. Gefordert wurde vor allem eine Wiederbelebung des Rates der Dreihundert, dem die Wahl der Magistratsmitglieder obliegen sollte. Dies war nicht „revolutionär“; vielmehr formulierten die Beschwerdeführer ein rückwärtsgewandtes Anliegen: die Wiederherstellung einer im späten Mittelalter bereits verwirklichten Stadtverfassung.

Im Verlauf der Wahlen zu den Generalständen formierte sich auch in Straßburg eine patriotische Partei. Ähnlich wie in zwei Dritteln der französischen Großstädte bildete sich ein Bürgerkomitee, das sich bemühte, den Magistrat durch publizistische und politische Aktivitäten zu Reformen zu bewegen ${ }^{11}$. Der Rat erklärte sich zwar zu Verhandlungen mit dem Bürgerkomitee bereit, doch tatsächlich hoffte er, durch eine Hinhaltetaktik die Krise überstehen und den Status quo verteidigen zu können. Sein stiller, aber beharrlicher Widerstand stieß auf wachsenden Unwillen des parti patriote.

Am 20. Juli 1789, kurz nach dem Bekanntwerden des Sturmes auf die Bastille, eskalierte der politische Konflikt in Straßburg. Eine Menschenmenge versammelte sich vor dem Rathaus und bewarf es mit Steinen. Als die ersten Scheiben zu Bruch gingen, sagten die Ratsherren zu, alle in den Cahiers genannten Mißstände einer Prüfung zu unterziehen; daraufhin zogen die Demonstranten ab. Die Verhandlungen zwischen Magistrat und Bürgerkomitee traten in eine neue Phase; die Hoffnungen auf politische Veränderung wuchsen. Doch am folgenden Tag verbreitete sich das Gerücht, der Magistrat sei nicht gewillt, seine ersten Zusagen in die Tat umzusetzen. Vor dem Rathaus ent-

\footnotetext{
${ }^{7}$ HERTNER, Stadtwirtschaft, S. 25; Paul GREISSLER, La classe politique dirigeante à Strasbourg 1650-1750, Strasbourg 1987.

${ }^{8}$ Suzanne DREYER-Roos, La population Strasbourgeoise sous l'Ancien Régime, Strasbourg 1969, S. 161.

${ }^{9}$ Claude BETZINGER, Chroniques du Strasbourg révolutionnaire. Les élections aux Etats Généraux. Printemps 1789, Strasbourg 1989. Zur Geschichte des Jahres 1789 in Straßburg: Manfred EIMER, Die politischen Verhältnisse und Bewegungen in Straßburg im Elsass im Jahre 1789, Straßburg 1897.

${ }^{10}$ FORD, Strasbourg in Transition, S. 238f.; STREITBERGER, Der königliche Prätor, S. 290f.; Robert STEEGMANN, Les cahiers de doléances alsaciens. Spécifités et problèmes, in: RA 116 (1989/90) S. 23-34.

11 Lynn A. HUNT, Commitees and Communes: Local politics and National Revolution in 1789, in: Comp. Stud. Soc. Hist. 18 (1976) S. 324.
} 
stand erneut ein Aufruhr; diesmal wurde das Gebäude gestürmt, geplündert und seine Archive zerstört ${ }^{12}$. Die Patrioten distanzierten sich von diesem Aufstand; das Bürgerkomitee gründete die Straßburger Nationalgarde, welche die Stadt vor weiteren Revolten schützen sollte. Einige Wochen später, als die ersten Meldungen von der Nachtsitzung der Nationalversammlung vom 4. August eintrafen, legte der Magistrat sein Amt nieder und Wahlen nach dem in den Cahiers geforderten Modus wurden angesetzt. Der Vergleich mit anderen Städten legt nahe, daß die Heftigkeit der munizipalen Revolution in Straßburg weniger aus einer explosiven gesellschaftlichen Konstellation, als vielmehr aus der beharrlichen Weigerung der alten Führung zu erklären ist, auch nur einen Zentimeter von ihrer Position zurückzuweichen ${ }^{13}$.

Die am 28. August 1789 gewählte Straßburger Stadtregierung ähnelte, trotz des neuen Wahlmodus, in der Zusammensetzung ihrer Vorgängerin ${ }^{14}$. Weitere Veränderungen der städtischen politischen Strukturen leitete jedoch wenig später die Nationalversammlung ein. Am 14. Dezember verabschiedete sie das Dekret zur Reform der munizipalen Verwaltungen und brachte damit die Révolution municipale zu einem Abschluß. Die Wahlberechtigung sollte nun nicht mehr an die Vollbürgerschaft und auch nicht an die Mitgliedschaft in einer Zunft, sondern an den Status des Aktivbürgers gebunden sein. RegelmäBige Wahlen sollten eine aus einem Bürgermeister, den Officiers municipaux und einer Notabelnversammlung bestehende Stadtverwaltung konstituieren. Diese grundlegende Reform ließ die Forderungen der lokalen patriotischen Partei geradezu als gemäßigt erscheinen ${ }^{15}$. Bei der Gründung des Clubs stand Straßburg also noch zwischen Altem und Neuem Régime. Der Magistrat war entmachtet und wartete auf das Ende seiner letzten Amtszeit; eine neue munizipale Verwaltung war noch nicht gebildet. Die Patrioten konnten sich dennoch bereits als Gewinner des lokalen revolutionären Konfliktes fühlen.

Die unmittelbare Vorgeschichte der Clubgründung am 15. Januar 1790 liegt weitgehend im Dunkeln; doch vieles deutet darauf hin, daß die patriotische Partei sich angesichts der im Dezember 1789 entstandenen Übergangssituation

${ }^{12}$ Claude BETZINGER, L'insurrection strasbourgeoise du 21, juillet 1789, in: RA 118 (1992) S. 71-98. Rodolphe ReusS, Le sac de l'Hôtel de ville de Strasbourg (juillet 1789). Episode de l'histoire de la Révolution en Alsace, in: RH 120 (1915) S. 26-55. Zum Vergleich: Colin LUCAS, Talking about Urban Popular Violence in 1789, in: FORREST, JONES, Reshaping France, S. 122-136.

${ }^{13}$ HUNT, Committees and Communes, S. $330 \mathrm{f}$.

${ }^{14}$ SEINGUERLET, Strasbourg pendant la Révolution, S. $29 \mathrm{f}$.

${ }^{15}$ Zur Reform der Munizipalitäten: Malcolm CROOK: „Aux urnes, citoyens!“ Urban and Rural Electoral Behavior During the French Revolution, in: FORREST, JONES, Reshaping France, S. 152-167. Peter DAWSON, Provincial Magistrates and Revolutionary Politics in France 1789-95, Cambridge (Mass.) 1972. Daniel Ligou, A propos de la Révolution municipale, in: RHES 38 (1960) S. 146-177. Alison PATRICK, French Revolutionary Local Governement, 1789-1792, in: Colin LUCAS (Hg.), The French Revolution and the Creation of Modern Political Culture, Bd. 2, Oxford 1988, S. 399-420. 
ein neues Forum schaffen wollte. Es gibt zahlreiche Hinweise auf Kontinuitäten zwischen der patriotischen Bewegung von 1789 und dem Club: Die Clubmitglieder bezeichneten sich häufig als patriotes. Einige von ihnen gehörten nachweislich zur Reformbewegung von 1789. Der Gründer des Clubs, Barbier de Tinan, und einige andere frühe Mitglieder waren in den reformorientierten Gremien des Jahres 1789 aktiv. Vergleicht man die Mitgliederkartei des neugegründeten Clubs mit der Liste der 126 Straßburger, welche 1789 mit der Wahl der Vertreter des Dritten Standes bei den Generalständen betraut worden waren, so zeigen sich einige Überschneidungen: Unter den Gründungsmitgliedern waren vier Wahlmänner von 1789; bis zum Ende des Jahres 1790 traten achtzehn weitere bei; insgesamt wurden 28 der 126 Wahlmänner des Dritten Standes, die den Protest gegen den alten Magistrat als erste vorgetragen hatten, Clubmitglieder ${ }^{16}$. Die Gründung des Clubs kann also mit Fug und Recht als eine Initiative der lokalen patriotischen Partei ${ }^{17}$ bezeichnet werden.

Der Zeitpunkt der Gründung, kurz nach dem Bekanntwerden des Gesetzes vom 14. Dezember ${ }^{18}$, erlaubt weitere Schlüsse über ihre Hintergründe: Das Reformgesetz machte die Arbeit in einem Bürgerkomitee überflüssig, denn das Komitee wäre eine Konkurrenz für den neuen Stadtrat gewesen. Gleichzeitig erlaubte das Gesetz ausdrücklich die Einberufung von Bürgerversammlungen im Vorfeld der Munizipalwahlen; in einem Flugblatt der Gesellschaft wurde auf das Gesetz als rechtliche Grundlage des Clubs verwiesen ${ }^{19}$. Die an der Gründung beteiligten Patrioten hatten das Ziel, ihrer politischen Arbeit einen neuen Rahmen zu geben, welcher den neuen Strukturen entsprach. Lynn Hunt nennt als Motiv für die Gründung von Clubs auch das Bestreben, trotz der Einrichtung neuer Verwaltungen den Geist und die Strukturen von $1789 \mathrm{zu}$ erhalten. Diese These trifft wohl nicht auf Straßburg zu, wo viele Patrioten den Club als Sprungbrett auf Ämter in der neuen Verwaltung benutzten. Daß die gerade erst gegründete Pariser Revolutionsgesellschaft ein Vorbild für die Straßburger Clubbisten war, steht hingegen außer Frage.

${ }^{16}$ Diese Angaben kamen durch den Vergleich der Mitgliederdatenbank (Anhang A) mit der von Claude Betzinger (Strasbourg) zusammengestellten Liste der 126 Wahlmänner des Dritten Standes bei den Wahlen zu den Generalständen zustande.

${ }^{17}$ Der Vergleich der Mitgliederliste der Straßburger „Société des Philantropes“ mit den Clubmitgliedern ergibt einige Übereinstimmungen; eine systematische Erforschung des $\mathrm{Zu}$ sammenhanges zwischen den vorrevolutionären Gesellschaften und Logen und den Clubbisten von 1790 ist jedoch im Rahmen dieser Arbeit nicht möglich. Vgl. Jürgen Voss, Die Straßburger "Société des Philantropes" und ihre Mitglieder im Jahre 1777, in: DERS., Deutsch-französische Beziehungen im Spannungsfeld von Absolutismus, Aufklärung und Revolution. Ausgewählte Beiträge von Jürgen Voss, Berlin, Bonn 1992, S. 121-138.

${ }^{18}$ Meldung der Ratifizierung des entsprechenden Gesetzes: Art. „Paris, den 28 Dez.“, in: Straßburgische Zeitung Nr. 2, 4. Jan. 1790.

${ }^{19}$ Die Société zitiert das Gesetz in rechtfertigender Absicht in: Adresse de la Société de la Révolution établie à Strasbourg à ses concitoyens des villes et campagnes d'Alsace, 26. Jan. 1790, in: HEITZ, Les sociétés politiques, S. 11. 


\section{Erste Selbstdefinitionen: die Hüter der neuen Ordnung}

Der neugegründete Club, der in der Anfangszeit in wechselnden Zunftstuben tagte, änderte, seinem Pariser Vorbild folgend, schon bald seinen Namen. Die Straßburger Société de la Révolution hieß ab dem Februar 1790 Société des Amis de la Constitution. Diese Namensänderung war programmatisch. Die Verfassung, deren spätere Präambel, die Menschenrechtserklärung, bald nach der Gründung den Sitzungssaal schmückte, war das Fundament der frühen Selbstdefinitionen. In diesem Sinne formulierten die Clubbisten erste Antworten auf die Frage „Wer sind wir?" in ihrem Règlement: La fidelité à la constitution, le dévouement à la défendre, le respect et la soumission aux pouvoirs qu'elle aura établis, seront les premières lois imposées à ceux qui voudront être admis à cette sociétét ${ }^{20}$. Im folgenden wird das politische Selbstverständnis dargestelit, das aus der Berufung auf die Verfassung erwuchs.

Das Ablegen des Namens „Revolutionsgesellschaft" dokumentiert den nur zu offensichtlichen Versuch, die gewalttätigen Momente der Revolution vergessen zu machen. Die Patrioten, die im Juli 1789 eine Bürgerwehr gegen die Aufständischen gegründet hatten, waren auch 1790 davon überzeugt, daß politisch motivierte Unruhen zu vermeiden waren. Schon bei der Gründungsveranstaltung des Clubs hatte Barbier de Tinan gefordert, der Club solle keineswegs die Gewalt von 1789 fortsetzen, sondern zur Enstehung einer neuen Ordnung beitragen. In diesem Sinne sprach auch Brunck, einer seiner Nachfolger auf dem Präsidentensessel, in seiner Antrittsrede: J'espère mériter au moins votre indulgence, et obtenir de votre justice l'éloge (...) de mon amour de l'ordre ${ }^{21}$. Im ersten Flugblatt, das die Clubbisten an die Straßburger richteten, versicherten sie, daß sie sich jedem entgegenstellen wollten, der versuchte, das Volk aufzuwiegeln ${ }^{22}$. Diese Aussagen belegen, daß die Clubbisten ihre Politik am Gegensatz von Unordnung und Ordnung orientierten; als Unordnung verstanden sie nicht nur die überkommenen Strukturen des Ancien Régime, sondern auch die Tumulte von 1789. Die Straßburger Patrioten wünschten sich eine Revolution ohne Revolution, welche die friedliche Durchsetzung neuer vernünftiger Regeln der Politik und des gesellschaftlichen Zusammenlebens mit sich bringen sollte.

An sich selbst erprobten die Mitglieder des Clubs die Regeln der neuen Ordnung zuerst; das Règlement drückt den Willen aus, einen festen Rahmen für politisches Verhalten abzustecken. In den ersten Monaten scheinen die Sitzungen tatsächlich mit der Regelmäßigkeit eines Uhrwerkes abgelaufen zu sein.

${ }^{20}$ Règlement de la Société des Amis de la Constitution, Strasbourg 1790, S. 10 [Arch. Dépt. Bas-Rhin, 133 L 277].

${ }^{21}$ Clubprotokoll vom 13. März 1790.

${ }^{22}$ Adresse de la Société de la Révolution établie à Strasbourg à ses concitoyens des villes et campagnes d'Alsace, 26. Jan. 1790, in: HEITZ, Les sociétés politiques, S. 11. 
Ein Glockenschlag forderte die Versammelten auf, Platz zu nehmen. Dann eröffnete der Präsident die Sitzungen mit knappen Begrüßungsworten und der Feststellung der Beschlußfähigkeit, die dann gegeben war, wenn mehr als die Hälfte der Mitglieder anwesend $w^{23}{ }^{23}$. Einer der Sekretäre verlas das Protokoll der letzten Sitzung, das von der Versammlung genehmigt werden mußte. Ein Mitglied des Korrespondenzkomitees gab den Inhalt eingegangener Briefe wieder; im Anschluß wurden neue Mitglieder zur Aufnahme vorgeschlagen. Wenn es Neuaufnahmen gab, traten diese vor den Präsidenten und schworen den Eid der Gesellschaft. Anschließend wurde die Tagesordnung bekanntgegeben. Jedes Mitglied war antragsberechtigt; Anträge zur Tagesordnung konnten auch noch während der Sitzung schriftlich eingereicht werden.

Die Diskussion der auf der Tagesordnung stehenden Punkte erfolgte nach der Redeordnung. Um das Rederecht zu beantragen, mußte sich das Mitglied erheben, den Aufruf durch den Präsidenten abwarten und dann im Stehen zur Versammlung sprechen. Der Präsident hatte das Recht, den Sprecher zur Ordnung zu rufen, wenn dieser vom Thema abwich oder sich nicht in der gebotenen Kürze äußerte. Während der Redebeiträge waren die anderen Mitglieder zum Schweigen verpflichtet. Die Glocke des Präsidenten rief zur Ruhe auf. Wer nach dem Erklingen der Glocke weitersprach, wurde vom Präsidenten getadelt. Debatten bestanden also in der Regel aus einer Folge von kurzen Ansprachen. Nach dem Ende der Diskussion mußte der Antragsteller sein Anliegen als Frage formulieren; dann wurde zur Abstimmung geschritten. Zustimmung signalisierte man, indem man sich von seinem Sitz erhob. Im Zweifelsfall wurde das Ergebnis durch namentlichen Aufruf kontrolliert. Eine einfache Mehrheit genügte für die Entscheidung ${ }^{24}$.

Wahrung der Ordnung hieß im Club nicht nur Einhalten von strengen Verhaltensregeln, sondern auch Anerkennung von Hierarchien und Amtsautorität. Höchste Instanz war der Präsident. Er saß den Sitzungen vor, erteilte das Wort, verlas die Fragen und Anträge, die zur Beratung anstanden, verkündete die Ergebnisse von Wahlen und den Wortlaut von Entscheidungen. Er lud zu Sitzungen ein, öffnete und schloß diese. Dem Präsidenten standen zunächst zwei Sekretäre zur Seite, die ihn in allen administrativen Belangen unterstützten. Sie sorgten mit ihm für die Durchführung der Beschlüsse und waren für die Führung der Protokolle und des Clubarchivs verantwortlich. Präsident, zwei Sekretäre und ein Schatzmeister bildeten den Vorstand.

Die Autorität des Präsidenten und des Vorstands spiegelte sich auch in der Sitzordnung wider: Bei den Sitzungen plazierten sich die Mitglieder mit Ausrichtung auf den Vorstand. Dieses saß um das bureau, die symbolische Verkörperung der präsidentialen Autorität, der man sich nicht ohne Erlaubnis nä-

\footnotetext{
${ }^{23}$ Später wurde diese Regelung aufgeweicht und die Beschlußfähigkeit auf zwölf Personen herabgesetzt. (Clubprotokoll vom 13. April 1790).

${ }^{24}$ Règlement, S. $29 f$.
} 
hern durfte. Die Hochachtung vor den Ämtern drückte sich auch in den Antrittsreden aus, in denen die neugewählten Vorsitzenden stets ihre Zweifel ausdrückten, ob sie der ihnen übertragenen Aufgabe gewachsen sein würden. So sagte der Präsident Brunck de Freundeck: Pénétré de mon insuffisance pour la place à laquelle vous m'avez élévé, ne pouvant vous assurer MM. que de la sévérité de mes principes constitutionnels de mon zèle pour le soutien de la bonne cause patriotique et de mon respect pour la société, je réclame votre indulgence ${ }^{25}$. Hinter diesem respektvollen Verhalten stand offenbar auch das Bedürfnis, die Rechtmäßigkeit einer Autorität zu unterstreichen, die aus einer demokratischen Wahl hervorgegangen war.

Der Glaube, daß Ordnung auch Unterordnung bedeutete, zeigte sich jedoch nicht nur im Respekt vor dem Clubpräsidenten, sondern vor allem in der Haltung der Straßburger Clubbisten gegenüber der Nationalversammlung. Die Politik der Straßburger Verfassungsfreunde war von Anfang an durch die demonstrative Unterordnung unter das durch die Revolution erneuerte politische Zentrum in Paris geprägt. Barbier de Tinan hatte in seiner eingangs zitierten Rede die Verpflichtung des Clubs gegenüber den edlen Bemühungen unserer Repräsentanten betont. Derartige verbale Verbeugungen vor der auguste assemblée nationale ${ }^{26}$ standen in der Anfangszeit täglich auf der Tagesordnung; es findet sich fast keine Rede, in welcher der Nationalversammlung nicht Bewunderung angetragen und Unterstützung zugesagt wurde: Nous devons donc porter toute notre attention à prévenir les obstacles qui pourroient arrêter les vues bienfaisantes de l'assemblée nationale constituante ${ }^{27}$, formulierte beispielsweise das Mitglied de Montferrand. Durch den Eid verpflichteten sich die Mitglieder de maintenir de tout mon pouvoir la Constitution, décrétée par l'Assemblée Nationale ${ }^{28}$. Die Satzung des Clubs bestand zur Hälfte aus Artikeln, die direkt aus dem Sitzungsreglement der Nationalversammlung übernommen waren.

Die Ausrichtung auf das Pariser Zentrum drückte sich auch im Wunsch der Mitglieder aus, sich mit aktuellen Informationen aus der Hauptstadt zu versorgen. Im März, dem Monat, in dem die Pariser Gesellschaft der Verfassungsfreunde den Straßburgern ihre Affiliation schriftlich bestätigte, wurde beschlossen, die Collection des décrets de l'assemblée nationale ${ }^{29}$ anzuschaffen. Einen Monat später wurde ein Règlement pour l'abonnement de papiers publics verabschiedet. Die Versammlung wünschte sich la connaissance la plus prompte des décrets émanés de l'assemblée nationale et généralement de tout ce qui a rapport à la révolution [...] La voie des journaux et ouvrages périodi-

\footnotetext{
${ }^{25}$ Rede von BRUNCK DE FREUNDECK im Clubprotokoll vom 14. Mai 1790.

${ }^{26}$ Aus dem provisorischen Règlement, It. Clubprotokoll vom 26. Jan. 1790.

${ }^{27}$ Antrag von DE MONTFERRAND im Clubprotokoll vom 30. März 1790.

${ }^{28}$ Die Eidesformel findet sich auf der Innenseite des Einbandes des ersten Protokollbandes.

${ }^{29}$ Clubprotokoll vom 13. März 1790.
} 
ques est la seule qui puisse satisfaire son empressement à cet égard ${ }^{30}$. Es wurde zunächst beschlossen, sieben Blätter zu abonnieren, die ohne Ausnahme in Paris erschienen ${ }^{31}$.

Diese ehrfurchtsvolle Haltung gegenüber den Gesetzgebern und den von ihnen aufgestellten Regeln zeigt nicht nur, daß die neue Ordnung auch eine neue Hierarchie bedeutete, der sich die Clubbisten gerne unterstellten, sie gibt auch Einblick in das Verhältnis von Metropole und Provinz. Die sich im Club formierende neue politische Elite Straßburgs akzeptierte die neue Pariser Führung. Lokale Alleingänge oder gar Widerstand gegen die in der Zentrale aufgestellten Grundsätze waren undenkbar. Ziel war vielmehr die möglichst getreue Orientierung an Pariser Vorbildern, die allein Legitimität in einer neuen Ära garantierte.

Ordnung und Unterordnung standen in engem Zusammenhang mit jenem Konzept von inhaltlicher Geschlossenheit oder Konsens, das François Furet in Anlehnung an Augustin Cochins Analyse als zentrales Element der jakobinischen Ideologie bezeichnet hat ${ }^{32}$. Dissens war allerdings in der Anfangszeit noch möglich. Die formale Strenge der Debatten hatte nicht das Ziel, die Konkurrenz unterschiedlicher Meinungen von vornherein zu unterbinden; dies belegen die Protokolle der Diskussionen ebenso wie die Aussage des allerdings als besonders liberal einzuschätzenden Präsidenten Gloutier in seiner Antrittsrede:

Un des grands avantages que chacun de nous doit s'étudier à rétirer de nos délibérations c'est de s'exercer à l'art difficile de la discussion et au talent de la parole, si nécéssaire dans un état libre, de s'accoutumer au conflit des

${ }^{30}$ Clubprotokoll vom 13. April 1790.

${ }^{31}$ Die Liste der abonnierten Blätter findet sich im Protokoll vom 17. April 1790: Le Moniteur, Annales de Mercier, La cocarde nationale, Journal des débats et décrets de l'assemblée nationale, Journal des décrets à l'usage des habitans de la campagne, Séances de Versailles servant d'introduction au journal précédent, Recueil général et journalier de jurisprudence françoise. Die Gesamtkosten für alle Abonnements für drei Monate werden mit 105 livres, 10 sous angegeben. Im Dezember wurde die Anzahl der Zeitungen verdreifacht; das Spektrum hatte sich deutlich verschoben: Es gab nun auch Zeitungen aus Straßburg, davon mehrere in deutscher Sprache, und auch Zeitungen aus Deutschland: Le Journal de Paris, Le Moniteur, Le procès verbal de l'ass. nat. avec le journal des débats et décrets, La chronique de Paris, Journal de la société des amis de la constitution de Paris, Le journal des clubs patriotiques, Le Journal pour les habitans des campagnes, Le Journal de Provence, Le Patriote français, La Feuille villageoise, Les Affiches de Strasbourg, Le Mémorial des Corps administratifs, La Chronique de Strasbourg, Le Journal de jurisprudence, de $M$. Merlin, La Politische Strassburger Zeitung, Die Geschichte der Gegenwärtigen Zeit, Le National-Blatt, Le Mercure allemand, Le Journal des droits de l'homme, Das Patriotische Wochenblatt, von André Ulrich, La Feuille de Hambourg. Das Zeitungsrèglement regelte nicht nur die Modalitäten der Anschaffung, sondern auch die Einrichtung eines Lesesaals, der von acht Uhr morgens bis acht Uhr abends geöffnet sein sollte.

${ }^{32}$ Vgl. auch Lucien JAUME, Le discours jacobin et la démocratie, Paris 1989, S. 263-388. 
opinions diverses, d'apprendre à considerer une question sous tous ses rapports, à se mettre en garde contre l'esprit de faction, et contre le despotisme oratoire, c'est d'apprendre à ne plus se trainer sur les pas et les idées d'autrui et à sortir enfin de cet état d'enfance, d'inertie et de servitude où l'Ancien Régime avoit plongé l'âme des françois ${ }^{33}$.

Gloutier forderte explizit zum Wettstreit der Meinungen auf; gleichzeitig verdammte er den „Parteigeist“. Im Denken der Verfassungsfreunde war dieser Widerspruch insofern aufgelöst, als sie das Für und Wider verschiedener Meinungen nur als eine Phase bei der Ergründung des gemeinsamen Willens verstanden. Diskussionen hatten also nicht die Funktion, unterschiedliche Auffassungen in Kompromissen miteinander zu versöhnen, sondern sie auf eine höhere Stufe zu führen und zu vereinigen. Auf alle Fragen sollte durch gemeinsames lautes Denken eine befriedigende Antwort gefunden werden.

Die Konkurrenz der Meinungen mußte deshalb in dem Augenblick beendet sein, in dem die Auffassung der Gemeinschaft ergründet war. Aus dieser Denkweise erklärt sich die Tatsache, daß die meisten Entscheidungen des Clubs einstimmig gefällt wurden und daß dies stets mit großer Zufriedenheit im Protokoll vermerkt wurde. Nach einem einstimmigen Beschluß war es unmöglich, noch anderer Meinung zu sein. Disharmonie war also nur als Schritt auf dem Weg zur Harmonie vorstellbar. Norman Hampson hat diese Denkweise anhand der Debatten der Nationalversammlung analysiert und ihre Konsequenzen zugespitzt dargestellt: „Die Minderheit war [...] nicht berechtigt, überhaupt gegen irgendetwas zu protestieren, da sie strenggenommen überhaupt kein Recht hatte zu existieren, sobald sie sich einmal als Minderheit erwiesen hatte. “34

In der Praxis waren der Wille zur Unterordnungen unter das revolutionäre Zentrum und das beschriebene Verfahren zur Ergründung des gemeinschaftlichen Willens nicht immer leicht zu verbinden. So wie der Club Einheit unter seinen Mitgliedern herstellte, war es die Aufgabe der Nationalversammlung, in ihren Debatten den Gemeinwillen der ganzen Nation zu ergründen. Die Straßburger konnten sich als Teil der Nation vor einem Beschluß der Assemblée, beispielsweise durch Petitionen, an den Debatten beteiligen, nach gefaßtem Beschluß mußten sie jedoch auf jede Form von Dissens verzichten. Wenn die gemeinsame Meinung des Landes einmal in der Debatte der Volksvertreter festgestellt war, galt sie als unumstößlich und allgemein verbindlich. Vorher gefaßte eigene Beschlüsse hätten, auch wenn sie der Meinung aller Straßburger Clubbisten entsprochen hätten, revidiert werden müssen. Dieses Konzept war Quelle einer gewissen Unsicherheit der politisch Aktiven in der Provinz: Jeder Beschluß, jede prononcierte Stellungnahme barg die Gefahr, als unzuläs-

${ }_{33}^{33}$ Rede von GLOUTIER im Clubprotokoll vom 17. Dez. 1790.

${ }^{34}$ Norman HAMPSON, Vor dem Terror, Köln 1989, S. 146. 
siger Vorgriff auf den nationalen Mechanismus zur Herstellung des Konsens interpretiert zu werden. Diese Auffassung schlug sich in den meist sehr vorsichtigen, abwartenden und am Pariser Vorbild orientierten Debatten und Ansprachen in den ersten Monaten der Clubgeschichte nieder.

Aus der Frage „Wer sind wir?" ergab sich die Frage „Wer gehört zu uns?“. Im Inneren des Clubs und selbst innerhalb der nationalen revolutionären Bewegung war der Glaube an eine neue Ordnung, an Unterordnung und Konsens leicht durchzusetzen. Um jedoch den selbstgesteckten Zielen näherzukommen, mußte der Club auch außerhalb seines Sitzungssaales wirken; die städtische Bevölkerung oder gar alle Elsässer mußten für das Projekt der Clubbisten gewonnen werden.

Ganz selbstverständlich ging der Club davon aus, daß es in der Bevölkerung noch an revolutionärem Bewußtsein mangelte und der Prozeß der Revolution, der in den Institutionen begonnen und sich auf der Straße fortgesetzt hatte, jetzt in die Stuben der Bürger und auf die Bauernhöfe getragen werden müß$\mathrm{te}^{35}$. Ausschlaggebend für die ersten Schritte in die Öffentlichkeit waren vereinzelte verbale Angriffe auf den Club, denen durch eine erste Propagandainitiative begegnet werden sollte. Am 23. Januar 1790, also eine gute Woche nach der Gründung, fand die erste Beratung darüber statt, ob und wie die Ziele des Clubs bei der Bevölkerung bekannt gemacht werden sollten ${ }^{36}$. Wenige Tage später fiel dann der Beschluß, eine Adresse an die Straßburger drucken zu lassen $^{37}$. Manchen der Mitglieder ging dies nicht weit genug; sie forderten freien Zugang der Öffentlichkeit zu allen Clubsitzungen ${ }^{38}$. Obwohl es im Reglement hieß, la publicité est le garant de toutes ses démarches, wurde die Initiative in der Gesellschaft vorerst nicht debattiert. Erst in der Sitzung vom 17. April 1790, in der das Clubmitglied Brunck de Freundeck sich grundsätzlich zur Frage der Öffnung äußerte und einen Kompromißvorschlag machte, kam die Debatte über die Öffentlichkeit der Sitzungen in Schwung:

Nulle société soit de gens de lettres ou de savans, ni même de bienfaisance et de charité n'est dans l'usage d'admettre le public à ses séances, si ce n'est à des jours déterminés dans l'année lesquels sont rares; que pour ces séances publiques les sociétés ont le soin de préparer une suite de lectures qui puissent intéresser les curieux soit en les instruisant ou en les amusant. Vos séances Messieurs, ne sont pas habituellement remplies par des lectures et des discussions qui fassent naître ces deux genres d'intérêt; à vous mêmes elles ont paru quelques fois avides ou fastidieuses. (...) De pareilles séances ouvertes indistinctement au public le rassureraient sans doute sur le but de

\footnotetext{
${ }^{35}$ Zur Propaganda der Vereine der Provinz s. Louis de CARDENAL, La Province pendant la Révolution, Paris 1929, S. 363-395.

${ }^{36}$ Clubprotokoll vom 23. Jan. 1790.

${ }^{37}$ Clubprotokoll vom 26. Jan. 1790.

${ }^{38}$ Clubprotokolle vom 2. Feb. 1790 und 13. April 1790.
} 
votre association, mais en vous sauvant de la calomnie elle vous exposeroient peut-être au ridicule ${ }^{39}$.

Im Anschluß an Bruncks Rede rang sich die Versammlung zu einem Kompromiß durch. Sie beschloß, daß die Sitzungen zwar nicht für die Öffentlichkeit zugänglich sein sollten, daß jedoch jedes Mitglied zu drei Sitzungen ein Nichtmitglied mitbringen durfte. Väter durften sich, mit Erlaubnis der Gesellschaft, von ihren Söhnen begleiten lassen. Dieser Kompromiß scheint aber, ohne daß sich allerdings ein entsprechender Beschluß finden läßt, bald aufgehoben worden zu sein. Ab 1791 gibt es Hinweise darauf, daß im Club Zuschauer zugelassen waren.

Als eine weitere Kompromißlösung wurde am 3. Juli 1790 beschlossen, öffentliche Lesungen der Dekrete der Nationalversammlung in französischer und deutscher Sprache abzuhalten ${ }^{40}$. Die praktische Umsetzung dieses Beschlusses erfolgte am 17. Juli 1790. Montags, mittwochs und freitags um 14.30 Uhr sollten französische und sonn- und feiertags um 13.15 Uhr deutsche Lesungen stattfinden ${ }^{41}$. Die Lesungen waren ein großer Erfolg. In Frieses Geschichte der Stadt Straßburg findet sich ein Augenzeugenbericht:

Sie [die Bürger und Soldaten] fanden sich auch, besonders in den deutschen Vorlesungen, in solcher Menge ein, daß der große Saal auf dem Spiegel der daran stoßende Hintersaal, die Gänge, Treppen und der Hof mit Menschen angefüllt, und der Redner genöthiget war, auf das Gesimse eines Kreuzstocks, gegen den Hof zu, zu stehen, um von der Menge gesehen und verstanden $z u$ werden ${ }^{42}$.

Schon in den ersten Sitzungen sollen 2000 Zuhörer, davon 6-700 Militärpersonen zugegen gewesen sein, heißt es in einem Brief des Clubs an die Comités de Constitution et militaire der Nationalversammlung. Le plus grand ordre et le silence le plus profond règnent pendant les lectures; aucun auditeur ne s'est jamais permis d'y élever la voix. ${ }^{43}$ Ordnung und Einheit manifestierten sich bei den Lesungen in der Stille der Zuhörer; es gab offenbar zwei verschiedene

${ }^{39}$ Clubprotokoll vom 17. April 1790.

${ }^{40}$ Clubprotokoll vom 3. Juli 1790.

${ }^{41}$ Clubprotokoll vom 17. Juli 1790. La Société des Amis de la Constitution à ses Concitoyens, 17. Juli 1790 [Bibl. Nat. Univ. Str., M 5941, 106]. Rede zur Eröffnung der öffentlichen Lesungen, 26. Juli 1790 [Arch. Mun. Str., Fonds 3/10, 16].

${ }^{42}$ Johann FRIESE, Neue vaterländische Geschichte der Stadt Straßburg, 6 Bde., Straßburg 1792-1801 [AMS D 46.] hier: Bd. 5, Straßburg 1801, S. 13.

${ }^{43}$ Brief der Société an das Comité de Constitution und das Comité militaire der Nationalversammlung, 25. Sept. 1790 [Arch. Mun. Str., Fonds 3/9, 67]. Die Komitees der Nationalversammlung bestätigten, daß die Beteiligung von Soldaten an der Veranstaltung durchaus in ihrem Interesse sei. (Brief Broglie an die Société, 5. Okt. 1790 [Arch. Mun. Str., Fonds 3/10, 53]). 
Konzepte: Bestimmte Bürger sollten die Einheit aktiv gestalten, andere sollten sie nur akzeptieren und sich still unterordnen.

Abgesehen von den öffentlichen Lesungen gab es noch andere Möglichkeiten, sich an die Öffentlichkeit zu wenden. Im Sommer des Jahres 1791 stellte man Überlegungen an, wie man die ländliche Umgebung Straßburgs aufklären könne. Im August wurde die Entsendung von missionnaires patriotes aufs Land beschlossen ${ }^{44}$. Häufiger waren jedoch die Versuche, die Bevölkerung durch gedruckte Schriften zu erreichen. Der Club ließ Flugblätter verfertigen und Beiträge in Zeitungen einrücken, die von Mitgliedern herausgegeben wurden. In der Frühzeit waren dies vor allem die Chronique de Strasbourg, die Straßburgische Zeitung, die Geschichte der Gegenwärtigen Zeit und die Wöchentlichen Nachrichten ${ }^{45}$. Am 30. Juli 1790 wurde der Vorschlag gemacht, eine eigene Clubzeitung ins Leben zu rufen. Es sollte ein Briefkasten eingerichtet werden, in den jeder Bürger Beiträge einwerfen konnte. Ein Komitee würde dann diejenigen Artikel auswählen, die für die Veröffentlichung geeignet waren. Dieses Projekt wurde wiederholt diskutiert, jedoch nicht in die Tat umgesetzt ${ }^{46}$.

Die vielfältigen Anstrengungen zeigen, daß die Clubbisten von der Notwendigkeit politischer Pädagogik überzeugt und gleichzeitig vom Glauben an den Sieg der Revolution im Elsaß beseelt waren. Ausdruck dieser Auffassung waren die häufig verwandten Bezeichnungen le bon peuple und les bons citoyens, welche nicht nur auf die überzeugten Revolutionäre angewandt wurden, sondern auch auf die große Menge von Bürgern, die sich beim intensiveren Kontakt mit den neuen Ideen für die Revolution begeistern würden. Verhaltensweisen, die nicht dem revolutionären Wertesystem entsprachen, entschuldigte man als Handlungen eines peuple égaré, das noch nicht durch die aufklärende Wirkung der neuen Gedanken verwandelt und von den Einflüsterungen der alten Machthaber befreit war. Ein zum falschen Glauben verführtes Volk konnte jedoch zum rechten Glauben bekehrt werden; es war nicht an sich

\footnotetext{
${ }^{44}$ S. auch Clubprotokoll vom 10. Aug. 1791: Un membre après avoir prouvé dans un rapport intéressant que les habitants des campagnes égarés par les prêtres ont besoin d'instruction propose que la société envoye des missionnaires patriotes dans les Campagnes; la société arrête cette motion et la renvoye au comité de correspondance pour lui [...] présenter le mode d'exécution. Clubprotokoll vom 16. Sept. 1791: Différents orateurs montèrent successivement à la tribune. Le premier démontre la nécessité d'envoyer des commissaires à la campagne pour prêcher la Constitution et détromper les campagnards séduits par les raisonnements vains et hypocrites des non Conformistes. Dazu: MARX, Recherches sur la vie politique, S. $101 \mathrm{f}$.

${ }^{45}$ S. Jean Pierre KINTZ, La presse alsacienne sous la Révolution, in: RA 116 (1989/90) S. 77-104; D. SCHWARTZ, Die Straßburger Zeitungen in der Revolution, ihre Zahl, ihre Verleger und Herausgeber, ihre Einrichtung und inhaltliche Einteilung, s.d., (BVS, MS 1147); Erich PElzer, Sprachpolitik und Propaganda in Straßburg während der Französischen Revolution, in: ARETIN, HÄRTER, Revolution und konservatives Beharren, S. 45-57.

${ }^{46}$ Clubprotokoll vom 30. Juli 1790.
} 
„schlecht", sondern stand nur unter schlechtem Einfluß. Straßburger Bürger und elsässische Bauern gehörten also potentiell zur revolutionären Bewegung.

Der Glaube an Ordnung und Harmonie ließ dementsprechend nur wenig Raum für Vorstellungen von Disharmonie oder gar Feindschaft; das Denken der frühen Clubbisten schloß Konflikte und Feindschaft jedoch nicht aus. Unterscheidungskriterium zwischen Freund und Feind war die Haltung gegenüber der Verfassung: Alle, die sich an ihrer Entstehung beteiligten oder sich zumindest nach den neuen Gesetzen verhielten, waren Freunde, alle anderen waren Feinde, die es zu bekämpfen galt. Bereits in der Unionsurkunde war zur Wachsamkeit aufgerufen und das Ziel definiert worden de porter un ceil vigilant sur la Révolution actuelle, sur tout ce qui peut contribuer à la maintenir et à lui assurer de la force et de la durée, ainsi que sur toutes les mancuvres et les ressorts que pourraient faire jouer pour la détruire ceux qui seraient intéressés à faire revivre les abus qu'on vient de renverser ${ }^{47}$. Im Reglement wurde festgelegt, daß jedes Mitglied, das sich in Wort, Schrift oder seinen Handlungen gegen Verfassung und Menschenrechte wendete, umgehend aus dem Club ausgeschlossen werden sollte ${ }^{48}$. Bereits wenige Tage nach der Gründung wurden drei konterrevolutionäre Flugblätter bei der Stadtverwaltung angezeigt. Die von den Feinden ausgehende Gefahr wurde jedoch in den ersten Monaten nicht als sehr groß eingeschätzt: Personne de nous ne croit sûrement à une contre-révolution, mais en même tems nous ne devons pas douter des efforts que feront les ennemis du bien public pour empêcher ou au moins retarder l'établissement de la constitution. Les amis doivent regarder un retard de quelques jours comme un malheur pour la France entière ${ }^{49}$, hieß es in einer Ansprache. Man glaubte also, durch Wachsamkeit und Aufklärung ein zum guten tendierendes Volk bald für die neue Ordnung gewinnen zu können.

Zusammenfassend kann festgehalten werden, daß die Selbstdefinition als „Freunde der Verfassung" verschiedene Implikationen hatte, die für die weitere Analyse von Bedeutung sind. Erstens zeigt sie, daß die Clubbisten die Politik als Ringen der antagonistischen Kräfte Unordnung und Ordnung, Bewegung und Stabilität verstanden und sich selbst als Verteidiger stabiler Ordnung sahen. Hier deutet sich bereits der spätere Wille der Barnavisten zur „Beendigung der Revolution" an. Zweitens beinhaltete der Verweis auf die Verfassung einen Willen zu Gehorsam und Unterordnung gegenüber dem Zentrum der Revolution. Zurufe der Peripherie an das Zentrum waren indes nicht verboten, sie mußten jedoch aus berufenem Mund kommen. Die Clubbisten verstanden es als ihre Aufgabe, sich zu kompetenten Zurufern zu qualifizieren. Drittens ging die Vorstellung, die sich die Clubbisten von der Verfassung machten, mit einem Konzept innerer Geschlossenheit einher. Ohne Konsens schien den

\footnotetext{
47 "Acte d'Union“ im Clubprotokoll vom 15. Jan. 1790.

${ }^{48}$ Règlement, S. $15 \mathrm{f}$.

${ }^{49}$ Clubprotokoll vom 30. März 1790.
} 
Clubbisten eine neue Ordnung nicht möglich. Viertens brachte das Verfassungsdenken eine neue Hierarchisierung der Gesellschaft mit sich. An der Spitze der Gesellschaftspyramide sollten die Gesetzgeber stehen, an ihrem FuBe die einfachen Bürger und Bauern, denen nicht viel mehr blieb, als aus Einsicht folgsam zu sein. Die Arbeit des Clubs zielte darauf ab, eine solche Haltung zu erzeugen. Fünftens führte der Bezug auf die Verfassung zu einer ersten Definition von Feindschaft. Zugehörigkeit entstand durch den Willen zur Gestaltung der neuen Ordnung oder wenigstens durch Zustimmung zum Konsens. Ein Feind war derjenige, der sich der neuen Ordnung, die ja auch für ihn die beste war, entgegenstellte. Eine solche Haltung konnte entweder aus Unbildung entstehen - manche Bürger hatten noch nicht verstanden, wie sehr ihr Wohl vom Gemeinwohl abhing - oder aus bösem Willen. Die Feinde der Revolution hielt man zu diesem Zeitpunkt noch für isoliert und schwach ${ }^{50}$.

\section{Wer waren die Verfassungsfreunde?}

Der politische Konflikt, aus dem der Club siegreich hervorgegangen war, ist im ersten Abschnitt bereits umrissen worden. Es stellt sich jedoch die Frage, ob sich hinter dieser Auseinandersetzung soziale Spannungen verbargen. Was für Männer waren es, die im Januar 1790 in Straßburg einen politischen Verein ins Leben riefen? Was könnte sie dazu getrieben haben, in der Revolution eine aktive Rolle zu spielen? Von den 51 bekannten Gründungsmitgliedern gehörte ein großer Teil, insgesamt 23, im weitesten Sinne dem Militär an. Es waren jedoch keine einfachen Soldaten, sondern neunzehn Offiziere und Quartiermeister, sowie einige königliche Verwalter (Commissaire des guerres) und Angestellte der Armee (Ärzte), die sich dem Club anschlossen. Des weiteren entstammten acht Mitglieder dem Wirtschaftsbürgertum; sie gaben als Beruf négociant an. Weitere sechzehn sind dem Bildungsbürgertum zuzurechnen: Rechtsanwälte und Notare, ein Architekt, ein Journalist, mehrere Professoren und Lehrer, höhere Angestellte verschiedener städtischer und königlicher Verwaltungen. Offiziere, Armeeangestellte, Wirtschafts- und Bildungsbürger machten mit insgesamt 39 Vertretern den größten Teil der Mitgliedschaft aus. Es läßt sich also ein deutliches Übergewicht der Oberschichten konstatieren. Dagegen gab es nur vier Mitglieder der unteren Schichten des Bürgertums: drei Künstler und ein einziger Handwerker ${ }^{51}$. Einige der Mitglieder der ersten

\footnotetext{
${ }^{50}$ Zum jakobinische Einheits- und Harmoniedenken im allgemeinen: HrGONNET, Goodness beyond Virtue, S. 183-209; Lynn A. HUNT, The Family Romance of the French Revolution, London u.a. 1992.

${ }^{51}$ Diese Angaben sind der von Claude Betzinger erstellten Mitgliederdatenbank entnommen, die im Kapitel II.2 eingehend kommentiert und im Anhang A abgedruckt wird.
} 
Stunde hatten im Ancien Régime politische Funktionen in der Stadt ausgeübt: Es finden sich zwei Senatoren, zwei Avocats généraux und sieben Schöffen ${ }^{52}$.

Die Bedingungen für die Aufnahme neuer Mitglieder deuten darauf hin, daß der elitäre Charakter der Versammlung aufrechterhalten werden sollte. Zwar war die Mitgliedschaft im Club theoretisch jedem Straßburger möglich, in der Praxis behielt sich dieser jedoch eine strenge Kontrolle der Neuaufnahmen vor. Jeder Kandidat mußte von einem „Paten“ und vier weiteren Mitgliedern vorgeschlagen werden. Der Vorschlag wurde eine Woche lang zur Überprüfung ausgehängt. Die endgültige Entscheidung wurde durch die ballotage gefällt: Jedes Mitglied warf eine schwarze oder weiße Kugel in einen Sammelbehälter. Fanden sich drei oder mehr schwarze Kugeln darin, so war der Antrag abgelehnt ${ }^{53}$. Für Männer, die keinen guten Bekannten im Club hatten, war es demnach kaum möglich, zugelassen zu werden. Der Mitgliedsbeitrag von 24 livres pro Jahr mag eine Barriere für weniger wohlhabende Straßburger dargestellt haben ${ }^{54}$.

Soziale Spannungen im Sinne eines „Klassengegensatzes“ kommen bei diesem Soziogramm als Erklärung nicht in Frage. Die Zusammensetzung der frühen Clubbisten deutet eher auf Spannungen innerhalb der städtischen Elite hin. Die Abgeschlossenheit der politischen Kaste, welche Straßburg bis 1789 bestimmt hatte, hatte auch Mitglieder der Oberschicht von der Partizipation ausgeschlossen. Es gab Clubmitglieder, denen es zwar im Ancien Régime gelungen war, sich in den oberen Rängen der städtischen Gesellschaft zu etablieren, die jedoch damals Schwierigkeiten hatten, politisch Einfluß zu nehmen. Die große Zahl von Zugereisten - von den 22 Mitgliedern, die nicht dem Militär angehörten und deren Geburtsort bekannt ist, war nur gut die Hälfte in Straßburg geboren ${ }^{55}$ - ließe sich so herleiten. Die Neuankömmlinge, die sonst mehrere Generationen benötigten, um in die Oligarchie einzudringen, sahen in der revolutionären Ordnung eine Chance zum schnellen politischen Aufstieg. Doch nicht nur einst von politischer Partizipation ausgeschlossene Teile der Oberschicht fanden sich im Club ein; es gab auch eine kleine Gruppe innerhalb der Straßburger Revolutionsbewegung, die schon vor 1789 zum inneren Kreis der Macht gehörte, aber verstanden hatte, daß es nötig war, die großen

${ }^{52}$ Senatoren und Generaladvokaten gehörten der Elite der städtischen Politik vor der Revolution an; sie waren Berater der Magistrate. Schöffen waren die Vertreter der Zünfte. Die Genannten gehörten also zur politischen Führung, sie standen jedoch nicht in der ersten Reihe.

${ }^{53}$ Clubprotokoll vom 19. Jan. 1790.

${ }^{54}$ Clubprotokoll vom 23. Jan. 1790.

s5 Der hohe Anteil von Immigranten kann nicht überraschen, wenn man bedenkt, daß das Bevölkerungswachstum in Straßburg im Laufe des 18. Jahrhunderts fast ausschließlich auf Einwanderung zurückzuführen ist. (DREYER-ROoS, La population Strasbourgeoise, S. 109138.) 
politischen Veränderungen aktiv mitzuvollziehen, um nicht von der Spitze vertrieben zu werden.

1789/90 ging es in Straßburg also vor allem um politischen und kaum um sozialen Wandel. Diese These wird nicht nur durch die Unterdrückung der lokalen Volksbewegung im Sommer 1789 bestätigt, sondern auch durch den offensichtlichen politischen Ehrgeiz der frühen Clubbisten. Bester Beleg dafür ist das Engagement der Clubmitglieder bei den Wahlen zur neuen Munizipalität. Dem Club ging es darum, die Wahlen durch eine Pressekampagne publik zu machen; vor allem aber engagierte er sich für den Erfolg von Kandidaten aus seinen eigenen Reihen. Die Straßburgische Zeitung, deren Redakteur Friedrich Rudolph Saltzmann zu den Gründungsmitgliedern der Straßburger Revolutionsgesellschaft gehörte und die sich mehr und mehr zum Sprachrohr des Clubs entwickelte, berichtete ausführlich über die Beratungen und Dekrete der Nationalversammlung, welche die Wahlen betrafen ${ }^{56}$. Noch umfangreicher war die Berichterstattung in der Straßburgischen Chronik, die ein Sprachrohr des Clubs war, auch wenn ihr Redakteur Jean Ehrmann erst einige Monate später beitrat. In einem längeren Artikel Über die bevorstehenden Wahlen ${ }^{57}$ erklärte der Redakteur die Kriterien für Aktiv- und Passivbürgerschaft. Wenige Tage später kommentierte er die Eigenschaften derer, die man in die Munizipalität wählen soll ${ }^{58}$. Der Autor ließ keinen Zweifel daran, daß die Kandidaten des Clubs alle Eigenschaften aufwiesen, die ein gewählter Vertreter haben sollte.

In einer Passage desselben Artikels schlägt sich das ambivalente Verhältnis der Patrioten zur alten politischen Elite nieder:

Einige Personen gehen in ihrem Mißvergnügen gegen die vorige Verwaltung so weit, daß sie keine der vorigen Magistratspersonen zu wählen gedenken. Das wäre nicht gut. Nicht nur sind sehr verdienstvolle Männer darunter, die alle Achtung verdienen, sondern es wäre ein wahrer Schade, wenn solche Personen, welche die Geschäfte verstehen, nicht wieder zu den Geschäften kämen. Es ist hier hauptsächlich nötig, ohne Vorurteil zu handeln ${ }^{59}$.

Dieses Zitat belegt die oben formulierte These einer Anpassung von Teilen der bestehenden politischen Elite an eine neue Zeit.

Die Ergebnisse der Wahlen, die zwischen dem 5. Februar und dem 4. März abgehalten wurden, entsprachen den Vorstellungen der Clubbisten. Die Wahl-

${ }^{56}$ Art. „Paris, den 28 Dez.", in: Straßburgische Zeitung, Nr. 2, 4. Jan. 1790. Beylage zur Straßburgischen Zeitung, 6. Jan. 1790. Art. „Paris, den 9. Jänner“, in: Straßburgische Zeitung Nr. 7, 15. Jan. 1790.

${ }^{57}$ Art. „Über die bevorstehenden Wahlen“, in: Straßburgische Chronik, Nr. 1, 6. Jan. 1790.

${ }^{58}$ Art. „Noch einiges über die Eigenschaften derer, die man in die Munizipalität wählen soll“, Straßburgische Chronik, Nr. 3, 11. Jan. 1790.

${ }^{59}$ Ibid. Weitere Berichte über die Wahlen: Extrablatt zur Straßburgischen Chronik Nr. 17. 
beteiligung war sehr hoch; bei den Bürgermeisterwahlen lag sie bei $73 \%{ }^{60}$. Die Kandidaten aus den Reihen des Clubs erreichten gute Ergebnisse: Sieben der Gründungsmitglieder waren bei den Wahlen zum Conseil général de la Commune erfolgreich. Fünf weitere Gewählte waren nach der Gründung, aber noch vor ihrer Wahl Mitglieder des Clubs geworden. Nach den Wahlen traten sechzehn Mitglieder der städtischen Verwaltung dem Club bei. Im ersten Conseil général de la Commune von Straßburg, der vom 18. März bis zum 22. November 1790 bestand, waren oder wurden 28 der 60 Amtsträger Mitglieder des Clubs $^{61}$. Auch Mitglieder des letzten Magistrats befanden sich unter den Gewähiten. Roland Marx nennt Zahlen für die ersten Jahre der Revolution: Sechzehn der im März 1790 gewählten Munizipalbeamten und Notabeln waren ehemalige Magistratsmitglieder; nach den Neuwahlen im Oktober 1790 waren es noch vierzehn ${ }^{62}$. Ihre Zahl ging bei den folgenden Wahlen weiter zurück. Die Aufstellung zeigt, wie groß der Einfluß des Clubs und damit einer teils bestätigten, teils nachrückenden politischen Führungsschicht wurde. In dieser Beziehung ähnelte Straßburg den meisten französischen Städten; auch anderswo war der vollständige Austausch städtischer Eliten in den Umwälzungen von $1789 / 90$ selten $^{63}$.

Im Laufe des Frühjahres 1790 entwickelte sich ein sehr enges Verhältnis zwischen der Munizipalität und dem Club $^{64}$. Dies lag nicht zuletzt am neuen Bürgermeister Friedrich Dietrich, der einer alteingesessenen, angesehenen und reichen Straßburger Familie angehörte, vor der Revolution Kontrolleur der königlichen Minen gewesen war und 1789 als Commissaire du Roi zwischen dem alten Magistrat und dem Bürgerkomitee vermittelt hatte ${ }^{65}$. Dietrich, dem es trotz seines Erfolgs im Ancien Régime gelungen war, zur Galionsfigur der Straßburger Revolution zu werden, hatte bereits vor seiner Wahl Kontakt mit

${ }^{60}$ MARX, Recherches sur la vie politique, S. $58 \mathrm{ff}$.

${ }^{61}$ Die Angaben entstanden aus dem Vergleich der Mitgliederdatenbank mit einer Aufstellung der Munizipalitätsmitglieder, die von Claude Betzinger (Strasbourg) erstellt wurde. (It. Procès-verbal d'installation de la municipalité de Strasbourg, Strasbourg 1790 [Arch. Mun. Str., Reg. Adm. Mun. 200]).

${ }^{62}$ Vgl. MARX, Recherches sur la vie politique, S. 153

${ }^{63}$ HUNT, Committees and Communes, S. 335-344.

${ }^{64}$ Der Beitritt von Mitgliedern der Munizipalität war immer ein besonders Ereignis, das mit feierlichen Reden begangen wurde. Am 13. April 1790 trat der Munizipalbeamte M. Weber dem Club bei und hielt eine Dankesrede (Clubprotokoll vom 13. April 1790). Auf diesen Tag bezieht sich der Präsident Brunck in seiner Ansprache vom 17. April 1790: Quelle confiance ne doit pas nous inspirer l'accession de trois officiers municipaux! C'est surtout l'exemple de ces pères choisis du peuple, de ces dignes chefs de la cité, qui nous fera triompher des préjugés de l'ignorance. (in: HEITZ, Les sociétés politiques, S. 32)

${ }^{65} \mathrm{Zu}$ Friedrich Dietrich: Gabriel G. RAMON, Frédéric de Dietrich, Nancy, Paris, Strasbourg 1919; L. SPACH, Frédéric de Dietrich. Premier maire de Strasbourg, Paris, Strasbourg 1857; Yves FREY, Strasbourg dans la Révolution: Frédéric de Dietrich, premier maire constitutionnel de Strasbourg, Strasbourg 1988. 
dem Club aufgenommen ${ }^{66}$. Am 19. März 1790 entsandte der Club eine erste Deputation ins Rathaus. Der Präsident der Gesellschaft sicherte dem neuen Chef der Munizipalität bei dieser Gelegenheit die volle Unterstützung des Clubs zu:

Une Société de citoyens, qui s'est spécialement dévouée à son maintien, et qui se décore du beau nom de ses amis, nous députe vers vous, pour vous assurer de la part qu'elle prend à la joie publique, et de l'empressement avec lequel elle donnera en toute occasion l'exemple du respect et de la soumission dus aux chefs de la cité. Elle se glorifie de posséder dans son sein plusieurs membres du corps municipal, et elle se flatte de l'espoir d'obtenir votre bienveillance. Vous avez manifesté, Monsieur, votre patriotisme de la manière la plus énergique; vous avez prouvé que vous êtes animés de la plus noble des passions, de l'amour du bien public. C'est par ces sentiments, par les actions qu'ils ont produites, que vous avez mérité la confiance de vos concitoyens et obtenu leurs suffrages ${ }^{67}$.

Der Bürgermeister lobte nun seinerseits die Arbeit des Clubs und versprach, diesen gegen alle Vorwürfe zu verteidigen. Für ihn war es selbstverständlich, daß Munizipalität und Club gemeinsam vorgehen sollten: Nous vous invitons à partager avec nous les honorables mais pénibles obligations que nous impose le vœu de nos concitoyens ${ }^{68}$. Das Bündnis zwischen der Stadtregierung und dem Club war in den ersten Jahren der Revolution von größter Wichtigkeit ${ }^{69}$. Die Mitgliedschaft im Club bereitete die Mitgliedschaft in der Munizipalität vor. Die Zusammenarbeit wurde durch die Aufnahme des Bürgermeisters Dietrich in den Club am 12 . Oktober 1790 noch verfestigt ${ }^{70}$. Warum trat Dietrich nicht früher in den Club ein? Vielleicht befürchtete er, die Mitgliedschaft in der anfangs mißtrauisch beobachteten Vereinigung könne seine Kandidatur für das höchste städtische Amt negativ beeinflussen.

Die ursprünglichen Motive für die Clubgründung scheinen damit auf der Hand zu liegen: Eine zumindest teilweise erneuerte politische Elite schaffte sich im Club eine Plattform zur Festigung eines bereits errungenen Sieges. Das

${ }^{66}$ Clubprotokoll vom 19. Jan. 1790.

${ }^{67}$ Protokoll des Besuchs vom 19. März 1790, in: HEITZ, Les sociétés politiques, S. 23f.

${ }^{68}$ Ibid. S. 24.

${ }^{69}$ Von der Zusammenarbeit zwischen dem Club und dem Bürgermeister zeugen mehrere Einträge im Protokoll; so der Beschluß, eine zweite Deputation zum Bürgermeister zu schicken, um diesen über ein Bureau in Kehl aufzuklären, das Elsässer bei der Emigration unterstützte (Clubprotokoll vom 16. März 1790). Am 20. April 1790 sandte Dietrich dem Club das Protokoll der Eröffnungssitzung der Munizipalität (Clubprotokoll vom 20. April 1790). Wenig später schrieb Dietrich dem Club einen Brief, in dem er sich für die Übersendung des Clubreglements bedankte. Brief Dietrichs an den Club vom 24. April 1790 [Arch. Mun. Str., Fonds, 3/10, 10, 24. April 1790].

${ }^{70}$ Clubprotokoll vom 12 . Okt. 1790. 
Bürgerkomitee und die inoffiziellen patriotischen Zirkel wurden durch den Club ersetzt, der es erlaubte, Einfluß auf die städtischen Wahlen zu nehmen und der vielen als Sprungbrett auf Posten in der neuen Stadtverwaltung diente. Die Gründung der Verfassungsfreunde war also Ausdruck einer Revolution, die Straßburg neue politische Strukturen, aber keinen Umsturz der gesellschaftlichen Verhältnisse gebracht hatte. Dem entsprach die in diesem Kapitel analysierte ideologische Ausrichtung auf Ordnung, Unterordnung und Einheit. Eine solche Ideologie stabilisierte und legitimierte die neue Elite, deren politische Ziele 1789 bereits verwirklicht und durch eine neue Zentralgewalt garantiert waren.

\section{Große Gesten - Judenemanzipation und Kosmopolitismus}

Auf die Frage „Wer gehört zu uns?““ antworteten die „Verfassungsfreunde“: Jeder, der bereit ist, die Regeln der neuen Ordnung anzuerkennen. Gleichzeitig strebten die frühen Clubbisten danach, möglichst viele Menschen an den Vorzügen der Revolution teilhaben zu lassen. Beide Grundsätze schlugen sich in ihren Versuchen nieder, verschiedenen Gruppen, die im Ancien Régime als „Fremde" gegolten hatten, die Hand zur Verbrüderung entgegenzustrecken. Im folgenden sollen zwei Beispiele für diese demonstrative Offenheit behandelt werden: die Initiative zur Gleichstellung der elsässischen Juden und der Kosmopolitismus. Beide Beispiele sind für die in dieser Studie verfolgte Fragestellung besonders interessant, weil sie eine Bestimmung des Verhältnisses von Politik und Kultur nötig machten. Während die korporative Gesellschaft des Ancien Régime auf dem Grundsatz beruhte, daß jede gesonderte Gruppe ihre eigene Rechtsform benötigte, sollten die Gesetze des revolutionären Zeitalters von kulturellen Unterschieden nicht beeinflußt werden. Gleichzeitig sollte die kulturelle Vielfalt als Ausdruck persönlicher Freiheitsrechte geschützt werden. Es mußten also Wege gefunden werden, die Einheit der neuen Ordnung und die Erhaltung kultureller Vielfalt gleichermaßen zu ermöglichen.

\section{Die Initiative zur Gleichstellung der elsässischen Juden}

Nach dem Zensus von 1784 lebten in 183 Orten des Elsaß 19.624 Juden. Diese machten 3\% der elsässischen Bevölkerung aus; es gab jedoch 21 Orte, in denen sie zwischen 15\% und 20\% der Einwohner steliten. Die elsässischen Juden wohnten vorwiegend in Dörfern und Kleinstädten, denn Straßburg und Colmar 
hatten ihnen den dauerhaften Aufenthalt verweigert. Sie bildeten eine Religionsgemeinschaft, die eine eigene Sprache, Jiddisch, sprach; aus französischer Perspektive waren sie „Fremde“, die im Royaume de France nur geduldet waren $^{71}$. Die besonderen Rechte, die den Juden einerseits ihre Religionsausübung und die Aufrechterhaltung ihrer Traditionen sicherten, andererseits aber ihre Bewegungsfreiheit und ihre Möglichkeiten zu beruflicher Entwicklung stark einschränkte, waren von der Revolution zunächst nicht angetastet worden. Den elsässischen Juden war der Besitz von Land und anderen Immobilien, sowie das Betreiben von Geschäften und Gasthäusern verboten; die Zünfte gewährten ihnen keinen Zutritt. Der größte Teil der Juden betrieb daher Handel: Die Ärmsten waren Krämer, die mit Waren des täglichen Bedarfs über die Dörfer zogen; die Wohlhabenderen handelten mit Korn, Vieh oder Pferden. Fast alle Juden sicherten sich einen Nebenverdienst durch das Verleihen von Geld; so gaben jüdische Händler Kredite zur Finanzierung von Waren, die sie verkauften. Die Juden zahlten besondere Abgaben an den König, der ihnen dafür Schutz zusagte; zusätzlich wurden bei Hochzeiten Abgaben erhoben. 1784 schaffte Ludwig XVI. den Leibzoll für Juden ab; ihre Beteiligung an industriellen Unternehmungen wurde erlaubt ${ }^{72}$.

Juden unterschieden sich durch ihre Religion, ihre Sprache, ihre Rechte, ihre Pflichten und durch ihren Broterwerb von den Untertanen Ludwigs XVI. Ihre Außenseiterrolle wurde ihnen immer wieder ins Bewußtsein gerufen. Beispielsweise sollen $1777 \mathrm{im} \mathrm{Elsaß} \mathrm{falsche} \mathrm{Schuldscheine} \mathrm{gedruckt} \mathrm{worden} \mathrm{sein,}$ um „Beweise" für die These zu liefern, daß ein Drittel des im Elsaß verliehenen Geldes von jüdischen Gläubigern stamme ${ }^{73}$. $\mathrm{Zu}$ Beginn der Revolution traten die anti-jüdischen Ressentiments erneut offen zutage. Der Cahier de doléances des Dritten Standes von Straßburg forderte eine Rücknahme der vorrevolutionären Zugeständnisse des Königs an die Juden ${ }^{74}$. Bei Pogromen im Juli 1789 wurden Juden in siebzig Orten des Elsaß angegriffen; jüdisches Eigentum wurde zerstört und Schuldbriefe vernichtet.

${ }^{71}$ Paula E. HYMAN, The Emancipation of the Jews of Alsace, New Heaven, London 1991, S. 12ff.; Freddy RAPHAËL, Robert WEYL, Juifs en Alsace. Culture, société, histoire, Toulouse 1977.

72 Jean DALTROFF, Le prêt d'argent des juifs de Basse-Alsace 1750-1791, Strasbourg 1993, S. 32ff.; Roland MARX, La Régénération économique des juifs d'Alsace à l'époque révolutionnaire et napoléonienne, in: Bernard BluMENKRANZ, Albert SOBOUL (Hg.), Les juifs et la Révolution française, Toulouse 1976, S. 105-120; Zosa SZAJKowSKI, The Economic Status of the Jews in Alsace, Metz and Lorraine 1648-1789, New York 1953.

${ }^{73}$ Die minutiöse Studie von Jean Daltroff hat unlängst gezeigt, daß der Anteil des von Juden im Elsaß verliehenen Geldes an der Gesamtsumme der Kredite deutlich geringer war. Zwischen 1736 und 1781 verringerte sich der Anteil der jüdischen Gläubiger an der Gesamtheit des im Elsaß geschuldeten Geldes von 7,32\% auf 4,35\%. (DALTROFF, Le prêt d'argent des juifs, S. 67f.).

${ }_{74}$ STEEGMANN, Les Cahiers de doléances alsaciens. Spécifités et problèmes, S. 30. 
Trotz dieser negativen Erfahrungen kämpften die elsässischen Juden 1789 gegen die einschränkenden Sonderrechte ${ }^{75}$. Der in Paris ansässige Jude Cerf Berr, Syndic général der Juden des Elsaß', Lothringens und der Trois Evêchés, erreichte, daß die Juden ein Heft mit Beschwerden und Wünschen abfassen durften. Am 25. Mai 1789 fanden sich Vertreter der jüdischen Gemeinden des Elsaß im Haus von Marx Berr in Straßburg ein, der als einziger Jude schon vor der Revolution ein Wohnrecht in Straßburg erworben hatte. Die Versammlung setzte ein Beschwerdeheft auf, das anschließend nach Paris geschickt und dort mit den Gravamina der übrigen Juden aus Ostfrankreich vereinigt wurde. In diesem jüdischen Cahier wurde die Abschaffung aller Sonderabgaben und die Besteuerung der Juden nach den allgemein üblichen Grundsätzen gefordert; außerdem verlangte man die freie Wahl des Wohnortes, freie Heirat, das Recht zum Kauf von Häusern und anderem Grundbesitz, sowie freien Zugang zu allen Berufen. Gleichzeitig wollten die Juden die freie Ausübung ihrer Religion und die eigene Gerichtsbarkeit beibehalten ${ }^{76}$. Abbé Grégoire trug die Forderungen der Juden am 3. August 1789 der Nationalversammlung vor. Eine Entscheidung über das Schicksal der elsässischen Juden wurde zu diesem Zeitpunkt aber noch nicht gefällt.

Erst durch die am 28. Januar 1790 dekretierte Zulassung der immigrierten portugiesischen, spanischen und avignonesischen Juden zur Aktivbürgerschaft kam erneut Bewegung in die Debatte ${ }^{77}$. Dies machte sich auch in Straßburg bemerkbar. Am 2. Februar 1790 erreichte den erst zwei Wochen alten Straßburger Club der Brief eines Pariser „Verfassungsfreundes", der die Straßburger aufforderte, sich mit dem Zivilstand der elsässischen Juden zu befassen:

Un objet bien digne d'occuper la Société de Strasbourg seroit l'état civil des juifs si nombreux en Alsace; croyez vous qu'ils désirent d'être mis au nombre des citoyens françois? Je pense que s'ils en formoient le vau, et que l'on fût bien assuré que cela ne produiroit aucun trouble dans une Province qui

\footnotetext{
${ }^{75}$ Robert BADINTER, Libres et égaux: l'émancipation des Juifs sous la Révolution française, 1789-1791, Paris 1989, S. 117-138; Friedrich BATTENBERG, Die Französische Revolution und die Emanzipation der Juden im Elsaß und in Lothringen, in: Volker RÖDEL (Hg.), Die Französische Revolution und die Oberrheinlande (1789-99), Sigmaringen 1991, S. 245-273; David FEUERWERKER, L'émancipation des juifs en France, Paris 1976, S. 293f.; Jacques GODECHOT, La Révolution française et les juifs (1789-1799), in: BLUMENKRANZ, SOBOUL, Les juifs, S. 47-70, bes. S. 56f; Ruth NECHELES, L'émancipation des juifs 1787-1795. Aspects intellectuels et politiques, in: BLUMENKRANZ, SOBOUL, Les juifs, S. 71-86, bes. S. 79. ${ }^{76}$ Robert WEYL, Jean DALTROFF, Les Cahiers de doléances des Juifs d'Alsace, in: RA 109 (1983) S. 65-80.

${ }^{77}$ F. MALINO, Les juifs sépharades de Bordeaux, assimilation et émancipation dans la France révolutionnaire et impériale, Bordeaux 1984.
} 
conserve peut-être encore des préjugés contre eux, l'assemblée nationale ne balanceroit pas à les mettre au nombre des citoyens ${ }^{78}$.

Das Schreiben versetzte die Straßburger Clubbisten in Aufregung. Es war eine große Ehre, von den Parisern um Rat gefragt und so direkt an der Verfassungsarbeit beteiligt zu werden. Darüber hinaus war die Frage der Judenemanzipation eine Herausforderung für die neue Ordnung. Eine gesellschaftliche Gruppe, die nach besonderen Regeln und Gesetzen lebte, war ein Hemmnis für die neue Ordnung, in deren Innerem Einheit herrschen sollte. Vor allem aber hatten die „Verfassungsfreunde“" proklamiert, die neue Ordnung solle für alle offen sein, die bereit seien, sich den neuen politischen Regeln zu unterstellen. Die Juden hatten wiederholt den Wunsch geäußert, dies zu tun. Welchen Grund konnte es geben, sie abzuweisen?

Der Straßburger Club beschloß, in einer der nächsten Sitzungen die Meinungen der Mitglieder zu diesem Thema zu hören; außerdem sollten die Korrespondenten im Elsaß zur Judenemanzipation befragt werden ${ }^{79}$. Der erste, der sich äußerte, war der Straßburger Publizist Rudolph Saltzmann, der sich bereits vor der Revolution an den judenfreundlichen Bestrebungen der Straßburger Société des Philanthropes beteiligt hatte. In der Sitzung vom 17. Februar berichtete er, daß er sich mit dem Juden Marx Berr besprochen habe und daß dieser die Verleihung der Staatsbürgerschaft an die Juden für ungefährlich halte. Im Gegenteil sei es gefährlich, sie ihnen zu verweigern, denn viele elsässische Gemeinden duldeten die Juden nur, weil sie glaubten, die Nationalversammlung hätte ihnen das Bürgerrecht bereits zugesprochen. Die Debatte über die Emanzipation der Juden wurde also mit Überlegungen zu ihrer Sicherheit eröffnet. Gleichzeitig führte sie erneut das Streben der Mitglieder nach Ordnung vor Augen: Die Sonderstellung der Juden hatte zu Konflikten und Unruhen geführt; Emanzipation und Integration sollten Harmonie stiften und so die Ordnung stabilisieren.

Das Mitglied Brunck machte in derselben Sitzung den Vorschlag Marx Berr, den einzigen Juden, der das Recht hatte, samt seiner Familie in Straßburg zu wohnen, in die Gesellschaft der Verfassungsfreunde aufzunehmen. Nach kurzer Debatte wurde die Frage zur Abstimmung gestellt, si l'on peut admettre les juifs dans la société $?^{80}$ Die Frage wurde positiv entschieden. Die Gesellschaft brüstete sich, le premier témoignage du mépris pour un injuste préjugé ${ }^{81}$ gegeben zu haben. In späteren Debatten wurde allerdings darüber verhandelt, ob das Adjektiv injuste aus dem Protokoll gestrichen werden sollte. Im Club gab

\footnotetext{
${ }^{78}$ Clubprotokoll vom 2. Feb. 1790.

${ }^{79}$ Ibid.

${ }^{80}$ Clubprotokoll vom 17. Feb. 1790.

${ }^{81}$ Clubprotokoll vom 20. Feb. 1790.
} 
es also durchaus auch Kritiker der Emanzipation. Dies darf jedoch nicht den Blick dafür verstellen, daß der Club mit der Aufnahme des Juden Marx Berr einen Akt von großer Tragweite vollzogen hatte. Da sich der Club als Miniatur der zu erneuernden Gesellschaft verstand, war Marx Berrs Beitritt symbolische Vorwegnahme der staatsbürgerlichen Gleichstellung der elsässischen Juden.

In der folgenden Sitzung, am 20. Februar 1790, schwor Marx Berr den Eid und reichte gleichzeitig seinen Aufnahmeantrag nach. Dieser enthält eine Passage, die zeigt, wie die Aufnahme der ehemals „Fremden“ in die neue Ordnung gedacht war:

Messieurs, [...] vous savez que tout homme né et domicilié dans le Royaume respectant et observant les loix contribuant à proportion de ses facultés aux charges de l'état, ne peut et ne doit être que considéré comme citoyen. L'auguste Assemblée des Représentants de la Nation ne tardera pas à consacrer par une loi solemnelle cet axiome politique, que les droits et l'état civil de l'homme sont indépendans des opinions religieuses et des pratiques du culte rendu à l'être suprème $e^{82}$.

Marx Berr nannte die Bedingungen für Zugehörigkeit (Wohnsitz in Frankreich, Gehorsam gegenüber den Gesetzen und Einhaltung der Steuerpflicht) und betonte auch, daß Glaube und religiöse Praktiken für die Bürgerschaft keine Rolle spielen dürften. Gleichzeitige Zugehörigkeit zu einer politischen und zu einer religiösen Gemeinschaft müsse möglich sein. Marx Berr hatte in knappen Worten ein Konzept umrissen, das politische Einheit und kulturelle Vielheit gleichermaßen berücksichtigte. Obwohl dieser entscheidende Schritt getan war, begann jetzt die Debatte über die Gleichstellung erst richtig. Offenbar war das Verhältnis von politischer und religiöser Zugehörigkeit nicht so unproblematisch wie Marx Berrs Formulierungen nahelegten.

Im Anschluß an den Eidschwur von Marx Berr wurde ein Komitee eingerichtet, das alle Diskussionsvorschläge zur Judenemanzipation sammeln und eine Adresse an die Nationalversammlung verfassen sollte. Brunck wurde zum Vorsitzenden des Komitees ernannt. Bereits eine Woche später legte er ein flammendes Plädoyer für die Gleichstellung vor, das allerdings auch gängige Bedenken widerspiegelte ${ }^{83}$. Brunck bestätigte zunächst Marx Berrs Ansichten über das Verhältnis von politischer und religiöser Zugehörigkeit:

\footnotetext{
${ }^{82}$ Clubprotokoll vom 20. Feb. 1790. M. Marx Berr réçu à la Société des Amis de la Constitution de Strasbourg, 20. Februar 1790 [Bibl. Nat. Univ. Str., M 5941, 107].

${ }^{83}$ Clubprotokoll vom 27. Feb. 1790.
} 
Die Frage kann nicht bezweifelt werden, ob Menschen, die sich von andern bloß durch ihre Lehrsätze und die Ausübung ihrer Gottesverehrung unterscheiden, wie Menschen behandelt werden sollen; ob, wenn sie die bürgerlichen Geschäfte und Obliegenheiten erfüllen, der Rechte des Bürgers theilhaftig gemacht werden müßen. Der Bürgerstand der Juden überhaupt kann nicht bestritten werden, wenn man ihn nur nach Gründen der Billigkeit, und nach einer natürlichen Politik beurteilen will ${ }^{84}$.

Ähnlich wie sein jüdischer Vereinsbruder ging Brunck davon aus, daß Religion und Politik zu trennen seien. Die Juden sollten ihrem Glauben und ihren Bräuchen treu bleiben und trotzdem Teil der Bürgergemeinschaft werden können. Auch er schlug vor, durch doppelte Zugehörigkeit politische Einheit und kulturelle Vielfalt miteinander zu verbinden.

Im folgenden entwickelte Brunck dieses Konzept weiter. Er prognostizierte, daß die befreiten Juden durch nützliche Arbeit zum Wohlergehen der Provinz beitragen würden: Laßt uns Ackers- und Handwerksleute aus ihnen machen; wir werden dann die Produkte unserer Provinz vervielfältiget und unsere Handlung vergrößert sehen ${ }^{85}$. Folge einer solchen Integration werde eine moralische Wiedergeburt ${ }^{86}$ der Juden sein. Laut Brunck diente die Emanzipation der Juden also nicht nur der politischen Einheit, sondern würde zusätzlich eine allmähliche Assimilation nach sich ziehen. Durch die Integration der Juden in die neue politische Ordnung würde sich also die kulturelle Vielfalt verringern und damit die Konflikte zwischen Einheit und Vielheit.

Darüber hinaus versuchte Brunck, die mit der Gleichstellung verbundenen Gefahren für die Ordnung als gering darzustellen. So wandte er sich gegen das Argument, daß das Volk, über die Gleichheit der Rechte, die es mit ihnen [den Juden] theilen soll, aufgebracht, sie seiner Wuth aufopfern würde ${ }^{87}$. Brunck versuchte, das Ausmaß der Judenfeindschaft im Elsaß herunterzuspielen. Die Judenverfolgungen im Sundgau im August 1789 stellte Brunck als ein isoliertes Ereignis dar, das einer kleinen Gruppe notorischer Judenfeinde zuzuschreiben sei. Die Lage im Sundgau habe sich inzwischen beruhigt und bereits im September seien die während der Ausschreitungen geflüchteten Juden wieder zurückgekehrt. In einem Ort des Sundgau sei sogar ein Vergleich zwischen Christen und Juden ausgehandelt worden. Im ganzen übrigen Elsaße sind die Juden nirgends gekränkt worden; und es läßt sich vermuthen, daß das Volk

\footnotetext{
${ }^{84}$ Richard François Philippe BRUNCK, Bericht welcher in der Gesellschaft der Freunde der Konstitution über die Frage vorgelesen wurde: Können die Juden im Elsaße des Bürgerrechts theilhaftig werden?, Straßburg 1790, S. 3 [Bibl. Nat. Univ. Str., M 5941, 13].

${ }^{85}$ Ibid. S. 23.

${ }^{86}$ Ibid. S. 25.

${ }^{87}$ Ibid. S. 4.
} 
überall das Bürgerrecht mit ihnen teilen wird ${ }^{88}$. Bruncks Bericht zufolge durften die aus der Judenfeindschaft erwachsenden Gefahren für die Ordnung nicht überschätzt werden. Durch die Emanzipation würde sich das Zusammenleben von Juden und Christen im Elsaß nach und nach harmonischer gestalten. Brunck legte also auch hier wert darauf, die Emanzipation als ein Mittel zur Beilegung gesellschaftlicher Konflikte darzustellen.

Die Straßburger Gesellschaft beschloß, daß die Grundsätze dieses Berichts die ihrigen seyen ${ }^{89}$. Der Bericht wurde mit der Bitte an die Pariser Muttergesellschaft gesandt, ihn der Nationalversammlung vorzulegen. Außerdem wurde er in 2500 Exemplaren in französischer und deutscher Sprache gedruckt und in den Orten der Umgebung verteilt, wo viele Juden wohnten. Überdies setzte sich die Gesellschaft für die Abschaffung städtischer Verordnungen ein, welche die Freiheit der Juden beschnitten. Von der Straßburger Munizipalität wurde gefordert, die Juden nicht länger bei Anbruch der Nacht aus der Stadt auszuweisen. Das Horn, welches bislang den Juden anzeigte, wann sie die Stadt zu verlassen hatten, sollte ab sofort verstummen. Der am Stadttor zu entrichtende Judenzoll sollte abgeschafft werden. An die Juden erging die Aufforderung, so zahlreich wie möglich in die Nationalgarde einzutreten, um ihr Engagement für die neue Ordnung zu bekunden. Der Club wollte durch einen Brief an den Kommandanten der Nationalgarde für den freien Zugang der Juden zur Bürgermiliz sorgen ${ }^{90}$.

Am 7. April 1790 wurde Bruncks Bericht der Nationalversammlung vorgelegt. Zu dieser Zeit gingen dort ähnliche Zuschriften von verschiedenen Seiten ein; die Pariser Juden waren in dieser Phase die vehementesten Vertreter der Gleichstellungsforderung ${ }^{91}$. Dennoch traf das Parlament wiederum keine Entscheidung. Die Verzögerung entstand unter anderem deshalb, weil andere Petitionen aus Straßburg eintrafen, welche die Darstellung des Clubs in Frage stellten. Der Straßburger Stadtrat hatte am 6. März 1790 an die Nationalversammlung geschrieben, die Emanzipation der Juden sei nicht nur gefährlich, sondern auch unerwünscht. In Straßburg kursierten Adressen gegen die Judenemanzipation; so ein Flugblatt unter dem Titel Observations sur la possibilité et l'utilité de l'admission des juifs en Alsace aux droits de citoyens, adressées aux membres de la S. par un ami de l'humanité und ein Avis aux Alsaciens ${ }^{92}$.

\footnotetext{
${ }^{88}$ Ibid. S. 14.

${ }^{89}$ Ibid. S. 30.

${ }^{90}$ Clubprotokolle vom 27. Feb. und 2. März 1790.

${ }^{91}$ FEUERWERKER, L'émancipation, S. 287-399.

${ }^{92}$ Beide zit. nach HEITZ, Les sociétés politiques, S. 29; P. HILDENFINGER, L'Adresse de la communauté de Strasbourg à l'Assemblée Nationale contre les juifs (avril 1790), in: REJ 58 (1909) S. 112-125; DERS., Les actes du district de Strasbourg relatifs aux juifs (juillet 1790fructidor an III), in: REJ 60 (1910) S. 235-255 u. 61 (1911) S. 102-123 u. 279-284.
} 
Xavier Levrault, ein „Verfassungsfreund“, der ein Amt in der Stadtverwaltung bekleidete und sich für die Gleichstellung eingesetzt hatte, mußte sich gegen scharfe Angriffe seiner Kollegen zur Wehr setzen. In einer Sitzung der zweiten Sektion von Straßburg wurde er als mauvais citoyen beschimpft; die Gegner der Gleichstellung griffen ihn in mehreren Flugblättern $\mathrm{an}^{93}$. Der Club brachte daraufhin mehrere Schreiben in Umlauf, in denen er Levrault verteidigte. Man erinnerte daran, daß Levrault die Petition des Clubs zur Emanzipation der Juden zu einem Zeitpunkt unterschrieben hatte, als er noch kein städtisches Amt innhatte. Als Amtsträger fühle er sich selbstverständlich der Meinung der Kommune verpflichtet und werde alles tun, um ihren Wünschen und Ansichten zu entsprechen ${ }^{94}$.

In einem weiteren Flugblatt verwiesen die Verfassungsfreunde auf das in der Erklärung der Menschen- und Bürgerrechte festgelegte Recht auf freie Meinungsäußerung:

La Commune, qui jouit du droit précieux de manifester librement son opinion, peut-elle faire un crime à la Société des Amis de la Constitution, d'avoir manifesté la sienne, surtout dans un temps où la Commune ne s'occupoit pas encore de cet objet? On ne reprochera pas à la société d'avoir cherché à capter l'assentiment de quelques citoyens, et à les engager dans une opinion contraire à celle à laquelle ils auroient incliné $e^{95}$.

Nach dieser halbherzigen Verteidigung trat die Société den Rückzug an; die Gleichstellung der Juden wurde von dieser Zeit an nicht mehr diskutiert. Marx Berr blieb zwar Mitglied des Clubs, aber außer ihm traten nur zwei weitere Juden bei. Sein Kontakt zum Club wurde von dieser Zeit an distanzierter. In einem Brief vom 1. Februar 1791 wandte er sich zwar noch mit der Bitte an die Gesellschaft, ihn gegen Anschuldigungen in Schutz zu nehmen; doch scheint es, als wäre er seit dem Frühjahr 1790 den Sitzungen ferngeblieben ${ }^{96}$. Immerhin beschloß die Assemblée nationale im folgenden Jahr, am 28. September 1791, die Zulassung der Juden zu den Bürgerrechten. Insofern war die Kampagne für die Emanzipation, an der sich der Club zwar nur kurz, aber intensiv beteiligt hatte, schließlich doch noch von Erfolg gekrönt.

Die Initiative der Verfassungsfreunde für die Emanzipation der Juden war anfänglich vom Willen zur Integration und zur Aussöhnung alter Feindschaf-

${ }^{93}$ Citoyens de Strasbourg, soyez sur votre garde pour votre liberté, in: HEITZ, Les sociétés politiques, S. 30 .

${ }_{94}$ Flugblatt des Clubs ohne Titel und Datum [Bibl. Nat. Univ. Str., M 5941, 103].

${ }^{95}$ Réflexions sur la Société des Amis de la Constitution, Strasbourg 0. D. [Bibl. Nat. Univ. Str., M 5943, 104].

${ }^{96}$ Brief von Marx Berr an den Club vom 1. Feb. 1791 [Arch. Mun. Str., Fonds, 4/11, 26]. 
ten geprägt. Sie beruhte auf einem Konzept, das politische Einheit und kulturelle Vielfalt verband. Die „Verfassungsfreunde“ propagierten ein neues politisches Zugehörigkeitsgefühl, das hergebrachte Identitäten überlagern und so eine harmonische Gemeinschaft aller Bürger begründen sollte. Die über Jahrhunderte aufgebauten Konflikte sollten durch die neuen Mechanismen des Ausgleiches befriedet werden. Unabhängig vom vorläufigen Scheitern der Initiative hatte der Club ein wegweisendes Konzept vorgelegt und im Rahmen seiner Möglichkeiten umgesetzt. Es gab also ursprünglich den Willen, Einheit zu schaffen und gleichzeitig Vielfalt zu tolerieren. $\mathrm{Da} \beta$ der Club die Initiative abbrach, gibt jedoch auch Aufschluß über die inneren Widersprüche der frühen revolutionären Ideologie und über die Prioritäten der Patrioten. Diese standen vor der Entscheidung, für eine Politik der Umarmung die innere Harmonie der revolutionären Bewegung zu gefährden. Durch einen Vorgriff auf die Entscheidungen der zuständigen politischen Stellen vor Ort und in Paris hätten sie Zwietracht und nicht Harmonie gestiftet und den landesweiten Konsensmechanismus in Gefahr gebracht. Welchem der beiden Ansprüche der Vorrang zu geben war, stand für die Straßburger Clubbisten außer Frage.

\section{Kosmopolitismus}

Am 26. August 1789 verabschiedete die Nationalversammlung die Erklärung der Menschen- und Bürgerrechte, die wegen ihres globalen Anspruchs als erstes außenpolitisches Manifest der Revolution bezeichnet werden kann. Am 22. Mai 1790 wurde in der sogenannten Déclaration de paix au monde der Verzicht Frankreichs auf Angriffskriege gegen andere Völker festgeschrieben $^{97}$. Im gleichen Zeitraum traten jedoch auch die Feindseligkeiten zwischen Frankreich und seinem deutschen Nachbarn in eine neue Phase. Während Frankreich den deutschen Fürsten vorwarf, den Gegnern der Revolution Asyl zu gewähren, nahmen die Fürsten Anstoß an der Enteignung deutscher Besitzungen im Elsaß ${ }^{98}$.

\footnotetext{
${ }^{97}$ Arch. Parl., Bd. 15, S. 661f.

${ }^{98}$ Zum Kosmopolitismus: Frank ATTAR, La Révolution Française déclare la guerre à l'Europe, Bruxelles 1992, bes. S. 9-30 u. S. 74-162; Timothy C. W. BLANNING, The Origins of the French Revolutionary Wars, London 1986; Eckhard BUDDRUSS, Die Deutschlandpolitik der Französischen Revolution. Zwischen Traditionen und revolutionärem Bruch, in: ARETIN, HÄRTER, Revolution und konservatives Beharren, S. 145-154; Franz DUMONT, Befreiung oder Fremdherrschaft? Zur französischen Besatzungspolitik am Rhein im Zeitalter der Französischen Republik, in: Peter HÜTTENBERGER, Hansgeorg MOLITOR ( $\mathrm{Hg}$.), Franzosen und Deutsche am Rhein 1789-1918-1945, Essen 1989, S. 91-112; Jacques GODECHOT, La Grande Nation. L'expansion révolutionnaire de la France dans le monde de 1789-1799, 2 Bde., Paris 1956; Michael JeISMANN, Das Vaterland der Feinde. Studien zum nationalen Feindbe-
} 
In der Straßburger Zunftstube „Zum Spiegel“, wohin der Club bald seine Sitzungen verlegte, griff man diese zweideutige Haltung auf. Universalistische und kosmopolitische Ideen fanden jedoch in der Zeit zwischen dem Sommer 1790 und dem Sommer 1791 in Straßburg größeren Anklang als feindselige Proklamationen. Die in dieser Zeit wieder und wieder ausgesprochene großzügige Einladung an alle Völker, sich in die neue Ordnung einzureihen, ist ein weiteres Beispiel für die anfängliche Offenheit des Clubs. Ähnlich wie dem bon peuple und ähnlich wie den Juden bot man den Ausländern, vor allem den deutschen Nachbarn, an, zur neuen Ordnung dazuzugehören. Es wird sich jedoch zeigen, daß das Konzept einer doppelten Zugehörigkeit in der kosmopolitischen Ideologie nicht in der gleichen Weise zum Tragen kam wie in den Initiativen zur Judenemanzipation. Die Konstruktion, mit deren Hilfe politische Einheit und kulturelle Vielheit verbunden werden sollten, sah hier etwas anders aus.

Im August 1790 faßte der Präsident Xavier Levrault die kosmopolitischen Ideen des Clubs in feierlichen Worten zusammen. Die weltweite Nachahmung der Revolution sei durch die breite Wirkung der Aufklärung vorbereitet und die Revolution sei deshalb le patrimoine du genre humain ${ }^{99}$. Er erinnerte an die kosmopolitische Initiative von Anarchasis Cloots ${ }^{100}$, dem orateur du genre humain, der beim Föderationsfest im Juli 1790 an der Spitze einer „Deputation des Menschengeschlechts" erschienen war. Dieses Ereignis hätte sich in Straßburg in bescheidenem Umfang wiederholt. Bei der Föderation der Nationalgarden der östlichen Départements im Juli 1790 seien auch Revolutionsanhänger aus Deutschland gewesen, die ihre Begeisterung und ihre Opferbereitschaft für die Revolution beteuert hätten. Dies war für Levrault ein sicherer Beweis dafür, daß die association de tous les peuples à la gloire et aux succès de notre nation ${ }^{101}$ sich bereits vollzöge. Levrault griff auch die für den kosmopolitischen Diskurs typische Metapher der grande famille européenne ${ }^{102}$ auf. Darüber hinaus konstruierte er, indem er von der liberté que nos ancêtres communs connaissaient, mais imparfaits, dans les forêts de la Germanie ${ }^{103}$ sprach, eine gemeinsame französisch-deutsche Geschichte.

griff und Selbstverständnis in Deutschland und Frankreich 1792-1918, Stuttgart 1992, bes. S. 103-158; Albert MATHIEZ, La Révolution et les étrangers. Cosmopolitisme et défense nationale, Paris 1918; Sophie WAHNICH, L'impossible citoyen. L'étranger dans le discours de la Révolution française, Paris 1997.

${ }_{99}$ Clubprotokoll vom 17. Aug. 1790.

${ }^{100} \mathrm{Zu}$ Anarchasis Cloots: MATHIEZ, La Révolution et les étrangers, S. 48-57. Roland MORTIER, Anarchasis Cloots ou l'utopie foudroyée, Paris 1995.

${ }^{101}$ Clubprotokoll vom 17. Aug. 1790.

${ }^{102}$ Ibid.

${ }^{103}$ Ibid. 
Die Öffnung nach Deutschland stand also unter anderen Vorzeichen als die Aussöhnung mit den Juden. Die Elsässer fühlten sich mit Deutschland verbunden; sie sahen keine Notwendigkeit für Aussöhnung. Während zur Integration der Juden die Fremdheit dieser Gruppe akzeptiert werden mußte, war die Eingliederung der Deutschen in die revolutionäre Ordnung nur eine Frage politischer Entscheidungen. Weil man der gleichen Familie angehörte, weil sich eine gemeinsame Vergangenheit konstruieren ließ, bedurfte es keiner doppelten Zugehörigkeit. Die Vielfalt der Sprachen, Religionen und Traditionen spielten in der kosmopolitischen Ideologie daher nur eine untergeordnete Rolle.

Die Suggestion einer bereits existierenden universellen Gemeinschaft wurde auch durch Briefe aus dem Ausland aufgebaut, die sich die kosmopolitische Ideologie zu eigen machten. Im Sommer 1790 schrieb Friedrich Cotta ${ }^{104}$, der Bruder des bekannteren Stuttgarter Verlegers, den Straßburgern und schilderte seine glühende Begeisterung für die Revolution: Je bénis le moment qui l'année passée a décidé de la liberté de toute une nation; et en même temps de la liberté future de toute la famille humaine ${ }^{105}$. Der Brief wurde im Club verlesen; Cotta wurde in Abwesenheit einstimmig zum Mitglied erklärt. Ein gewisser Wernhardt Hubert aus Basel schrieb:

La Constitution de votre patrie ne force pas simplement l'admiration de tous les cosmopolites raisonnables; elle intéresse plus particulièrement le caur de chaque homme qui apprécie la dignité de sa nature. C'est cette constitution qu'il donneroit à l'univers s'il était l'autocrate; c'est la seule qu'il accepterait librement pour lui et pour sa postérité, en tant qu'elle est conforme aux droits déclarés de l'homme et du citoyen, qui sont à peu près le Code social de la raison. Oui, tous les bons esprits de notre globe, que les préjugés n'ont point aveuglés, que l'ignorance ne retient plus dans l'abrutissement à vos principes. Toutes les âmes grandes et élévées qui ne sont point tiranisées par les petits passions; que l'orgueil et l'ambition n'ont point isolées s'unissent à vos sentiments ${ }^{106}$.

Auch Ludwig Leuchsenring, ein Arzt aus Karlsruhe, bat in einem begeisterten Brief darum, in den Club aufgenommen zu werden ${ }^{107}$. Ihm wurde der Status des associé étranger zugebilligt - ein Zeichen der Anerkennung und Bestäti-

\footnotetext{
${ }^{104}$ NeUGEBAUER-WÖLK, Revolution und Constitution.

${ }^{105}$ Clubprotokoll vom 15. Juni 1790.

${ }^{106}$ Brief von Wernhardt Hubert aus Basel, in: Clubprotokoll vom 30. Juli 1790.

${ }^{107}$ Clubprotokoll vom 10. Aug. 1790.
} 
gung für Mitglieder außerhalb Frankreichs ${ }^{108}$. Im Zuruf eines deutschen Mädchens an die Franken fand der Glauben an die Verbreitung der neuen Ordnung ähnlichen Ausdruck:

Wenn sich dann durch Vernunft und Tugend Eure Freiheit immer fester gründet - dann wird der wohltätige Ausfluß ihres himmlischen Lichtes auch andere Länder für sie empfänglich machen. Ferne Nationen werden dann Euer Andenken segnen, werden Euch als die Wiederhersteller der Vernunft, der Wahrheit, des Menschenrechts in ihren Annalen der Nachwelt bekannt machen, und künftige Geschlechter werden mit Ehrfurcht den Namen der Franken nennen! ${ }^{109}$

Die Korrespondentin legte, ähnlich wie schon der Clubpräsident Levrault, durch die Verwendung des Begriffes „Franken“ eine historische Zusammengehörigkeit von Franzosen und Deutschen nahe ${ }^{110}$.

Die deutschen Kosmopoliten bestätigten so den Glauben an die baldige Ausbreitung der neuen Ordnung. Sie gaben Grund zu der Annahme, daß die Unterschiede zwischen Franzosen und Deutschen gegenüber den Übereinstimmungen als gering einzuschätzen waren. Mit der neuen Ära, so wollte man glauben, waren die alten Grenzen hinfällig geworden.

Im Sinne des Kosmopolitismus entstanden vielfältige Kontakte zu deutschen Revolutionsanhängern. Manche von ihnen machten sich im Laufe des Jahres 1791 auf den Weg nach Straßburg. Der Berliner Jurist und Publizist Carl Clauer, der Stuttgarter Staatsrechtler und Publizist Friedrich Cotta, der Mainzer Theologe und Philosoph Anton Dorsch, der Mönch und Professor Eulogius Schneider und der Mainzer Arzt Georg Wedekind waren die prominentesten Köpfe unter den deutschen Immigranten, deren Gesamtzahl auf weit über hundert geschätzt werden mu $\beta^{111}$. Der Club bot ihnen eine erste

${ }^{108}$ Die Mitgliederliste vom April 1791 nennt allerdings nur fünf ausländische Mitglieder. (Namensverzeichnis sämtlicher Mitglieder der am 15. Januar $1790 \mathrm{zu}$ Straßburg gegründeten Constitutionsgesellschaft, Straßburg 1790 [Bibl. Nat. et Univ. Str., M 5941, 52]).

${ }^{109}$ Argos, Nr. 13, 14. Aug. 1792, Bd. 1, S. 104.

${ }^{110}$ Dazu: Karin RICHTER, Andreas Ulrich und die Sprachenfrage im Elsaß. Eine fast vergessene Straßburger Persönlichkeit aus der Zeit der Französischen Revolution, in: ZfGO 134 (1986) S. 234.

${ }^{111}$ Zur Emigration nach Straßburg: Martia GILLI, Pensée et pratiques révolutionnaires à la fin du XVIII ${ }^{e}$ siècle en Allemagne, Paris 1983, S. 219-227; Joseph HANSEN (Hg.), Quellen zur Geschichte des Rheinlandes, 4 Bde., Bonn 1931-38, hier: Bd. 1, S. 1035-1043. Zu einzelnen Emigranten: BETZINGER, Vie et mort d'Euloge Schneider; Hans-Werner ENGELS, Karl Clauer. Zum Leben und zu den Schriften eines deutschen Jakobiners, in: Jb. Tel Aviv 2 (1973) S. 101-144; Axel KUHN, Revolutionsbegeisterung an der Hohen Karlsschule, Stuttgart 1989; Helmut MATHY, Anton Joseph Dorsch, in: MZ 62 (1967) S. 1-55; F. H. MÜLLER, Johann Friedrich Butenschoen und die „Neue Speyerer Zeitung“ 1816-1821, Speyer 1986; 
Anlaufstelle und kümmerte sich in Einzelfällen auch um die berufliche Integration der Neuankömmlinge ${ }^{112}$. Die meisten Immigranten aus Deutschland waren Priester. Im Département Bas-Rhin hatten, wie im Kapitel I.3 im Detail ausgeführt wird, nur 9\% der Geistlichen den Verfassungseid geschwo$\mathrm{ren}^{113}$. Das Départementsdirektorium bemühte sich, die vakanten Stellen durch deutsche Seelsorger zu besetzen ${ }^{114}$. Der Club ließ am 26. Februar 1791 ein Rundschreiben an die Schwestergesellschaften drucken; darin forderte er, deutsche Priester, die der französischen Sprache mächtig waren, auf freie Stellen ins Elsaß zu berufen ${ }^{115}$. Er griff damit dem Dekret der Nationalversammlung vom 4. April vor, das die Eingliederung von zweisprachigen Deutschen in die konstitutionelle Kirche zuließ. Der Straßburger Jakobinerclub forderte im August in einer Adresse sogar eine Ausweitung der Rechte deutscher konstitutioneller Priester: Que les prêtres venant d'Allemagne et qui seront nommés fonctionnaires publics dans les lieux où l'idiome allemand est nécessaire pour administrer aux peuples français les secours spirituels, jouiront, du moment où ils auront été élus des cures [...] de tous les avantages communs aux Français, notamment les droits de citoyen actif ${ }^{16}$. Etwa hundert deutsche

Neugebauer-WölK, Revolution und Constitution; PELZER, Die Wiederkehr des girondistischen Helden, S. 86-105; Martin WEBER, Georg C. G. Wedekind 1761-1831. Werdegang und Schicksal eines Arztes im Zeitalter der Aufklärung und der Französischen Revolution, Stuttgart, New York 1988; Friedrich A. ZIMMERMANN, Rede über die gegenwärtige Situation des Vaterlands (Straßburg 1793), hg. und mit einer biographischen Skizze versehen von Hellmut G. HAASIS, Reutlingen 1992.

${ }^{112}$ Vgl. z.B. die Protokollnotiz über den Brief an den Wormser Professor Böhmer: On lit une lettre du Prof. Böhmer de Worms qui remercie la Société de l'interêt qu'elle prend à son sort, à la suite de cette lettre les commissaires nommés pour conférer sur les moyens de lui procurer de l'entretien en France font leur rapport à la société qui arrête d'écrire à Bohmer pour lui exposer que l'ass. nat. n'ayant pas encore arrêté un plan d'éducation nationale, il était impossible de lui procurer un établissement que cependant, s'il voulait se contenter d'une subsistance provisoire, il pourroit peut-être se la procurer par un cours d'une utilité générale tel qu'un cours d'histoire de France. (Clubprotokoll vom 4. Jan. 1792).

${ }^{113}$ TACKETT, Religion, Revolution and Regional Culture, S. 351.

${ }^{114}$ René EPP, Le Bas-Rhin, département français au pourcentage de prêtres jureurs le plus faible, in: RA 116 (1989/90) S. 237-244; Louis KAMMERER, Les prêtres allemands dans le clergé constitutionnel en Alsace, in: RA 116 (1989-90) S. 285; DERS., Le destin du clergé d'Alsace 1790-1803, in: AEA 46 (1987) S. 109-172; DERS., Le clergé constitutionnel en Alsace (1791-1803), in: AEA 48 (1989) S. 1-55.

${ }^{115}$ Rundschreiben des Clubs vom 26. Feb. 1791, in: HEITZ, Les sociétés politiques, S. 127.

${ }^{116}$ Adresse des Clubs an die Nationalversammlung vom 8. Aug. 1791 [Arch. Mun. Str., Fonds 3/10/208]. Der entsprechende Beschluß des Clubs findet sich jedoch bereits im Protokoll vom 2. Sept. 1791: Sur la motion d'un de ses membres la société arrête que par adresse l'on demanderoit à l'Assemblée nationale en foveur de prêtres étrangers et surtout allemands qui se présenteront pour la nomination des cures et vicariats vacants les mêmes avantages qu'elle a accordés aux étrangers qui fondent dans notre empire quelques manufactures ou autres établissements. 
Priester kamen dem Aufruf aus dem Elsaß nach ${ }^{117}$; von ihnen traten zehn dem Straßburger Club bei ${ }^{118}$. Wieviele anderen elsässischen Verfassungsvereinen beigetreten sein mögen, ist unklar. Die Ankunft der Immigranten wurde zunächst als Erfolg und als Bestätigung der eigenen Politik verstanden ${ }^{119}$. Die Integration der aus Deutschland Kommenden im Club war zunächst leicht, da sich dort - aufgrund sprachpolitischer Weichenstellungen - bereits 1790 eine zweisprachige Sitzungspraxis eingespielt hatte ${ }^{120}$.

Die Immigration aus Deutschland verstärkte ihrerseits den Einfluß der kosmopolitischen Ideologie und ließ die Zahl der für Deutschland verfaßten Propagandaschriften anschwellen. Es entstanden Zeitungen der Immigration, von denen insbesondere Friedrich Cottas Straßburgisches Politisches Journal und Eulogius Schneiders Argos auch für die Beeinflussung Deutschlands gedacht waren ${ }^{121}$. Auch von Straßburgern gegründete deutschsprachige Zeitungen, wie die Geschichte der Gegenwärtigen Zeit von Johann Friedrich Simon und Andreas Meyer, waren ein Forum für deutsche Autoren und erreichten ein deutsches Publikum: Von dieser Schrift sind seit gestern 2000 Exemplare nach Deutschland spediert worden, und es werden ihnen noch mehr nachfolgen ${ }^{122}$.

$\mathrm{Da} ß$ auch die deutschen Immigranten den Einfluß von Kultur und Tradition auf den politischen Prozeß als gering einschätzten, zeigt die für Deutschland bestimmte Verfassungspropaganda des Clubs. Das Flugblatt Ein Wort von einem Vortheil, welcher Frankreichs Konstitution eigen ist ${ }^{123}$ spielt die Übertragung der französischen Konstitution auf Deutschland durch. Angefangen von Urwahlen in den Dörfern und Städten, über die Bildung von Distrikten und Kantonen, bis hin zur Bestimmung der Départementsvertreter beschreibt

${ }^{117}$ KAMMERER, Les prêtres allemands, S. 286. Zu einzelnen Priestern: Erwin DITTLER, Jakobiner am Oberrhein, Kehl 1976; Robert SCHMITT, Simon Joseph (Gabriel) Schmitt (17661855). Mönch der Aufklärungszeit, Französischer Funktionär, Deutscher Beamter, Dozent der Philosophie und Gutsbesitzer, Lebensgeschichte, Vorfahren und Nachkommen. Zugleich ein Beitrag zur kurmainzischen und pfälzischen Landes- und Geistesgeschichte, Koblenz 1966; Johannes WERNER, Der Fall Fahrländer oder Über die Entwicklung vom Mönch zum Revolutionär, in: Ortenau 67 (1987) S. 163-172.

${ }^{118}$ Die Zahl ergibt sich aus dem von L. Kammerer gesammelten Datenmaterial: KAMMERER, Le clergé constitutionnel en Alsace.

119 Il nous arrive tous les jours encore des ecclésiastiques éclairés, qui quittent des places lucratives, sans aucun égard à ces prétendus dangers et oppositions. Ce qu'il y a de frappant, c'est que le plus grand nombre nous vient des contrées mêmes où nos ennemis ont établi le foyer de leurs projets. Bonn, Mayence et Trèves nous ont fourni leurs professeurs les plus éclairés. (Art. „Strasbourg“, in: Courrier de Strasbourg, „Prospectus“ vom 21. Dez. 1791.)

${ }^{120}$ Siehe dazu Kapitel I.3, Abschn. „Sprachpolitik“.

${ }^{121}$ Eine Dissertation über die Presse der deutschen Immigranten in Straßburg wird von Susanne Lachenicht (Heidelberg) vorbereitet.

${ }^{122}$ Geschichte der Gegenwärtigen Zeit, 31. Aug. 1791.

${ }^{123}$ Flugblatt abgedruckt in: Straßburgisches Politisches Journal, 1. Heft, Mai 1792, S. 484-487. 
es schrittweise den Übergang vom Ancien Régime zur neuen Ordnung. Es wird behauptet, daß ohne die mindeste Unordnung, sich innerhalb eines oder zween Monate eine ziemlich wohl eingerichtete konstituierende Versammlung ${ }^{124}$ bilden ließe. Man sieht hieraus, folgert der Pamphletist, wie leicht es ist, daß ein Volk oder ein Theil des Volks Frankreichs Konstitution annehme, ohne deswegen sich mit Frankreich zu vereinigen ${ }^{125}$.

Auch andere Schriften beschrieben, wie die deutschen Fürstentümer zu reformieren seien. Unter der Überschrift Constitutions-Gesellschaften in Teutschland $^{126}$ veröffentlichte Friedrich Cotta in seinem Straßburgischen Politischen Journal den Vordruck einer Urkunde der Stiftung für die Gesellschaft der Freunde der Verfassung in (Land)....... ${ }^{127}$. In die Lücke sollten die deutschen Patrioten ihr Heimatland eintragen; es kann wohl kein sinnfälligeres Beispiel für den Glauben an die Allgemeingültigkeit der neuen französischen Ordnung geben. Mit der Gründungsurkunde wurden den deutschen Jakobinern auch die Statuten für die zu gründende Gesellschaft zugestellt. Als wichtigstes Ziel der Constitutions-Gesellschaft formulierte Cotta die Umänderung oder (...) Herstellung der Verfassung ${ }^{128}$. Damit keinerlei Mißverständnisse entstehen konnten, gab er auch noch die Grundsätze der Verfassung in (Land)..... in zwölf Artikeln bei. Diese stellten eine Kurzfassung der französischen Verfassung dar, die keine Zugeständnisse an die deutschen Verhältnisse beinhaltete. In den Regeln für unsere Gesellschaft und die Zusammenkünfte derselben ${ }^{129}$ wird die Satzung des zu gründenden Vereins entworfen; nur die Aufforderung zur Wahl eines sichern Ort $[\mathrm{es}]^{130}$ weist auf die Rahmenbedingungen einer solchen Gründung hin.

Im zweiten Heft der Januar-Ausgabe des Straßburgischen Politischen Journals druckte Cotta einen Aufsatz ab, der die Frage Wie könnte eine Volks-Versammlung in Wirtemberg und deren Ausschuß zweckmäßig organisirt werden $?^{131}$ zum Thema hatte. Aus dem Naturrecht leitete er das Recht jedes einzelnen Bürgers auf politische Partizipation ab und forderte die Einrichtung einer württembergischen Volksversammlung. Es folgt ein ausführlicher Entwurf in 51 Paragraphen, der die Wahlmodalitäten für eine solche Versammlung in allen Einzelheiten auseinandersetzt.

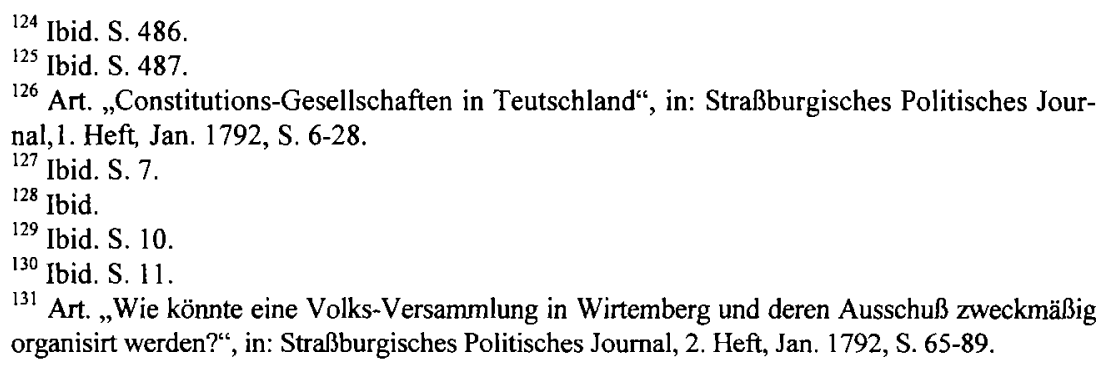


Die Straßburger Verfassungsfreunde hatten also zwei unterschiedliche Wege gefunden, gleichzeitig Einheit und Ausbreitung der Revolution zu befördern. Die Integration der Juden, die im Elsaß auch zu Beginn der Revolution noch als Fremde gesehen wurden, legte es nahe, diesen das Angebot einer doppelten Zugehörigkeit zu machen. Weil sie bereit waren, sich den neuen Regeln zu unterstellen, konnten sie ihrer religiösen Identität treu bleiben. Für die Deutschen hingegen, denen sich die Elsässer auch nach hundert Jahren als Untertanen des französischen Königs verbunden fühlten, war eine doppelte Zugehörigkeit überflüssig. Weil die Elsässer zur Revolution fähig gewesen waren, mußten es auch die ihnen ähnlichen Deutschen sein. Das kosmopolitische Denken erfuhr unter den besonderen Bedingungen des Elsaß noch eine Steigerung. Die Unterschiede zwischen dem bei der Judenemanzipation und dem im Kosmopolitismus verwandten Konzept mögen jedoch auch daher gerührt haben, daß die Emanzipation der Juden ein konkretes politisches Projekt war, während die Ausweitung der Revolution auf Deutschland nur ein $\mathrm{Zu}-$ kunftstraum sein konnte.

Ansätze für die Entstehung des Terrors gegen Sprache und Religion lassen sich in diesen ersten Monaten der Clubgeschichte noch nicht finden. Es war eine ausgesprochen tolerante Haltung gegenüber der kulturellen Vielfalt entstanden, die in keiner Weise die späteren Entgleisungen ahnen ließ. Kulturelle Identität galt zu dieser Zeit als Privatsache, die ohne Einfluß auf politische Vorlieben blieb. Jedem wurde zugetraut, sich über seine hergebrachten Zugehörigkeiten erheben und in die neue Ordnung eingliedern zu können. Deshalb stellte kulturelle Vielfalt in dieser ersten Phase der Clubgeschichte keinen Stein des Anstoßes dar. Wie läßt sich diese tolerante Haltung gegenüber der Kultur, die gleichsam der Ausgangspunkt der Radikalisierung war, mit der im Kapitel I.1 beschriebenen Konstellation von äußeren Einflüssen und lokalen Konflikten in Zusammenhang bringen? Offenbar wollte die erneuerte politische Elite von Straßburg durch die beschriebenen Initiativen ihren Sieg festigen und ihre Vorherrschaft legitimieren. Der Club berief sich auf Nationalversammlung und Verfassung, um seine Führungsansprüche zu legitimieren. Ebenso griff er die großen Gesten der Zentrale auf, die auf den elsässischen Kontext anwendbar waren. Durch die Aussöhnung alter Konflikte hätte die Überlegenheit der neuen Ordnung bewiesen und damit der Führungsanspruch ihrer Vertreter vor Ort untermauert werden können. Das Projekt der Judenemanzipation, das in der Stadt auf Widerstand stieß, ließ der Club daher rasch wieder fallen. $\mathrm{Da} \beta$ er die in Straßburg verbreitete Germanophilie in die Sprache der neuen Zeit übersetzte, brachte ihm hingegen Sympathien ein. Weil die kosmopolitische Ideologie dem Club erlaubte, sich als erfolgreichen Vermittler zwischen Franzosen und Deutschen darzustellen, blieb sie über längere Zeit bestimmend. 


\section{3. „Unsichtbare Grenzen“ - Konfessionskonflikte und der Beginn der Radikalisierung}

Die Straßburger Verfassungsfreunde hatten sich die Verwirklichung einer neuen, auf Einheit basierenden Ordnung zum Ziel gesetzt; doch bereits ein halbes Jahr nach der Clubgründung kollidierte dieses Ideal mit der Wirklichkeit. Nicht Eintracht und Harmonie verbreitete sich, sondern heftige Konflikte brachen aus; kulturelle Vielfalt und Identitäten wurden zum Problem.

Auslöser der Erschütterungen auf der lokalen Bühne war die Kirchenpolitik der Nationalversammlung: Während den französischen Protestanten durch ein am Heiligen Abend des Jahres 1789 verabschiedetes Dekret die vollen Bürgerrechte und einige Monate später der Erhalt ihrer alten Privilegien zugesprochen wurden, sahen sich die Katholiken mit einem revolutionären Erneuerungsprogramm konfrontiert. Am 4. und 11. August 1789 wurde die Abschaffung des Kirchenzehnten beschlossen; am 2. November 1789 die Verstaatlichung der Kirchengüter; am 18. März 1790 die Auflösung der katholischen Orden. Im Zentrum der „Zivilverfassung des Klerus“, die am 12. Juli 1790 verabschiedet wurde, stand die Anpassung der Diözesen an die Départementsstruktur, sowie die demokratische Wahl und die staatliche Besoldung der katholischen Priester. Am 27. November 1790 wurde die Zivilverfassung durch ein Gesetz ergänzt, das die Priester zum Eid auf die Verfassung verpflichtete ${ }^{132}$.

In vielen Gegenden Frankreichs riefen die kirchenpolitischen Entscheidungen der Nationalversammlung Konflikte hervor. Insgesamt war nur etwa die Hälfte der französischen Priester bereit, sich auf die Verfassung vereidigen zu lassen. Die Regionen mit besonders geringen Anteilen konstitutioneller Priester lagen an der Peripherie Frankreichs: Im Westen waren es die Bretagne, Maine, Anjou und das Bas-Poitou ${ }^{133}$, im Süden das Languedoc, im Norden die Normandie, Flandern, das Artois und der Hennegau ${ }^{134}$. In einigen dieser Gegenden gab es 1790 religiös motivierte Volksaufstände, so z.B. im Département Pas-de-Calais, im Gard, in der später als Vendée militaire bezeichneten Zone und an verschiedenen Orten des Massif Central ${ }^{135}$.

${ }^{132}$ Claude LANGLOIS, Le serment révolutionnaire, archaïsme et modernité, in: Jean-Clément MARTIN (Hg.), Religion et Révolution. Actes du Colloque de Saint-Florent-le-Vieil 13-15 mai 1993, Paris 1994, S. 25-56; TACKETT, Religion, Revolution and Regional Culture, S. 3-33.

${ }^{133}$ S. dazu die Studie von Claudy Valin, La Rochelle, la Vendée 1793: Révolution et contre-révolution, Paris 1997.

${ }^{134}$ TACKETT, Religion, Revolution and Regional Culture, S. 52-56.

${ }^{135}$ Ibid. S. $166 f$. 
Auch im Elsaß waren die Reaktionen auf die Kirchenpolitik vielfältig und heftig. Viele elsässische Protestanten wurden angesichts der staatlichen Maßnahmen zu glühenden Verfechtern der Revolution. Ein großer Teil der Katholiken des Département Bas-Rhin hingegen wehrte sich zunächst in Wort und Schrift, dann in Akten zivilen Ungehorsams gegen die Revolutionierung ihrer Kirche. Daß das Elsaß zu den Zonen des Widerstands gehörte, hing sicherlich mit der Bikonfessionalität der Region zusammen. Die Katholiken verglichen ihre Behandlung direkt mit derjenigen der ortsansässigen Lutheraner und stellten fest, daß die vielbesungene Gleichheit in Religionsdingen nicht verwirklicht wurde. Allgemein hatte die konstitutionelle Kirche in Regionen, in denen Protestanten und Katholiken lebten, einen schweren Stand. In einigen bikonfessionellen Städten - Montauban ${ }^{133}$ und Nîmes ${ }^{134}$ - kam es anläßlich der Reformen sogar zu Straßenkämpfen zwischen Calvinisten und Katholiken, die Todesopfer forderten ${ }^{135}$.

Für die Straßburger Patrioten, Verfechter von Ordnung und Einheit, stellte der katholische Widerstand ein großes Problem dar. Der Wille zur Versöhnung mit den Juden und zur Verbrüderung mit den Deutschen zeugte von hohen Idealen; viel bedeutsamer war jedoch die Frage, ob die neue Führung auch in der Lage war, innere Geschlossenheit herzustellen, d.h. die heterogene Stadtbevölkerung hinter sich zu vereinen. Der Gründervater Barbier de Tinan hatte in diesem Sinne verkündet, daß die Société für ein Ende der affections und inimitiés particulières ${ }^{136}$ in Straßburg eintreten müsse. Er spielte damit auf die „unsichtbare Grenze“"137 zwischen Protestanten und Katholiken an, welche die Straßburger Gesellschaft im gesamten 18. Jahrhundert geprägt hatte und welche es nun zu überwinden galt. Prinzipiell war es durchaus denkbar, daß das bereits im Kontext von Judenemanzipation und Kosmopolitismus analysierte Modell, welches kulturelle Zugehörigkeit zur Privatsache erklärte, wie ein Dach die heterogenen Strukturen der Straßburger Gesellschaft überspannen konnte.

${ }^{133}$ Daniel LıGoU, Le monde contre-révolutionnaire à Montauban, in: Anne-Marie DUPORT (Hg.), Religion, Révolution, Contre-Révolution dans le Midi. 1789-99, Nîmes 1990, S. 4958.

${ }^{134}$ HOOD, Protestant-Catholic Relations; DERS., Revival and Mutation of Old Rivalries; DERS., Patterns of Popular Protest; DERS., Permanence des conflits traditionnels; Gwynne LEwIS, The Second Vendée: The Continuity of Counter-Revolution in the Département of the Gard, 1789-1815, Oxford 1978, S. 1-40.

${ }^{135}$ Der Vollständigkeit halber muß hier erwähnt werden, daß sich diese unruhigen Gegenden von anderen unterschieden, in denen Protestanten und Katholiken zusammenlebten und wo trotzdem durchschnittliche und sogar überdurchschnittliche Beteiligung an der konstitutionellen Kirche erreicht wurde, z.B. Dauphiné, Saintonge, Guyenne. Vgl. TACKETT, Religion, Revolution and Regional Culture, S. 223f.

${ }^{136}$ Clubprotokoll vom 15. Jan. 1790.

137 Etienne FrançOIS, Die unsichtbare Grenze. Protestanten und Katholiken in Augsburg 1648-1806, Sigmaringen 1991. 
Die Entscheidung der „Verfassungsfreunde“ über den Umgang mit dem elsässischen Bilingualismus wurde durchaus in diesem Sinne gefällt: Der Club rief eine zweisprachige Sitzungspraxis ins Leben; die Gleichzeitigkeit von politischer Einheit und kultureller Vielfalt war weiterhin möglich. Im Umgang mit den Teilen der katholischen Kirche, die sich im Elsaß gegen die von der Nationalversammlung vorgesehenen Reformen stemmte, wurde der Club jedoch seinen ursprünglichen Zielen untreu. Die Konfrontation zwischen revolutionärer Bewegung und eidverweigernder Kirche führten zu grundsätzlichen ideologischen Verschiebungen. Die Konzepte von Einheit, Zugehörigkeit und vom Umgang mit kultureller Vielfalt, welche die großen Gesten der Verbrüderung getragen hatten, mußten angesichts der Konflikte modifiziert werden. Es entstand ein erstes kulturell fundiertes Feindbild: der „Eidverweigerer“. Weil sich die Ansicht verbreitete, Katholizismus und Konterrevolution seien einund dieselbe Sache, hörte man auf, kulturelle Zugehörigkeit als Privatsache anzusehen. Einheit wurde nun nicht mehr durch Integration, sondern durch Exklusion angestrebt. Diese Entwicklungen legen es nahe, den Beginn der Radikalisierung in Straßburg auf die Zeit der Einführung der „Zivilverfassung des Klerus" zu datieren.

Das folgende Kapitel beschreibt erstens die Entstehung und Entwicklung der heterogenen Gesellschaftsstruktur von Straßburg. Zweitens werden die sprachpolitischen Weichenstellungen des Jahres 1790 als Beispiel einer gelungenen integrativen Politik untersucht. Drittens wird der Konflikt zwischen revolutionärer Bewegung und Katholizismus und seine Konsequenzen für den Proze $\beta$ der Radikalisierung in den Blick genommen. Abschließend wird das Verhalten der Protestanten angesichts der revolutionären Herausforderung betrachtet und die Frage gestellt, in welchem Verhältnis der politische Konflikt zwischen der revolutionären Bewegung und der eidverweigernden Kirche zum Bikonfessionalismus stand.

\section{Die zweigeteilte Gesellschaft - Konfession und Sprache im 18. Jahrhundert}

Straßburg, im 16. Jahrhundert eines der wichtigsten Zentren der Reformation, war auch am Ende des 17. Jahrhunderts fast ausschließlich protestantisch. Die Katholiken stellten eine kleine und fast unsichtbare Minderheit dar, die um ihre Duldung bangen mußte ${ }^{138}$. Erst die Annexion im Jahre 1681 brachte

${ }^{138}$ Einen Überblick über die Religionsgeschichte des Elsaß und Straßburgs bieten: Thomas BRADY, Ruling Class, Regime and Reformation at Strasbourg 1520-1555, Leiden 1978; Louis CHÂTELLIER, Tradition chrétienne et renouveau catholique dans l'ancien diocèse de Strasbourg, 1650-1770, Paris 1981; Marc LIENHARD, Jakob WILlER, Straßburg und die Reformation, Kehl u.a. 1982; Claude MULLER, „Ils brandissent les torches du fanatisme“. La suppression des ordres religieux masculins en Alsace (1789-92), in: RA 116 (1989/90) S. 245-271; Dominique VARRY, Claude MULLER, Hommes de Dieu et Révolution en Alsace, 
grundsätzliche Veränderungen. Ludwig bestätigte in den Kapitulationsverhandlungen zwar das Recht der Straßburger Protestanten auf freie Religionsausübung, strebte aber gleichzeitig eine Rekatholisierung der Stadt an. Erstes Ergebnis dieser Politik war die Rückgabe der Kathedrale an die Katholiken. Wenige Wochen nach der Kapitulation fand dort eine pompöse Zeremonie statt, in deren Verlauf eine protestantische Straßburgerin zum katholischen Glauben übertrat. Wenig später organisierte der königliche Gouverneur Marquis de Chamilly eine katholische Prozession zur Kathedrale; dazu bot er einen Zug von über tausend Garnisonssoldaten auf, die nicht nur Fackeln und Kerzen, sondern auch ihre Säbel trugen ${ }^{139}$.

Diesen Veranstaltungen folgte eine Phase struktureller Umgestaltung. Die protestantische Gemeinde mußte aus der Kathedrale in die Predigerkirche der Dominikaner, die nun „Temple Neuf" genannt wurde, umziehen. Neue katholische Gemeinden wurden geschaffen; die Kirchen Saint-Pierre-le-Vieux und Saint-Pierre-le-Jeune wurden durch Trennwände für zweierlei Gottesdienste verfügbar gemacht - eine Praxis, die „Simultaneum“ genannt wurde. Der Magistrat, der bis dahin neben dem Kirchenkonvent die Oberaufsicht über die Kirchenpolitik hatte, gab diese Kompetenzen an ein Gremium aus „Kirchenpflegern" $a b^{140}$.

Der katholische Fürstbischof und das Domkapitel kehrten aus dem Exil nach Straßburg zurück; die Bischofsfamilie Rohan sollte bald ein prachtvolles Leben im Herzen der einst protestantischen Stadt entwickeln. Wenig später zogen auch die katholischen Orden wieder in Straßburg ein. Kapuziner, Augustiner, Récollets (Franziskaner) und Jesuiten errichteten Niederlassungen in Straßburg, um die Stadt durch Mission wieder für den rechten Glauben zu gewinnen ${ }^{141}$. In Straßburg wurde darüber hinaus eine bischöfliche Universität eingerichtet, die katholische Kleriker ausbildete ${ }^{142}$.

Der König ergriff vielfältige Maßnahmen, um die Rekatholisierung durchzusetzen, er ging jedoch nicht so weit, offene Gewalt anzuwenden oder zu dulden. Ludwig und sein Minister Louvois setzten vielmehr auf den langfristigen Erfolg der missionarischen Tätigkeit und auf katholische Immigration: Konvertiten erhielten für drei Jahre Steuerbefreiung und Aufschub für die Schuldentilgung; Katholiken wurde es streng verboten zu konvertieren ${ }^{143}$; Kinder aus Mischehen mußten katholisch getauft werden. Während Protestanten der Zuzug nach Straßburg verboten war, wurde die katholische $\mathrm{Zu}$ -

Tournai 1993; Bernard VOGLER, Histoire des chrétiens d'Alsace des origines à nos jours, Tournai 1994.

${ }^{139}$ Zur Annexion und den Folgen: FORD, Strasbourg in Tansition, S. 28ff.; Simone HERRY, Une ville en mutation. Strasbourg au tournant du grand siècle, Strasbourg 1996.

${ }^{140}$ FORD, Strasbourg in Transition, S. $102 \mathrm{f}$.

${ }^{141}$ Ibid. S. 106.

${ }^{142}$ STREITBERGER, Der königliche Prätor, S. 88.

${ }^{143}$ FORD, Strasbourg in Transition, S. 109. 
wanderung durch finanzielle und andere Anreize unterstützt. So wuchs der katholische Bevölkerungsteil im Laufe des 18. Jahrhunderts stark an: Zur Zeit der Annexion gab es unter den 22.000 Straßburger Bürgern nur fünf katholische Familien. 1686 wurden 2.400 Katholiken gezählt, 1726 über 10.000, 1760 fast 20.000 . Während dieses Zeitraumes waren die Zahlen für die protestantische Bürgerschaft leicht rückläufig. Gegen 1770 waren beide Bevölkerungsgruppen etwa gleich stark. Am Vorabend der Revolution, als die Gesamtbevölkerung auf etwa 45.000 angestiegen war, übertraf der katholische den protestantischen Anteil um 2-3.000 Personen ${ }^{144}$.

Ludwig XIV. bemühte sich darüber hinaus, den Protestanten die politische Führung der Stadt aus den Händen zu nehmen. Mit dem prêteur royal wurde dem Magistrat ein katholischer Verwaltungsbeamter an die Spitze gestellt; die ersten, die dieses Amt innehatten, waren Konvertiten aus den großen Straßburger Familien ${ }^{145}$. Die Alternative von 1687 regelte die abwechselnde Besetzung der Magistratsposten durch Protestanten und Katholiken; dies hatte zur Folge, daß die Katholiken im Verhältnis zu ihrem geringen Bevölkerungsanteil am Ende des 17. Jahrhunderts überrepräsentiert waren ${ }^{146}$.

Die religiösen und politischen Veränderungen führten in Straßburg zunächst $\mathrm{zu}$ einer scharfen Konkurrenz der traditionellen protestantischen und der katholischen Elite, zu der nicht nur der prêteur royal, sondern auch der Intendant der Provinz, die hohen Offiziere der Garnison und der Fürstbischof samt dem hohen Klerus der Diözese gehörten. Es waren insbesondere die im tiefen Vertrauen auf die eigene Rechtgläubigkeit unternommenen Missionsbemühungen des katholischen Klerus, die das interkonfessionelle Klima vergifteten.

Die beiden konfessionellen Gemeinschaften waren jedoch nicht nur in Glaubensfragen voneinander getrennt. Der Zugang zu den Ämtern in der königlichen Verwaltung war den Protestanten verwehrt, wodurch sich protestantische und katholische Berufsprofile bildeten. Die protestantische Oberschicht lebte vornehmlich vom internationalen Großhandel. Dieser. wurde durch den Status des Elsaß als province d'étranger effectif befördert, welcher den Handel mit Frankreich erschwerte, aber den mit dem Heiligen Römischen Reich erleichterte. Ein hoch entwickeltes Bildungswesen, dessen Zentrum die Universität von Straßburg war, prägte die protestantische Gemeinschaft.

Der konfessionelle Gegensatz wurde des weiteren durch unterschiedliche Sprachen vertieft. Zumeist waren die Alteingesessenen protestantisch und deutschsprachig, die Immigranten katholisch und frankophon. Der Grad der Verbreitung des Französischen nahm ab, je mehr man sich dem Fuß der Gesellschaftspyramide näherte. In seiner zweibändigen Sprachgeschichte des Elsaß und Lothringens versucht Paul Lévy, aus der Vielfalt der Aussagen in

\footnotetext{
${ }^{144}$ DREYER-ROOS, La société strasbourgeoise, S. 98.

${ }^{145}$ STREITBerger, Der königliche Prätor, S. $31 \mathrm{ff}$.

${ }^{146}$ FORD, Strasbourg in Transition, S. $112 \mathrm{f}$.
} 
Zeitzeugenberichten ein Bild der sprachlichen Situation in Straßburg und Umgebung zusammenzusetzen: „Les immigrés parlaient français et ignoraient l'allemand; les masses populaires parlaient allemand et ignoraient le français; la noblesse et la haute bourgeoisie parlaient français, mais savaient encore l'allemand; la bourgeoisie moyenne parlait allemand, mais savait déjà le français. “ ${ }^{147}$ Die französische Sprache war am Ende des 18. Jahrhunderts also vor allem in den Oberschichten verbreitet. Dies war eine Folge der Sprachpolitik des Ancien Régime, das die Beherrschung der "langue royale“ für den Zugang zu Staatsämtern voraussetzte. Im dörflichen Milieu dürfte die Verbreitung des Französischen noch geringer gewesen sein. Eine Zählung im lothringischen Dorf Boulay, vorgenommen anläßlich der Abfassung der Cahiers de doléances, ergab, daß von den 300-400 Bewohnern des Fleckens nur zwischen acht und zehn der französischen Sprache mächtig waren ${ }^{148}$.

Innerhalb der deutschsprachigen und protestantischen Bildungselite der Stadt gab es bereits in den 1770er Jahren eine Bewegung, welche zwar die Souveränität des französischen Königs über Straßburg anerkannte, die sich aber trotzdem der Pflege der deutschen Sprache verschrieben hatte. Zentrale Figur war der Oberschreiber der Vogteistube Johann Daniel Saltzmann, der in seiner "Tischgesellschaft" Gleichgesinnte aus der protestantischen Gemeinschaft, vor allem Christoph Wilhelm Koch, Jeremias Jakob Oberlin, Isaac Haffner, Johann Lorenz Blessig, Johann Friedrich von Turckheim und seinen Cousin Friedrich Rudolph Saltzmann empfing; die meisten dieser Männer wurden später „Verfassungsfreunde“. Vor der Revolution gründeten sie die „Deutsche Übungsgesellschaft“ und 1775 die "Gesellschaft zur Ausbildung der deutschen Sprache", welche das Wochenblatt Der Bürgerfreund herausgab. Die Gruppe war auch durch ihre engen Kontakte mit deutschen Schriftstellern beeinflußt, die in Straßburg Station gemacht hatten, vor allem von Herder, Goethe und Lenz ${ }^{149}$. Die Verbindungen des Kreises um Saltzmann zur Société philanthropique und zu den Straßburger Freimaurern waren eng, was ein Zeichen dafür ist, daß sich die aufgeklärten protestantischen Kreise zwar für eine Pflege der Germanophonie, aber nicht für eine Absonderung von den Katholiken einsetzten.

Eine unlängst von Kevin McQuillan vorgelegte Studie hat darüber hinaus gezeigt, daß sich die beiden Konfessionsgruppen auch in ihren Lebensweisen und -rhythmen unterschieden. So heirateten Katholiken in höherem Alter als Protestanten; ein vergleichsweise hoher Prozentsatz von ihnen blieb unverhei-

${ }^{147}$ Paul LÉVY, Histoire linguistique d'Alsace et de Lorraine, 2 Bde., Paris 1928, hier; Bd. 1, S. 345 .

${ }^{148}$ Ibid. S. 343. Vgl. auch Paul IMBS, Notes sur la langue française dans la bourgeoisie alsacienne, in: J. SCHLUMBERGER, Paul SPINDLER (Hg.), La Bourgeoisie Alsacienne, Strasbourg 1967, S. 307-327.

${ }^{149}$ BELL, Nation-Building and Cultural Particularism, S. 472ff. 
ratet. Katholische Paare setzten mehr Kinder in die Welt als protestantische, die offenbar die Empfängnis regulierten; dafür war in katholischen Familien die Kindersterblichkeit höher ${ }^{150}$. Die „unsichtbare Grenze“ zeigte sich auch in der Alltagskultur: deutsche Trachten gegen französische Mode, bürgerliche Küche gegen cuisine.

Im Laufe der letzten Jahrzehnte vor der Revolution schwächten sich die Gegensätze zwischen Protestanten und Katholiken allerdings ab; der Wille zur Koexistenz entwickelte sich trotz fortbestehender Unterschiede. Das Verbot des Jesuitenordens und der allgemeine Rückgang der Religiosität verringerte den missionarischen Eifer ${ }^{151}$. Auch in Straßburg scheinen jene Mechanismen gewirkt zu haben, die Rebecca McCoy „culture of accommodation “152 genannt hat, d.h. eine Mischung aus Pragmatismus, Großzügigkeit in Einzelfällen und Praktiken des Ausgleichs, die dafür sorgten, daß das Zusammenleben trotz des gegenseitigen Mißtrauens funktionierte. Dafür gibt es zahlreiche Hinweise: Die prêteurs royaux betrachteten es immer wieder als ihre Aufgabe, zwischen den Konfessionen zu vermittein ${ }^{153}$. Die Alternative von 1687 regelte die abwechselnde Besetzung der Magistratsposten durch Protestanten und Katholiken und sicherte so die gleichmäßige Repräsentation beider Konfessionen in der Politik ${ }^{154}$. Auch im Alltag hatten sich die Konfessionen arrangiert. Dafür spricht beispielsweise die Duldung von Mischehen, das gemeinsame Studium von protestantischen und katholischen Studenten an der Universität oder die Gemeinschaft von Protestanten und Katholiken in Logen, gelehrten Gesellschaften und Salons ${ }^{155}$.

Betrachten wir die Struktur der Stadtgesellschaft im 18. Jahrhundert: Protestanten und Katholiken beanspruchten vor allem, den richtigen Weg zu Gott $\mathrm{zu}$ kennen. Konfessionelle Gruppen unterschieden sich jedoch auch in ihrer Wirtschaftsweise, ihrer Sprache, Lebensweise und Alltagskultur. Nur in den ersten Jahrzehnten unter französischer Souveränität, in den Zeiten einer offensiven Rekatholisierung durch Mission, brachten die kulturellen Unterschiede jedoch heftige Konflikte mit sich. Je weiter das 18. Jahrhundert fortschritt,

${ }^{150}$ Kevin MCQUILlaA, Culture, Religion and Demographic Behavior. Catholics and Lutherans in Alsace, 1750-1870, London 1999.

${ }^{151}$ Der Aspekt der prärevolutionären Dechristianisierung kann in dieser Arbeit nicht behandelt werden. Literatur zum Thema: Roger CHARTIER, Déchristianisation et laïcisation, in: DERS., Les origines culturelles de la Révolution française, Paris 1990, S. 116-137; Gérard CHOLVY, Les peuples de France entre religion et révolution (1760-1830), in: MARTIN (Hg.), Religion et Révolution, S. 11-24; Bernard PLONGERON (Hg.), Pratiques religieuses dans l'Europe révolutionnaire (1770-1820). Colloque de Chantilly, Tournai 1988.

${ }^{152}$ Rebecca K. MCCOY, The Culture of Accomodation: Religion, Language, and Politics in an Alsatian Community, 1648-1870, Diss. Univ. of North Carolina 1992; DIES., The Société Populaire at Sainte-Marie-aux-Mines, S. 438f.

${ }^{153}$ STREITBERGER, Der königliche Prätor, S. $31 \mathrm{ff}$.

${ }^{154}$ FORD, Strasbourg in Transition, S. $112 \mathrm{f}$.

${ }^{155}$ CHÂTELLIER, Tradition chrétienne, S. 356f. 
desto deutlicher ist der Wille zum Ausgleich. Am Vorabend der Revolution betrachteten sich die kulturellen Gruppen nach wie vor mit Unverständnis, Mißtrauen und gegenseitigen Ressentiments; die Phase offener Feindschaft war allerdings vorbei.

\section{Sprachpolitik}

Wollte sich die Gesellschaft der Verfassungsfreunde als führende Kraft der Straßburger Politik etablieren, so konnte sie die Zweiteilung der Straßburger Gesellschaft nicht ignorieren. Vielmehr mußte es ihr gelingen, sich als Kraft darzustellen, die über den alten Grenzen stand. Ein gelungenes Beispiel dafür, $\mathrm{da} ß$ die Patrioten in der Lage waren, mit heterogenen Strukturen umzugehen, waren ihre Maßnahmen im Bezug auf die Zweisprachigkeit.

Die Impulse für diese Maßnahmen kamen auch in diesem Fall aus der Metropole: 1789 hatte sich die französische Sprache durch die Pariser Unruhen, durch Reden, Versammlungen, Schriften und die Beschlüsse der Nationalversammlung als langue révolutionnaire etabliert. Mit den patois und Regionalsprachen und so auch mit der im Elsaß verbreiteten deutschen Sprache assoziierte man hingegen das Verharren im Alten ${ }^{156}$. Vielen Abgeordneten der Nationalversammlung schien deshalb eine Erziehung aller Bürger zur französischen Sprache der einzig richtige Weg. Der Plan, Französisch als für alle verbindliche Sprache durchzusetzen, war jedoch nicht unumstritten. Neben der Unsicherheit über die praktische Durchführbarkeit gab es auch ideologische Bedenken: Die zwangsweise Durchsetzung des Französischen als einzige im politischen Kontext zulässige Sprache schien unvereinbar mit der in der Menschenrechtserklärung proklamierten persönlichen Freiheit der Staatsbürger.

$\mathrm{Zu}$ den entschiedensten Befürwortern einer einheitlichen Sprache gehörte der Abbé Grégoire. Der Abbé hatte im Januar 1790 begonnen, einen Fragebogen in alle Teile Frankreichs zu verschicken, mit dem er einerseits auf die Probleme der Sprachenvielfalt aufmerksam machen und andererseits den sprachlichen Zustand Frankreichs erforschen wollte. Sein Rundbrief enthielt 43 Fragen, die sich auf den Charakter und den Verbreitungsgrad der Regionalsprachen, aber auch auf den Bildungsstand der einfachen Leute bezogen.

${ }^{156}$ Zur revolutionären Sprachpolitik: BRUNOT, Histoire de la langue française, Bd. 9.1, S. $3 \mathrm{ff}$;; Jean-Pol CAPUT, La langue française. Histoire d'une institution, Bd. 2, Paris 1975, S. $100 \mathrm{ff}$; Michel de CERTEAU, Dominique JULIA, Jacques REVEL, Une politique de la langue. La Révolution Française et les patois, Paris 1975; DIES., Une ethnographie de la langue: L'enquête de Grégoire sur les patois, in: Annales 30 (1975) S. 3-41; JEISMANN, Das Vaterland der Feinde, S. 146-152; Brigitte SCHLIEBEN-LANGE, Die Sprachpolitik der Französischen Revolution, in: Komparatistische Hefte 1 (1980) S. 41-53; Ulrich RIECKEN, Zur Sprachdiskussion während der Französischen Revolution, in: Beiträge zur Romanischen Philologie 13 (1979) S. 303-318. 
Grégoire verbreitete den Fragebogen über befreundete Gelehrte, über Brissots Patriote français und über das Netz der patriotischen Gesellschaften in ganz Frankreich ${ }^{157}$. Der Fragebogen ließ keinen Zweifel an Grégoires Wunsch, gegen die Patois vorzugehen. Seine Fragen zielten darauf ab, einen Zusammenhang zwischen den Patois und konterrevolutionären Einstellungen nachzuweisen. So erfragte er beispielsweise, ob die Verdrängung der Patois politische und religiöse Konsequenzen nach sich ziehen würde ${ }^{158}$.

Im Laufe der Jahre 1790 bis 1793 sammelten sich bei Grégoire Antworten aus allen Landesteilen. Gerade die Antworten auf die zitierte Frage zeichnen ein Bild von den gängigen Vorurteilen der Franzosen gegenüber den regionalen Sprachen. François Chabot aus Saint-Geniès im Département de l'Aveyron schrieb an Grégoire: Nous sommes tous Français, nous ne devons avoir qu'une même langue, comme nous n'avons tous qu'un même cour ${ }^{159}$. M. J. P. Rochejan aus Sully antwortete:

L'effet de la destruction du patois serait d'élever l'âme, de réunir les cours, d'éclairer les esprits; comme l'effet du patois est de dégrader l'âme par une des distinctions qui placent le pauvre au-dessous du riche, de conserver dans les campagnes une ignorance qui met sans cesse les hommes aux prises avec l'erreur et la fourberie, d'empecher entre les hommes la communication des sentiments et des pensées, de traiter facilement de leurs intérêts, de diviser les départements, les districts et les communes en autant de peuples différents ${ }^{160}$.

Beide Zitate dokumentieren eine grundsätzliche Ablehnung der Minderheitensprachen; aus politischen Gründen wurde ihre Abschaffung gefordert ${ }^{161}$.

Die Ansichten Grégoires und seiner Anhänger konnten sich in der Nationalversammlung zunächst nicht durchsetzen; dies war vor allem das Werk Bouchettes. Der Abgeordnete aus Bailleul überzeugte die Versammlung davon, daß eine Politik der sprachlichen Anpassung gegen den Willen der Betroffe-

${ }^{157}$ Der Straßburger Jakobinerclub erhielt den Fragebogen am 7. November 1790, s. Clubprotokoll vom 7. Nov. 1790.

${ }^{158}$ Roger CHARTIER, Lesende Landsleute. Abbé Grégoires Umfrage und die Lektüre der Bauern, in: DERS., Die unvollendete Vergangenheit. Geschichte und die Macht der Weltauslegung, Berlin 1989, S. 141.

${ }^{159}$ Augustin GAZIER, Lettres à Grégoire sur les patois de France, documents inédits sur la langue, les mœurs et l'état des esprits dans les diverses régions de la France au début de la Révolution, suivis du rapport de Grégoire à la Convention, Paris 1880, Neudr.: Genf 1969, S. 71 .

${ }^{160}$ Ibid. S. 215.

${ }^{161}$ Auch den Straßburger Jakobinerclub erreichte der Brief Grégoires, eine eigene Antwort des Clubs liegt jedoch nicht vor. Der Straßburger Professor Oberlin, ein Clubmitglied, schickte 1791 eine ausführliche Broschüre an Grégoire, die jedoch nicht mehr auffindbar ist. Erhalten sind zwei Briefe Oberlins von 1791 (GAZIER, Lettres à Grégoire, S. 228f). 
nen nicht mit der Selbstbestimmung des Staatsbürgers vereinbar sei. Da im folgenden die Argumente der Befürworter der Übersetzungspolitik ausführlich behandelt werden, erübrigt sich eine detaillierte Darstellung von Bouchettes sprachpolitischen Ansichten an dieser Stelle. Wichtig ist jedoch das Resultat der Debatte: Am 14. Januar 1790 wurde in der Nationalversammlung das sogenannte Übersetzungs-Dekret beschlossen - un décret qui dit que le pouvoir exécutif sera supplié de faire publier les décrets de l'Assemblée dans tous les idiomes qu'on parle dans les différentes parties de la France ${ }^{162}$. Vorerst hatten die Anhänger einer liberalen Sprachpolitik gesiegt. In Paris wurde ein Übersetzungsbüro eingerichtet, das vor allem für die Sprachen im Süd-Westen des Königreichs zuständig war. Im Norden und Osten, also auch im Elsaß, fiel die Übersetzungstätigkeit ins Aufgabenfeld der Provinzialverwaltung.

Das Elsaß war bei weitem nicht die einzige Region im Royaume de France, in der andere Sprachen als französisch gesprochen wurden - dies war vielmehr in zwei Dritteln des Territoriums der Fall. In den Pariser Debatten um die Sprachpolitik hatte der Osten dennoch eine wichtige Rolle gespielt, und auch vor Ort war man sich der Risiken einer kulturellen Sonderentwicklung durchaus bewußt. In einem Schreiben des Straßburger Jakobinerclubs an die Stadtverwaltung hieß es: Ces démarches [gemeint ist konterrevolutionäre Propaganda] sont plus punissables encore en Alsace, où les habitudes étrangères, et l'ignorance de la langue française exposent les habitants à être égarés plus facilement sur les véritables intentions de l'assemblée ${ }^{163}$. Die Verbreitung der deutschen Sprache ließ befürchten, daß die Elsässer für die Einflüsterungen der Konterrevolution in Deutschland ein offenes Ohr haben könnten, während sie die Dekrete der Nationalversammlung mit einem verständnislosen Schulterzucken beantworteten.

Trotz des Übersetzungsdekretes der Nationalversammlung zeigte sich die Provinzialverwaltung des Elsaß, der Conseil souverain d'Alsace, zunächst nicht bereit, Schriften in größerem Umfang zu übersetzen. In einem Schreiben der Verwaltung an die Nationalversammlung hieß es: Nous n'avons pas cru devoir multiplier inutilement ces traductions et impressions d'autant que, dans la vérité du fait, il y a aujourd'hui très peu d'Alsaciens qui n'entendent le français ${ }^{164}$. Letzteres war eine bloße Behauptung, und so wurde nach einigem Drängen der zuständigen Stellen doch noch ein Übersetzungsbüro eingerichtet. Der Elsässer Andreas Ulrich, ein Pädagoge und Publizist, der zum Kreis

\footnotetext{
${ }^{162}$ Arch. Parl., Bd. 11, S. 182-185.

${ }^{163}$ Clubprotokoll vom 23. Jan. 1790. In einem Brief des Clubs an die Pariser Muttergesellschaft werden die Befürchtungen folgendermaßen zusammengefaßt: Des établissements pareils [gemeint sind Revolutionsgesellschaften] sont peut-être plus utiles dans la Province d'Alsace que dans beaucoup d'autres: son éloignement du centre commun, sa position frontière, un grand nombre d'interêts particuliers contraires à l'intérêt général y rendent une surveillance de cette nature bien nécessaire (s. Clubprotokoll vom 15. Jan. 1790).

${ }^{164}$ BRUNOT, Histoire de la langue française, Bd. 9.1, S. 103.
} 
um die Saltzmanns und die „Deutsche Übungsgesellschaft“ zu rechnen ist, wurde zum Übersetzungssekretär für das Département Bas-Rhin berufen ${ }^{165}$. Ulrich sorgte zunächst für eine komplette deutsche Übersetzung der Menschenrechtserklärung und der bisherigen Dekrete der Nationalversammlung. In seinen Wöchentlichen Nachrichten wandte er sich an die germanophone Bevölkerung.

Im Juli 1790 wurde Ulrich Mitglied der Gesellschaft der Verfassungsfreun$\mathrm{de}^{166}$. Am Tag seiner Aufnahme hielt er eine Rede, in der er sich vehement für ein zweisprachiges Elsaß einsetzte. Rhetorisch wirksam erinnerte er an die domination de langue française im Ancien Régime. In der Zeit der Freiheit dürfe es solche Formen sprachlicher Beeinflussung nicht mehr geben. In Analogie zur politischen Freiheit forderte Ulrich eine Freiheit der Sprache, die er aus den bürgerlichen Selbstbestimmungsrechten ableitete: Si la volonté de la pluralité est suffisamment éclairée et reconnue généralement utile, elle doit servir de base et de règle à tous les projets. [...] Or je vous demande, Messieurs, cette volonté de la majeure partie n'est-elle pas fondée sur les droits de l'homme et dans l'esprit de la Constitution? ${ }^{167}$ Ulrich empfahl eine zweisprachige Entwicklung:

Voulez vous donc en [des alsaciens] former des Français, employez les moyens de douceur et étudiez vous à diriger cet esprit de province vers le but général, je veux dire, l'harmonie d'ensemble. Alors, ou tout me trompe, ou cet esprit de province finira par se perdre dans l'esprit universel qui anime tous les Français [...] Le moyen le plus sûr de rendre les Alsaciens les meilleurs citoyens de la France, c'est de les familiariser avec les principes humains et la loi sainte de la Constitution [...] Ne vous flattez donc jamais d'éteindre en Alsace la langue allemande ${ }^{168}$.

Ulrich fand mit seinem Plädoyer für die Einbeziehung der deutschen Sprache breiten Anklang im Club, der seit seiner Gründung mit Verständigungsproblemen zu kämpfen hatte. Ein polnischer Student, der für längere Zeit in Straßburg studierte, liefert folgende Beschreibung einer Clubsitzung:

Rendre ce que j'ai entendu est difficile: ce mélange d'allemand et de français rendait les dicussions, je ne dirais pas plus embrouillées, car elles l'étaient déjà assez, mais au moins très comiques. Un Français demanda la parole et tint un long discours dans lequel il comparait l'état à un vaisseau

\footnotetext{
${ }^{165}$ RICHTER, Andreas Ulrich.

${ }^{166}$ PELZER, Sprachpolitik und Propaganda in Straßburg.

${ }^{167}$ Andreas ULRICH, Discours prononcé dans la séance allemande des Amis de La Constitution de Strasbourg, 6. Juli 1790 [Bibl. Nat. Univ. Str., M 5941, 79]. Nachdr. in: CERTEAU, JULIA, REVEL, Une politique de la langue, S. 277.

${ }^{168}$ CERTEAU, REVEL, JULIA, Une politique de la langue, S. 278.
} 
battu par une tempête [...] Pendant qu'il parlait, j'entendis derrière moi un bon Allemand qui demandait: 'Qu'est-ce qu'il dit?' Un autre répondit: 'Je ne sais rien, mais il faut que ce soit beau, car on rit.' Lorsqu'il eut fini, ils furent les premiers à applaudir et l'un dit: 'N'a-t-il pas bien fait son affaire? Cela fera un orateur' ${ }^{\prime 69}$.

Die ersten Schritte zu einer bilingualen Sitzungspraxis wurden im April 1790 unternommen. Das Mitglied Jacques Mathieu machte den Vorschlag, getrennte Sitzungen in deutscher Sprache einzurichten ${ }^{170}$. Die Durchsetzung seines Plans, der faktisch die Zweiteilung des Clubs bedeutete, verzögerte sich noch bis zum Sommer. Am 22. Juni wurde eine Vorlage ausgearbeitet, welche vorsah, daß vor Beginn der französischen deutschsprachige Sitzungen stattfinden sollten. Ein Vizepräsident, dem die Leitung der séance allemande oblag, sollte eingesetzt werden. Um $18 \mathrm{Uhr}$, beim Beginn der französischen Sitzung, sollte dann ein Resümee der Ergebnisse in französischer Sprache verlesen werden. Der Entwurf wurde am 26. Juni 1790 angenommen ${ }^{171}$. Am 13. Juli wurden der deutsche Präsident und seine Sekretäre gewählt; ab dem 20. Juli tagten die beiden Versammlungen separat nacheinander ${ }^{172}$. Am 3. Juli einigte man sich, daß auch die öffentlichen Lesungen, die der Club mehrmals in der Woche in seinen Räumen veranstaltete, abwechselnd in französischer und deutscher Sprache durchgefürt werden sollten. Im September war das neue Modell allerdings bereits harter Kritik ausgesetzt:

Messieurs, Cette division de nos séances en allemandes et françoises ne me paroit pas remplir le but que la société esperoit s'atteindre. On croiroit qu'il se pratiqua dans cette salle, deux cultes differens! Pourquoi séparer les françois des françois? La différence du langage doit elle être un sujet de séparation entre eux, quand leurs cours et âmes sont parfaitement d'accord! Nous avons tous juré de répandre jusqu'à la dernière goutte de notre sang pour le maintien de la constitution, et il devroit nous en coûter de consacrer quelques heures de nos loisirs à la satisfaction de nos concitoyens qui tendent avec nous au même but ${ }^{173}$.

Es wurde ein Antrag eingebracht, die Sitzungen wieder zu vereinigen und in Zukunft nur eine zweisprachige Sitzung abzuhalten ${ }^{174}$. Der Club nahm diesen Antrag an und beschloß am 17. September, Anträge und Protokolle in die je-

\footnotetext{
${ }^{169}$ H. LONGIN (Hg.), Souvenirs d'un étudiant de l'Université de Strasbourg, 1783-93, Neudr.: Strasbourg 1922, S. 28.

${ }^{170}$ Clubprotokoll vom 24. April 1790.

${ }^{171}$ Clubprotokoll vom 26. Juni 1790.

${ }^{172}$ Clubprotokoll vom 20. Juli 1790.

${ }^{173}$ Clubprotokoll vom 10. Sept. 1790.

${ }^{174}$ Antrag zur Vereinigung der Sitzungen, 14. Sept. 1790 [Arch. Mun. Str., Fonds 5/15, 6]. Rede von J. F. Weiler, 4. Sept. 1790 [Arch. Mun. Str., Fonds 5/15, 5].
} 
weils andere Sprache zu übersetzen ${ }^{175}$. Im Sommer 1791 wurde ein erneuter Versuch unternommen, eigene Sitzungen in deutscher Zunge zu etablieren; diesmal mit dauerhafter Wirkung: Am 18. Juni verabschiedete der Club ein Reglement, das drei französische und eine deutsche Sitzung pro Woche vorsah und das schließlich am 28. Oktober in die Tat umgesetzt wurde ${ }^{176}$.

Die Einfuhrung der Zweisprachigkeit zeigte, daß die Revolutionäre durchaus in der Lage waren, souverän mit Heterogenität umzugehen. In der Gesellschaft der Verfassungsfreunde wurde erneut die bereits ausführlich behandelte ideologische Konstruktion angewandt: Die durch die Sprachgrenze gegebenen Trennungen wurden unter dem Dach der politischen Einheit zusammengefaßt. Die Zugehörigkeit zu einer Sprachgemeinschaft wurde als Freiheitsrecht akzeptiert. Keine der beiden Sprachen wurde privilegiert. Auch wenn in Paris das Französische als langue révolutionnaire bezeichnet wurde, ließ man in Straßburg das Deutsche als gleichberechtigte politische Sprache zu. Weiterhin waren politische Einheit und kulturelle Vielfalt vereinbar.

\section{„Eidverweigerer" - die Kampagne gegen die katholische Kirche}

Wenige Monate nachdem es gelungen war, eine zweisprachige Sitzungspraxis einzuführen, wurde jedoch die Integrationsfähigkeit der örtlichen revolutionären Bewegung einer neuen und weitaus härteren Belastungsprobe ausgesetzt: Die geringe Akzeptanz der Kirchenpolitik der Nationalversammlung im Elsaß zeichnete sich schon seit dem Herbst 1789 ab. Seit dem Dekret über die Einziehung des Kirchenbesitzes und über dessen Verkauf als "Nationalgüter“ gärte im Niederelsaß der katholische Widerstand ${ }^{177}$. Schon an dem Tag, als das Dekret vom 2. November 1789 in Ostfrankreich bekannt wurde, sollen in Rosheim, wenige Kilometer von Straßburg entfernt, zwei Priester von der Kanzel herab alle Käufer von nationalisierten Kirchengütern mit der Exkommunikation bedroht haben ${ }^{178}$. Wenig später formulierten elsässische Katholiken ihren Protest in zahlreichen Flugblättern; kirchliche Würdenträger sandten Petitionen nach Paris, welche von den Vertretern des elsässischen Klerus, dem Abbé de Murbach, dem Abbé de Pinelle und dem Abbé d'Eymar, der Nationalversammlung bekanntgemacht wurden. Auch die Repräsentanten kritisier-

\footnotetext{
${ }^{175}$ Clubprotokoll vom 17. Sept. 1790.

${ }^{176}$ Daniel ScHÖNPFLUG, Der Straßburger Jakobinerclub und seine Propagandatätigkeit in Deutschland (1790-1794), Mag. TU Berlin 1995, S. 24-30.

${ }^{177}$ Beste Einführung in die Auseinandersetzungen zwischen Revolution und Religion im Elsaß ist nach wie vor REUSS, La Constitution civile du Clergé.

${ }^{178}$ Bericht des Kantonskommissars aus dem Jahre IV [Arch. Dépt. Bas-Rhin, 1 L 765], zit. nach R. MARX, La Révolution et les classes sociales en Basse-Alsace. Structures agraires et vente des biens nationaux, Paris 1974, S. 161f.
} 
ten die geplante Verstaatlichung: Les biens ecclésiastiques appartiennent avant tout au culte, aux pauvres, à l'éducation publique, aux hôpitaux ${ }^{179}$.

Der Club reagierte in ausgesprochen aggressivem Ton auf die weit verbreitete Verweigerungshaltung: Des prêtres factieux osent tous les jours profaner la chaire de vérité par des discours incendiaires. Profitant de l'ascendant qu'ils ont sur le peuple, ils essayent de s'en servir en confondant les interêts de la religion avec celui de leurs richesses. Ils représentent la vente des biens ecclésiastiques comme une impiété impardonnable, voulant imaginer une prière scandaleuse propre à faire renaître cet esprit de fanatisme, source des plus grands crimes ${ }^{180}$, hieß es beispielsweise in einer Ansprache des Mitgliedes Dufort vom 1. Mai 1790. Die Priester seien nur deshalb gegen die Neuerungen, weil sie um ihren Status fürchteten. Ihre frommen Worte hätten den einzigen Zweck, ihre Gier nach Macht und Reichtum zu bemänteln. Dieses Zitat belegt, wie früh die Priester im Brennpunkt der Kritik standen ${ }^{18 !}$.

Den Priestern wurde also vor allem der Vorwurf gemacht, sich zu sehr um weltliche und zu wenig um geistige Güter zu bemühen. Sie kümmerten sich nicht um die Verbreitung der Aufklärung, sondern um die Verbreitung des Fanatismus, das heißt eines der Vernunft nicht zugänglichen Glaubenssystems, um das Volk in Dummheit und Unterwürfigkeit zu halten: Défiez-vous également de ceux qui parlent de la Religion, ce n'est qu'une masque à leur hypocrisie $^{182}$, warnten die Clubbisten in einem an die Landbevölkerung gerichteten Flugblatt. Auffällig ist die häufige Verwendung des Begriffes fanatisme in engem Zusammenhang mit dem Begriff despotisme, wie zum Beispiel in dem folgenden Propagandagedicht: On voit le fer du despotisme/Epouvanter tous les mortels, Et les horreurs du fanatisme/Ternir l'éclat de tes autels./Là, des Pontifes hypocrites,/Profanant la sainte Sion,/Sous leurs pieds foulent les lévites/Et chantent les lois de Mammon ${ }^{183}$. Der anfängliche katholische Protest gegen einzelne kirchenpolitische Maßnahmen wurde unmittelbar zum Widerstand gegen die Revolution umgedeutet. Den unzulässigen Widerspruch gegen den Konsens werteten die Verfassungsfreunde als konterrevolutionär. Das schon zu dieser Zeit stark ausgeprägte Einheitsdenken führte also zur Entstehung einer ersten konkreten Freund-Feind-Konstellation auf der Grundlage kultureller Unterschiede. In dem Augenblick, als sich die Einheit als proble-

\footnotetext{
${ }^{179}$ Moniteur universel vom 12. April 1790, zit. nach MARX, La Révolution et les classes sociales, S. 163.

${ }^{180}$ Clubprotokoll vom 1. Mai 1790.

181 Weitere Hinweise auf Propaganda für die Zivilverfassung: Der Antrag des Mitgliedes Brunck, eine Adresse an die Landbevölkerung zu verfassen (Clubprotokoll vom 9. März 1790). Das Verlesen einer deutschen Adresse zum Verkauf der Kirchengüter (Clubprotokoll vom 22. Mai 1790).

${ }^{182}$ Les Amis de la Constitution aux Citoyens Cultivateurs du Département du Bas-Rhin [Bibl. Nat. Univ. Str., M 5941, 110].

${ }^{183}$ Gedicht im Clubprotokoll vom 7. Dez. 1790, in: HEITZ, Les sociétés politiques, S. $71 \mathrm{f}$.
} 
matisch erwies, wurde aus einem integrativen ein aggressives Einheitskonzept. Die Katholiken wurden ohne weitere Vermittlungsversuche ausgegrenzt; der Konflikt wurde, wegen des unbedingten Willens zur Einheit, nicht geschlichtet, sondern geschürt.

Die Verabschiedung der Zivilverfassung des Klerus im Juli 1790 führte zur Ausweitung des Konfliktes zwischen Revolutionären und traditionellen Katholiken und damit auch zu einer Verschärfung des Feindbildes vom „Eidverweigerer". Bereits im Juni 1790 emigrierte der Kopf des katholischen Widerstandes, der Kardinal de Rohan, Fürstbischof von Straßburg. Er siedelte sich wenige Kilometer von Straßburg entfernt im rechtsrheinischen Teil seiner Diözese an. In Ettenheimmünster schmiedete er Pläne zur Beendigung der Revolution mit militärischen Mitteln; von dort aus ließ er Flugblätter in Straßburg verbreiten, in welchen die revolutionäre Bewegung massiv angegriffen wurde ${ }^{184}$.

Durch Rohans offenen Widerstand bekam das Feindbild vom fanatischen, geld- und machthungrigen Priester ein noch klareres Profil. Die Propagandisten des Clubs hätten sich keine passendere Personifikation des Eidverweigerers wünschen können als eben den Mann, der einst Protagonist der Halsbandaffaire gewesen war. Nicht $\mathrm{zu}$ unrecht bezeichneten sie ihn als cet homme qui avec quinze cent mille livres de revenus, a toujours été criblé de dettes, sans avoir jamais fait un heureux; ce prêtre sans mouurs, ce vil courtisan, esclave de l'intrigue et flétri depuis longtemps par les aventures les plus scandaleuses - c'est lui que l'on met en avant comme le protecteur de la religion, quelle dérision! quand vous a-t-il donné des preuves de sa religion? Etait-ce quand il envahissait vos terres pour en faire des parcs ${ }^{185}$ ? Rohan war der Kleriker, der bedauerte, nicht mehr 1.500 .000 livres zu verdienen auxquels il n'avait pas plus de droit personnellement que le dernier de prêtres; la Religion n'est qu'un vain prétexte dont ils se masquent pour vous intéresser en leur faveur. Ce que craignent vos prêtres menteurs, ces hommes vils et fourbes, c'est d'être réduits à leurs fonctions de ministres des autels; ce que craignent leurs adhérents, c'est un gouvernement libre et équitable qui met chacun à sa place, et qui les fera un jour reconnaître comme traîtres à la patrie et ennemis du bien public ${ }^{186}$.

Der Club bemühte sich darüber hinaus, sämtliche Flugblätter Rohans und seiner Anhänger bei den Behörden anzuzeigen und durch Gegenschriften zu widerlegen ${ }^{187}$. In diesem Kontext weitete sich das Feindbild des Priesters aus:

184 Jörg SIEGER, Kardinal im Schatten der Revolution. Der letzte Fürstbischof von Straßburg in den Wirren der Französischen Revolution von Oberrhein, Kehl 1986.

${ }^{185}$ Les Amis de la Constitution aux Citoyens Cultivateurs, S. 7.

${ }^{186}$ Ibid. S. 9.

${ }^{187}$ Am 24. September 1790 wird ein Flugblatt der „Fermiers des Prébendiers de la Cathédrale", das behauptet, der Verkauf der Nationalgüter sei vertagt worden, im Club denunziert (Clubprotokoll vom 24. Sept. 1790). Am 14. Dezember 1790 wurde im Club die 
Les décrets de l'assemblée nationale, relatifs à la constitution civile du clergé catholique, sont conformes à l'écriture sainte, aux conciles et aux pères de l'église [...] Sous la Constitution déchue ce n'était que très rarement la véritable piété qui conduisit à la place d'évêque, mais [...] c'étaient presque toujours la ruse, l'égoisme, la faveur d'une maîtresse, et ainsi qu'on l'appelait jadis, la haute naissance, qui frayaient le chemin à la prélature ${ }^{188}$.

Der Angriff auf die Priester wurde insofern verschärft, als behauptet wurde, daß die Bestimmungen der Zivilverfassung zu einer Besinnung der Kirche auf ihre geistigen Wurzeln führen würden. Auch in einer Instruction patriotique et canonique des Clubs wurde so argumentiert: Les vertus des premiers pasteurs, et surtout leur charité éprouvée, leur avoient mérité le respect, l'amour et la confiance des fidèles. [...] Le temps et les passions altèrent insensiblement et finissent presque toujours par corrompre les meilleures institutions ${ }^{189}$. Diese Argumentation erlaubte es, die eidverweigernden Kleriker nicht nur als schlechte Revolutionäre, sondern auch als schlechte Christen darzustellen.

Die Verfassungsfreunde hielten dennoch an ihrem Glauben an die Vereinbarkeit von kultureller Vielfalt und neuer Ordnung fest. Ihre Angriffe richteten sich keineswegs gegen die Gesamtheit der Katholiken. Der Mehrheit der Laien traute man im Gegensatz zu den Priestern weiterhin zu, ihr religiöses Bekenntnis durch ein politisches zu ergänzen. Dennoch schwand das anfängliche Vertrauen der Clubbisten in die Solidarität der Bevölkerung merklich. Dies läßt sich an der Entstehung erster Verschwörungsängste ablesen. So wurde

schlechte Nachricht verbreitet, daß das „Mandement“ des Bischofs Rohan dennoch Verbreitung fände: Plusieurs lettres lues à la S. annoncent que, malgré la défense de l'administration, le mandement de l'Evêque a été lu publiquement dans les églises de plusieurs villages et qu'il a produit partout une certaine effervescence; que différents curés ont reçu des instructions secrètes de l'évêque; que l'on cherche à rendre douteuse la vente des biens ecclésiastiques en Alsace; que l'on calomnie d'une manière affreuse le Maire Dietrich, duquel an dit entre autres qu'il allait piller la Cathédrale. (Clubprotokoll vom 14. Dez. 1790, in: HEITZ, Les sociétés politiques, S. 72f.) Ein Beispiel für die Diskussion über Argumente gegen katholische Propaganda ist die Sitzung vom 3. November 1790: Un membre donne lecture d'une soi-disante Instruction pastorale, par laquelle le Cardinal Rohan engage, par des passages de l'ancienne loi canonique, ses ouailles à une véritable rébellion et à la guerre civile. A l'instant même un autre membre prouve le contraire de ce que l'évêque a avancé, par des décisions des pères de l'Eglise les plus respectables et les plus estimés. Un autre membre prouve par les citations des canons de plusieurs Conseils, que les Evêques doivent être élus par le peuple. La $S$. arrête la rédaction de cette réfutation, qui contiendra un extrait des canons dont il a été fait mention. (Clubprotokoll vom 3. Nov. 1790, in: HEITZ, Les sociétés politiques, S. 69).

${ }^{188}$ Flugblatt vom 31. Dez. 1790, in: HEITZ, Les sociétés politiques, S. 81.

${ }^{189}$ ANONYM, Instruction patriotique et canonique en réponse à l'Instruction pastorale de $\mathrm{M}$. l'Evêque de Strasbourg, Strasbourg 1790, S. 3/4 [Bibl. Nat. Univ. Str., M 5941, 36]. Dies war eine direkte Antwort auf eine Adresse des Kardinals Rohan vom 6. Dez. 1790: Instruction pastorale de son Altesse éminentissime Mgr le Cardinal de Rohan, prince-évêque de Strasbourg, Strasbourg 1790. 
beispielsweise die Meldung verbreitet, auf der Rheinbrücke sei eine Frau mit Rohanschen Flugblättern unter dem Rock verhaftet worden ${ }^{190}$. In einer Denunziationsschrift vom 12. Juni 1791, welche sich gegen die Eidverweigerer richtet, ist von projets des conspirateurs contre notre liberté, von complots tramés sous nos yeux, von rebelles à la loi die Rede. Ein düsteres Bild von den Eidverweigerern wird entworfen, welche den Gemeindemitgliedern mit der Exkommunikation drohten und welche mit ihren nach Deutschland geflohenen Gesinnungsgenossen heimlich in Kontakt standen, um das Land mit détestables libelles ${ }^{191} \mathrm{zu}$ überfluten.

Nach der Dekretierung des Priestereides im November 1790 entstanden in mehreren Straßburger Gemeinden Unruhen. Die Auseinandersetzungen spitzten sich im Januar $1791 \mathrm{zu}$, als das Gerücht kursierte, die Stadtverwaltung wolle die Kathedrale und einige andere Kirchen schließen oder dem protestantischen Gottesdienst zur Verfügung stellen. Am 3. Januar 1791 formierte sich in der Gemeinde von Saint-Pierre-Le-Vieux der Widerstand gegen den Versuch, das Kirchenarchiv für die Vorbereitung des Nationalgüterverkaufes auszuwerten. Eine Menge von mehreren hundert Menschen, davon offenbar der Großteil Frauen, sammelte sich in der Kirche und den umgebenden StraBen. Die Glocken wurden geläutet. Als die Nationalgarde anrückte, wurde sie mit Steinwürfen empfangen. Es gelang erst Stunden später, die Aufrührer zu zerstreuen $^{192}$.

Am 17. Januar übergab eine Abordnung von katholischen Frauen dem Départementsdirektorium eine Adresse, in der gegen die Verpflichtung zum Eidschwur Stellung bezogen wurde ${ }^{193}$. Außerdem sollen Frauen in den Kasernen der Stadt um Schutz für die katholische Religion gebeten haben ${ }^{194}$. Am selben Tag versammelten sich Vertreter der traditionellen Katholiken, um Petitionen an das Départementsdirektorium, an den König und an den Papst zu verfassen; darin wurde gefordert, die Zivilverfassung bis zu einem endgültigen Urteil des Papstes zu suspendieren; sollte dieser das Gesetz ablehnen, womit zu rechnen war, so würden sie unter Berufung auf die Religionsfreiheit an ihren alten Gewohnheiten festhalten ${ }^{195}$. Die patriotische Gesellschaft forderte den Conseil général de la Commune auf, weitere Versammlungen zu verhindern; dieser zog wenig später eine bereits erteilte provisorische Zustimmung zu den Ver-

\footnotetext{
${ }^{190}$ Clubprotokoll vom 26. März 1791, in: HEITZ, Les sociétés politiques, S. 144.

191 Adresse des Clubs an die Nationalversammlung vom 12. Juni 1791 [Arch. Mun. Str., Fonds 3/10, 199].

${ }^{192}$ REUSS, La Constitution civile, Bd. 1, S. $20 \mathrm{f}$.

${ }^{193}$ Ibid. S. 37 f.

${ }^{194}$ Ibid. S. 44f.

${ }^{195}$ Schriftstücke der katholischen Gesellschaft finden sich in: HEITZ, Les sociétés politiques, S. 96-108; sowie in [Arch. Dépt. Bas-Rhin, 1 L 832] und [Arch. Mun. Str., Fonds, 4/11, 36].
} 
sammlungen zurück ${ }^{196}$. Er verstärkte gleichzeitig die Präsenz von Militär und Nationalgarde, um für weitere Aufstände gewappnet zu sein. Der Bürgermeister bat um Beistand aus der Hauptstadt.

Die Angelegenheit hatte zu diesem Zeitpunkt bereits viel Staub aufgewirbelt. In Paris war man empört über die Entwicklung, welche die Einführung der Zivilverfassung in Straßburg nahm. Am 24. Januar 1791 erreichte die Verfassungsfreunde ein Schreiben der Pariser Muttergesellschaft, in dem diese die Ankunft dreier Volksvertreter aus Paris ankündigte. Der Straßburger Jakobinerclub beschlo $\beta$ daraufhin, diese durch eine Abordnung feierlich zu begrüBen und sie in den Club einzuladen ${ }^{197}$. Am 27. Januar 1791 waren die Kommissare Dumas, Hérault de Séchelles und Foissey anwesend. Der Präsident hielt eine Ansprache zum Lob der weisen Gesetzgebung der Nationalversammlung. Dumas antwortete mit einer Laudatio auf die Bürgertugenden der Clubmitglieder, Ihre Wachsamkeit, Ihre Festigkeit, Ihre unermüdliche Sorgfalt [...], mit welcher Sie durch die Fackel der Wahrheit die Finsternis zu zerstreuen bemüht sind ${ }^{198}$. Die Kommissare bestätigten das Verbot der katholischen Zusammenkünfte ${ }^{199}$. Am 11. Februar beschloß die Nationalversammlung, das niederrheinische Départementsdirektorium aufzulösen, das ausschließlich mit Katholiken besetzt war und das die katholischen Forderungen immer wieder unterstützt hatte ${ }^{200}$. Der Beschluß wurde von den Kommissaren wenig später umgesetzt; sie bestimmten die Zusammensetzung des neuen Gremiums ${ }^{201}$.

Das Verbot der katholischen Versammlung stellte keineswegs das Ende der offenen Opposition gegen die Zivilverfassung des Klerus dar. Katholische Flugblätter und Protestadressen kursierten weiterhin im Elsaß und gelangten auch nach Paris. Im November 1791 wurde ein Mémoire im Namen des gesamten elsässischen Klerus an die Nationalversammlung geschickt, welches daran erinnerte, daß der Vertrag von Münster der elsässischen Kirche ihren Besitz und ihre Einkünfte garantierte ${ }^{202}$. Die religionspolitischen Ziele der Revolutionäre wurden durch die Repression also wenig gefördert; das niederrheinische Département hatte im landesweiten Vergleich den geringsten Anteil von konstitutionellen Priestern. Nur 9\% der Gemeindepriester schworen dort

${ }^{196}$ Clubprotokoll vom 18. Jan. 1791. Arrêté du Conseil-Général de la Commune de Strasbourg, 24. janv. 1791 und Extrait des Registres du Corps Municipal de la Ville de Strasbourg, 13. fév. 1791 [Arch. Dépt. Bas-Rhin, 1 L 832].

${ }^{197}$ Clubprotokoll vom 24. Jan. 1791.

${ }^{198}$ Rede in der Gesellschaft der Freunde der Konstitution zu Straßburg, den 27. Jänner 1791 gesprochen von Herrn Dumas [...] in Gegenwart der Herren Fossey und Herault [Bibl. Nat. Univ. Str., M 5941, 24].

199 Proclamation des commissaires du Roi, Strasbourg 12 fév. 1791 [Arch. Dépt. Bas-Rhin, 1 L 832].

${ }^{200}$ REUSS, La Constitution civile, Bd. 1, S. $105 \mathrm{f}$.

${ }^{201}$ Ibid. S. 115.

${ }^{202}$ Mémoire du clergé d'Alsace [Arch. Nat. Paris $C^{93} 82$ (22-24)], zit. nach: MARX, La Révolution et les classes sociales, S. 162. 
den Eid. Der Distrikt Straßburg lag allerdings mit 14\% etwas über diesem Wert ${ }^{203}$. Das änderte sich auch nicht als im März das Haupt der konstitutionellen Kirche, Bischof Brendel, gewählt war ${ }^{204}$.

Die prompte Reaktion auf die Gründung einer Gegengesellschaft zeigt, daß die lokale revolutionäre Bewegung sich schnell auf die neue Situation eingestellt hatte. Das vorhandene diffuse Bild der „Gegner der Revolution“ hatte durch den Widerstand von Teilen der katholischen Kirche ein Gesicht bekommen. Die Gruppe, welche das Angebot einer neuen Ordnung ausgeschlagen hatte, war angegriffen und mit repressiven Maßnahmen konfrontiert worden. Die Verbindung von politischer Einheit und kultureller Vielfalt erschien dadurch zum ersten Mal als problematisch; auf die Katholiken begann ein Generalverdacht zu fallen. Schon zu diesem frühen Zeitpunkt dachte man an Zwangslösungen: Il faut en outre, que ces prêtres rebelles qui abusent des faveurs de la loi, soient écartés de leurs paroisses et forcées de s'éloigner de ce département ${ }^{205}$. Zu derartigen Schritten kam es 1790 und 1791 noch nicht. Es spielte sich eine Praxis der feindseligen Duldung ein, welche die lokale revolutionäre Bewegung keineswegs als Niederlage interpretierte: Erlauben sie mir hier zu bemerken, wie sehr tolerant die Freyheit, wie intolerant hingegen der Religionsdespotismus ist ${ }^{206}$. Die Entscheidung für Toleranz gegenüber der eidverweigernden Kirche erklärt sich einerseits aus praktischen Problemen: Es fehlten schlicht die Mittel, um den kirchlichen Widerstand zu brechen. Andererseits zeigt sie auch, daß das entstehende Freund-Feind-Schema nicht sofort den Traum von der allgemeinen Versöhnung zerstörte.

${ }^{203}$ TACKETT, Religion, Revolution and Regional Culture, S. 351; EPP, Le Bas-Rhin, département français au pourcentage de prêtres jureurs le plus faible; KAMMERER, Le destin du clergé d'Alsace; DERS., Le clergé constitutionnel en Alsace.

${ }^{204}$ REUSS, La Constitution Civile, Bd. 1, S. 148f. Brendel hatte selbst nur widerstrebend den Eid auf die Verfassung geschworen. In einer Rede anläßlich des Eidschwurs hatte er gesagt: Il faut donc prêter ce serment? La loi le veut, le bon citoyen obéit [...] je rendrai à César ce qui est à César, et à Dieu ce qui est à Dieu. En remplissant ce dernier devoir, je réunirai aussi religieusement ces dewx objets importants, l'Etat et la Religion. " (Discours prononcé par M. Brendel, professeur en droit canonique de l'université [...] avant de prêter son serment dans l'église cathédrale [...] le 21 févr. 1791, zit. nach: REUSs, La Constitution Civile, Bd. 1, S. 130.)

${ }^{205}$ Adresse des Clubs an die Nationalversammlung vom 12. Juni 1791 [Arch. Mun. Str., Fonds 3/10, 199].

${ }^{206}$ Rede in der Gesellschaft der Freunde der Konstitution zu Straßburg, den 27. Jänner 1791 gesprochen von Herrn Dumas [...] in Gegenwart der Herren Fossey und Herault [Bibl. Nat. Univ. Str., M 5941, 24]. 


\section{Der protestantische Weg - eine Zivilverfassung des protestantischen Klerus?}

Ganz anders als die Katholiken erlebten die Protestanten die neue Ära ${ }^{207}$. Die bereits in der Einleitung erwähnte Übertragung der Bürgerrechte an die einst als Ketzer Ausgegrenzten und die Zusicherung, daß die Straßburger Lutheraner ihre vorrevolutionären Sonderrechte behalten durften, knüpfte ein festes Band zwischen Revolution und Protestantismus. Wie die Debatte über eine eventuelle Zivilverfassung des protestantischen Klerus zeigt, taten die Straßburger Lutheraner alles, um ihre Unterstützung für das neue Regime zu demonstrieren.

Am 15. Oktober 1790 erreichte die Gesellschaft der Verfassungsfreunde ein Brief vom Comité ecclésiastique der Nationalversammlung, der die Straßburger über eine erneute Debatte der Assemblée nationale über die Kirchengüter und die Verfassung der protestantischen Kirche unterrichtete ${ }^{208}$. Das Clubmitglied Jacques Matthieu reichte gleichzeitig einen ausführlichen Antrag ein, der konkrete Vorstellungen hinsichtlich einer Reform der protestantischen Kirchenorganisation formulierte. Mathieu, ein Katholik, forderte eine vollständige Gleichbehandlung der beiden Konfessionen, sowohl in bezug auf ihre Güter als auch ihre Organisation. Die Verfassungsfreunde setzten den Antrag unverzüglich auf die Tagesordnung. Die Mitglieder wurden aufgefordert, schriftlich ihre Meinung zum Thema einzureichen ${ }^{209}$.

Die erste Reaktion kam von Christoph Willhelm Koch, Professor an der protestantischen Universität und seit November 1789 Fürsprecher der Straßburger Protestanten bei der Nationalversammlung ${ }^{210}$. Dieser gab durchaus zu, daß es philanthropische Prinzipien waren, welche den Antrag von Mathieu geleitet hätten. Er ging jedoch auf die Ideale der Revolution mit keinem weiteren Wort ein. Koch sprach als Interessenvertreter; er brachte ganz und gar pragmatische Argumente vor. Sein wichtigster Bezugspunkt war das Dekret vom 17. August 1790, das vor allem durch seinen außergewöhnlichen Einsatz entstanden war. Das Dekret nahm die Güter und Einkünfte der protestantischen Kirche vom Verkauf der Nationalgüter aus.

Dieses Dekret sei, so Koch, von den entscheidenden Gremien der Nationalversammlung für gut befunden worden, weshalb er für eine Revision weder einen Grund noch eine praktische Chance sehe. Die Vertreter der Nationalver-

\footnotetext{
${ }^{207}$ Zur Politik der Straßburger Protestanten in der Revolutionszeit: Jean RicherateaU, Le rôle politique du professeur Koch, Strasbourg 1936, S. 29-77; Rodolphe REUSs, Les églises protestantes d'Alsace pendant la Révolution, Paris 1906; Bernard VOGLER, Les protestants et la Révolution, in: RA 116 (1989/90) S. 197-205.

${ }^{208}$ Clubprotokoll vom 15. Okt. 1790.

${ }^{209}$ Clubprotokoll vom 19. Okt. 1790.

${ }^{210} \mathrm{Zu}$ Koch: RICHERATEAU, Koch; VOGLER, Les protestants et la Révolution, S. 200; Jürgen Voss, Christoph Guillaume Koch (1737-1813): homme politique et historiographie contemporaine de la Révolution, in: History of European Ideas 13 (1991) S. 531-543.
} 
sammlung hätten diese Frage im vollen Bewußtsein ihrer Bedeutung ein für allemal entschieden. Überdies seien die Güter der protestantischen Kirche zum großen Teil nicht, wie die der katholischen, Kirchenbesitz, sondern Besitz der Herrschaften und Städte. Das Dekret vom 2. November 1789, das die Verstaatlichung der Kirchengüter anordnete, behandele keinen Laienbesitz. Die Nation habe darüber hinaus kein Interesse daran, die Kirchengüter der Protestanten einzuziehen, weil sie dann auch die Pastoren besolden müßte. Der Erlös des Verkaufes der nationalisierten Güter könnte aber keineswegs die bei der staatlichen Besoldung entstehenden Kosten decken.

Koch zeigte sich vollends als Pragmatiker und Interessenvertreter als er die Versammlung fragte, wieso die Protestanten gegen ein Gesetz vorgehen sollten, das vom Porteur général des cahiers de tous les protestans für gut befunden worden sei. Er fügte hinzu: Rien de si naturel, rien de si louable même que l'empressement des Protestans à profiter du nouvel ordre des choses ${ }^{211}$. Koch machte der Versammlung einen einzigen Vorschlag: Sie möge sich an alle elsässischen Protestanten wenden, um diese von den Gesetzen in Kenntnis zu setzen, welche ihre weisen Gesetzgeber für sie verabschiedet haben und um ihnen zu erklären, daß die Revolution die Protestanten von jahrhundertelanger Unterdrückung errettet habe.

Am 26. Oktober trat ein zweiter Protestant, Friedrich Schöll ans Rednerpult und äußerte ein Wort über das Decret der Nationalversammlung vom 17ten August 1790, die Protestanten des Elsaß betreffend ${ }^{212}$. Schöll, ein Schüler Kochs, bestätigte dessen Argumente und seine Berufung auf ein Decret, um welches die Abgeordneten von fünf Gemeinen des Elsasses acht Monathe lang nachgesucht, und welches unter dem größten Theile der Protestanten eine lebhafte Freude und eine vollkommene Zufriedenheit erregt hatte. Mathieus Angriffe auf das Gesetz bezeichnete er als letzte[n] Versuch eines sterbenden Ultramontanismus, den Untergang noch einen Augenblick von sich zu entfernen. Schöll wies den Vorwurf des partheyischen Eigennutzes scharf zurück; riet jedoch dazu, den Status quo beizubehalten.

Eine erste selbstkritische Reflexion von seiten der Protestanten lieferte wenig später Philipp Jacob Engel, Diakon der Gemeinde St. Thomas. Er hielt drei Vorlesungen über die Frage: Sollen die Protestanten im ehemaligen Elsaß, ungeachtet des am 17ten August dieses Jahrs erhaltenen Dekrets, welches ihnen den Besitz ihrer geistlichen Güter bestätigt, dennoch dieselben der Nation übergeben, um ihre Geistlichkeit auf den gleichen Fuß, wie es für die katholi-

${ }^{211}$ Discours de M. KOCH sur la motion de M. Mathieu concernant les protestants d'Alsace; prononcé à la société des Amis de la Constitution à Strasbourg, le 15 Octobre 1790 [Bibl. Nat. Univ. Str., M 5941, 39].

${ }^{212}$ [Bibl. Nat. Univ. Str. M 5941, 17]. 
sche Geistlichkeit dekretiert ist, besolden und constituieren zu lassen? ${ }^{213}$ Engel beließ es nicht bei abwehrenden Erörterungen; er versuchte, die großen Fragen einzubeziehen: den Wunsch nach einer allgemeinguiltigen Verfassung ohne Sonderrechte, die Forderung nach Gleichheit auch in Religionsfragen. Die von ihm gestellte Frage - Ja wäre es nicht unser eigener Vortheil, würden wir nicht constitutionsmäßiger und der Nation inniger, vester einverleibt seyn, wenn wir derselben auch alle unsre Kirchen- und Pfarrgüter, alle Quellen der Besoldungen unserer Geistlichen hergäben, und sie von der Nation auf den gleichen Fuß, wie es für die katholische Geistlichkeit dekretiert ist, besolden und constituieren ließen ? $^{214}$ - erwog Engel ernsthaft. Ein solcher Schritt sei weder für die Nation, noch für die Protestanten vorteilhaft. Eine Nationalisierung der protestantischen Kirchengüter wäre nicht lohnend:

Ihr wisset ja unsere Armuth, oder könnet sie doch wissen. Es ist bekannt, daß die meisten unserer Prediger und Priester so gar geringe Besoldung haben, daß sie ohne alle Unterstützungen und freye Geschenke ihrer Gemeinden gar nicht leben könnten. [...] Ihr lieben Mitbürger und Brüder von der katholischen Kirche, ihr habt gewiß keine Ursache, eifersüchtig auf uns zu seyn und über Ungleichheit zu klagen; wir befinden uns gar nicht in eurem Falle. Wir hätten vielmehr Ursache, eifersüchtig auf euch zu seyn, daß wir keine solche Reichthümer besitzen, die wir der Nation anbieten können, um dem Staat aufzuhelfen ${ }^{215}$.

In einer zweiten Vorlesung ging Engel daran, ein Reformprojekt zu skizzieren, das keine Nationalisierungen vorsah und auch in dem vom Dekret vom 17. August gesteckten Rahmen durchgeführt werden konnte. Er forderte, die auffallend ungleiche und ungerechte Vertheilung der Besoldung der Geistlichen $^{216}$ aufzuheben. Weiterhin schien es ihm notwendig, die vielen vakanten Stellen im Kirchenkonvent zu besetzen. Überhaupt müsse ein besserer Ersatz für den Magistrat gefunden werden, der einst die höchste Instanz im Kirchenregiment war. Der Kirchenvorsitz müsse durch Wahlen legitimiert werden. Nur Aktivbürger der jeweiligen Konfession sollten für die Ämter der Kirche wählbar sein. Das Fundament meines Gebäudes ist, wie Sie, meine Herren, neulich gehört haben, Assimilation mit der Organisation der bürgerlichen Verwaltungen $^{217}$. Engel faßte seinen Vorschlag zusammen:

${ }^{213}$ Erste Vorlesung, gehalten in der Gesellschaft de Freunde der Constitution zu Strasbourg, den 26. October 1790, von Philipp Jacob ENGEL, Diac. zu St. Thomä [Bibl. Nat. Univ. Str., M 5941, 26].

${ }^{214}$ Ibid. S. 9.

${ }^{215}$ Ibid. S. 14 f.

${ }^{216}$ Zweyte Vorlesung, gehalten den 20. Nov. 1790, S. 5 [Bibl. Nat. Univ. Str., M 5941, 27].

${ }^{217}$ Dritte Vorlesung, gehalten den 30sten November 1790, S. 30 [Bibl. Nat. Univ. Str., M 5941, 27]. 
Laßt uns also die National-Versammlung bitten, folgendes Dekret zum Grunde einer neuen Verfassung einer Kirche zu legen: 'In Betrachtung, daß die Kirchengüter der Protestanten in den beyden Départements vom Oberund Niederrhein und die Besoldung ihrer Geistlichen so gar ungleich vertheilt sind, [...] beschließt die Nationalversammlung, daß alle protestantischen Gemeinden der Augspurgischen Confession in beiden Departements inskünftige nur eine zusammenverbundene große Commune ausmachen und alle ihre eigenthümlichen Kirchengüter zu einer allgemeinen Religionskasse vereinigen sollen ${ }^{218}$.

Zusätzlich legte Engel den Plan einer neuen auf die Grundsätze der gegenwärtigen französischen Staats-Constitution gebauten Organisation der protestantischen Kirche Augspurgischer Confession in den beyden rheinischen Departements $^{219}$ vor, der einer Zivilverfassung des protestantischen Klerus gleichkam.

Der Straßburger Club ließ sich vom Elan des reformwilligen Protestanten anstecken; die Debatten begannen am zweiten Weihnachtsfeiertag $1790^{220}$. Gleichzeitig beschäftigte sich auch eine Kommission der protestantischen Kirche mit der Frage einer Zivilverfassung. Dort wurden konkrete Vorschläge ausgearbeitet, welche denen des Clubs durchaus vergleichbar waren. Ab dem 18. Januar 1791 tagten in Straßburg Vertreter aus dem ganzen Elsaß, um einen Antrag an die Nationalversammlung fertigzustellen. Der Entwurf der Protestanten wurde am 24. Januar abgesandt ${ }^{221}$. Am 8. März reichten die Verfassungsfreunde ihren Entwurf nach, der dem der protestantischen Kommission ähnelte ${ }^{222}$.

Im Verlauf der Debatte um die Zivilverfassung des protestantischen Klerus artikulierten sich mehrere Parteien, die sehr unterschiedliche Positionen bezogen. Zunächst ergriff mit Mathieu ein Katholik das Wort, der sich, anders als die Eidverweigerer, den revolutionären Neuerungen offen zeigten. Koch und Schöll äußerten sich als Vertreter protestantischer Interessen und Privilegien. Engel und viele andere, die hier nicht zu Wort kommen konnten, plädierten für eine Revolutionierung der protestantischen Kirche. Ausgelöst durch den Antrag eines Katholiken entstand so eine Debatte, welche eindrucksvoll die Reformbereitschaft der Protestanten und ihre Verbundenheit mit der Revolution

${ }^{218}$ Ibid. S. $34 \mathrm{f}$.

${ }^{219}$ Ibid. S. 45.

${ }^{220}$ Clubprotokoll vom 26. Dez. 1790. Zwischenbericht der Kommission vom 2. Jan. 1791 [Arch. Mun. Str., Fonds 3/10, 68].

${ }^{221}$ REUSS, Les églises protestantes, S. 81.

${ }^{222}$ Ibid. S. 88. Bis zum April wurden weiterhin Einzelheiten diskutiert. Besonderen Anlaß zu Debatten bot die Frage, ob zu den Urversammlungen für die Pfarrerwahl nur die protestantischen oder alle Aktivbürger einer Gemeinde zugelassen sein sollten. Die Nationalversammlung rückte trotz dieser Eingaben nicht von ihren einmal gefaßten Beschlüssen über den Status der Protestanten im Elsaß ab. Clubprotokolle vom 29. März u. 15. April 1791. 
zeigte. Was eine wirkungsvolle Gegenattacke der Katholiken hätte sein können, endete als Bestätigung der ohnehin schon engen Bindung zwischen Protestantismus und Revolution. Die Verweigerungshaltung der meisten elsässischen Katholiken trat im Vergleich mit der demonstrativen Anpassungsbereitschaft der Protestanten besonders deutlich zum Vorschein. Zu längerfristigen Streitigkeiten zwischen protestantischen Konservativen wie Koch und dem Reformflügel kam es wegen der Untätigkeit der Nationalversammlung nicht. Das Gegenteil war der Fall: Koch und seine Anhänger zeigten durchaus Kompromißbereitschaft und halfen bei der Ausarbeitung von Reformplänen; Koch wurde im März 1791 sogar als Clubpräsident gewählt. In einem Schreiben des Comité de Surveillance des Clubs hieß es: Les Luthériens et les Calvinistes [...] sont fermes; et si l'on excepte quelques têtes aristocratiques de l'ancienne magistrature, tous sont dévoués à la patrie ${ }^{223}$.

Katholischer Widerstand und demonstrative Reformbereitschaft der Protestanten legen die Vermutung nahe, daß der Konflikt zwischen revolutionärer Bewegung und Katholizismus eine Fortsetzung des vorrevolutionären konfessionellen Dualismus unter neuen Vorzeichen war. Für eine solche Deutung spricht auch eine statistische Analyse der Clubmitglieder: Die Gesellschaft der Verfassungsfreunde wurde zunehmend von den Protestanten dominiert. Bei der Gründung des Clubs waren die Katholiken noch deutlich in der Überzahl: Wir kennen die Konfession von 23 der Gründungsmitglieder, von denen 19 Katholiken, drei Lutheraner und einer Reformierter waren. Im Verlauf des Jahres 1790 ging der katholische Anteil jedoch zurück und der protestantische nahm signifikant zu. Das starke Übergewicht der Katholiken bei der Gründung blieb bis zum Juli 1790, also bis zu dem Monat, in dem die Zivilverfassung des Klerus dekretiert wurde, erhalten. Im Juli trat kein einziger Katholik dem Club bei, dagegen elf Protestanten. Nach den Unruhen am Anfang des Jahres 1791 gab es mehr als doppelt so viele Protestanten wie Katholiken im Club ${ }^{224}$. Eine Analyse der Munizipalität bestätigt die These einer zunehmenden protestantischen Dominanz in der revolutionären Bewegung. Die Munizipalität von 1790 setzte sich aus 32 Katholiken, 22 Lutheranern und zwei Reformierten zusammen. Bei den Wahlen im November 1790 besetzten die Protestanten bereits sechs Posten mehr als die Katholiken. Im Laufe der nächsten beiden Jahre gelang es den Protestanten, doppelt so viele Stadtratssitze zu besetzen wie die Katholiken ${ }^{225}$. War der Konflikt zwischen den Verfassungsfreunden

\footnotetext{
${ }^{223}$ Rundschreiben des Clubs vom 13. Feb. 1791, S. 3 [Arch. Mun. Str., Fonds 4/11, 44].

${ }^{224}$ Siehe auch Kapitel II.2, Diagramm XIV.

${ }^{225}$ Diese Aufstellung entstand durch den Vergleich der Mitgliederliste mit den von Claude Betzinger (Strasbourg) zusammengestellten Listen der Straßburger Munizipalität (lt. Procès verbal d'installation de la municipalité de Strasbourg, Strasbourg 1790 u. [Arch. Mun. Str., Reg. Adm. Mun. 200].
} 
und den Katholiken also vor allem die Fortsetzung des konfessionellen Dualismus unter neuen Bedingungen?

Gegen diese Annahme sprechen einige Argumente: Erstens darf die zahlenmäßige Überlegenheit der Protestanten im Club und in der Munizipalität nicht überinterpretiert werden. Verantwortlich dafür war nicht nur die zunehmende Identifikation der Protestanten (oder die abnehmende Identifikation der Katholiken) mit der Revolution, sondern auch die spezifische gesellschaftliche Situation des Jahres 1790. Die katholischen Gründungsmitglieder waren vor allem Garnisonsoffiziere und königliche Verwaltungsbeamte gewesen. Während Offiziere regelmäßig von Straßburg abberufen wurden, löste man die königlichen Verwaltungen nach und nach auf, so daß sich die katholische Oberschicht zusehends verkleinerte. Die Mehrheit der Straßburger Katholiken, die dann noch in Straßburg verblieb, bestand aus ehemaligen "Schirmbürgern". Diese waren arm und ungebildet; der Zugang zur Politik, d. h. zur Aktivbürgerschaft und zum Club war ihnen versperrt. Der protestantische Überschuß in Club und Verwaltung spiegelte insofern mehr und mehr die konfessionelle Verteilung in der Straßburger Aktivbürgerschaft wider.

Es muß berücksichtigt werden, daß selbst im Januar 1791 noch ein Drittel der Mitglieder katholisch war; überdies ging das Übergewicht der Protestanten im Club im Verlauf des Jahres 1791 wieder zurück. Schließlich ist in diesem Kontext zu bedenken, daß der Club das Forum der vehementesten katholischen Vertreter der konstitutionellen Kirche war. Beleg dafür sind die 31 Clubmitglieder, welche Posten in derselben innehatten ${ }^{226}$. Der Angriff auf die „Eidverweigerer“ war insofern durchaus ein protestantisch-katholisches Gemeinschaftsunternehmen.

Zweitens ist daran zu erinnern, daß es in Straßburg am Vorabend der Revolution keinen ausgeprägten Konfessionskonflikt mehr gab und daß spätestens in den 1780er Jahren Feindschaft und Konflikt einem zwar mißtrauischen und prekären, aber im großen und ganzen funktionierenden Nebeneinander gewichen waren. Um die oben umrissene These zu untermauern, wäre demnach nachzuweisen, daß die konfessionellen Konflikte in der Revolution wieder auflebten. Dafür sprechen jedoch nur wenige Indizien: In den elsässischen Cahiers de doléances hatte sich vereinzelt gezeigt, daß sich Katholiken und Protestanten von einer Phase der Veränderungen auch eine Stärkung der eigenen Position erhofften. Am plakativsten ist die - allerdings isolierte - Forderung des Klerus von Belfort und Huningue, daß die katholische Kirche die

${ }^{226}$ EPP, Le Bas-Rhin, département français au pourcentage de prêtres jureurs le plus faible. KAMMERER, Les prêtres allemands, S. 285ff. DERS., Le destin du clergé d'Alsace. DERS., Le clergé constitutionnel en Alsace. 
einzige rechtmäßige Kirche des Elsaß werden solle ${ }^{227}$. Weitaus moderater, aber durchaus in scharfem Ton abgefaßt, war die Beschwerde des katholischen Klerus von Colmar und Schlettstatt. Die unrechtmäßig erbauten Kultstätten der Protestanten in Straßburg und Ribeauvillé sollten abgerissen werden; auch nach dem Edikt vom November 1787 sollten alle Hoffnungen der Protestanten auf königliche Chargen im Keim erstickt werden ${ }^{228}$. Auf diese Forderungen reagierten die protestantischen Städte, die in ihrem unautorisierten Cahier mehrere Kirchen, die in den letzten Jahrzehnten katholisch geworden waren, zurückforderten, sowie die Zulassung der Protestanten zu Ämtern in der königlichen Verwaltung und die Möglichkeit der Ehescheidung und der protestantischen Taufe von Kindern aus gemischten Ehen verlangten ${ }^{229}$. Diese Forderungen zeigen, daß die Konkurrenz zwischen den Konfessionen nach wie vor bestand, daß es jedoch übertrieben wäre, von einem heftigen konfessionellen Konflikt im Jahr 1789 zu sprechen.

Darüber hinaus muß betont werden, daß auch in der Zeit des Kampfes für und wider die Zivilverfassung des Klerus von beiden Seiten kaum Argumente kamen, welche eine Verankerung des allerdings vehementen Streites zwischen Revolution und eidverweigernder Kirche im konfessionellen Dualismus nahelegen. Die Protestanten, so könnte man argumentieren, hatten es nicht nötig, die alten Argumente zu mobilisieren, weil ihnen das neue Regime in so vieler Hinsicht entgegenkam. Aber auch die katholische Seite berief sich in ihrem Abwehrkampf gegen die Zivilverfassung lediglich auf den Grundsatz der Gleichheit. So hatte das vollständig mit Katholiken besetzte Départementsdirektorium in einer Adresse an die Nationalversammlung gefordert: Au moins vous ne refuseriez pas à la catholique ce que vous avez accordé aux deux religions protestantes. L'égalité des droits de l'homme déviendrait l'appui, si on ose le dire, de l'égalité du droit de religion ${ }^{230}$. Die katholische Versammlung vom Januar 1791 forderte, auch wenn sie den König daran erinnerte, daß der Katholizismus ,seine" Religion war, lediglich d'être traités comme nos frères les protestants ${ }^{231}$. Sollte also interkonfessioneller Neid in den Konflikten von 1790/91 eine Rolle spielen, so war er zumindest in die Sprache einer neuen Zeit gekleidet.

\footnotetext{
${ }^{227}$ VOGLER, Les protestants, S. 198.

${ }^{228}$ Instructions que le Clergé des districts réunis de Colmar et Selestat donne à ses députés aux Etats Généraux, in: Robert STEEGMANN (Hg.), Les Cahiers de doléances de la BasseAlsace, Strasbourg 1990, S. 90.

${ }^{229}$ Projet d'un cahier de doléances pour les magistrats et consistoires protestans des villes d'Alsace, in: STEEGMANN, Les Cahiers de doléances, S. 399ff.; REuSS, Les églises protestantes, S. 23.

${ }^{230}$ Zit. nach REUSS, La constitution civile, S. 8.

${ }^{231}$ Extrait du procès-verbal de l'assemblée des citoyens actifs, catholiques, apostoliques et romains, in: HEITZ, S. 97.
} 
Auch die Tatsache, daß sich die Katholiken an der Diskussion um die Zivilverfassung des protestantischen Klerus kaum beteiligten, spricht gegen eine konfessionelle Dynamik. Zwar hatte der Katholik Mathieu den ersten diesbezüglichen Antrag gestellt und war dafür von Schöll als Vertreter eines sterbenden Ultramontanismus beschimpft worden; danach nutzte aber kein Katholik und auch keiner der protestantischen Interessenvertreter diese delikate Debatte zu Polemiken gegen die jeweils andere Konfession. Wenn Protestanten über Katholiken und Katholiken über Protestanten sprachen, so vor allem, um durch einen Vergleich der beiden Kirchen Gleich- bzw. Ungleichbehandlung zu rechtfertigen.

Die hier diskutierten Argumente zeigen, daß sich der Konflikt zwischen revolutionärer Bewegung und eidverweigernder Kirche nicht unmittelbar aus dem konfessionellen Dualismus herleiten läßt. Vielmehr ist davon auszugehen, daß religionspolitische Auseinandersetzung und konfessionelle Unterschiede parallel bestanden und sich nur an einigen Punkten gegenseitig beeinflußten. Erstens ist, dies ist bereits angesprochen worden, die im landesweiten Vergleich besonders negative Reaktion der Straßburger Katholiken auf die Zivilverfassung vor allem durch ihr Gefühl der Zurücksetzung gegenüber den lokalen Protestanten zu erklären. Dies belegt deren häufige Berufung auf die Gleichbehandlung der Konfessionen. Der konfessionelle Dualismus prägte also die spezifische Rezeption der Zivilverfassung im Elsaß. Die Kirchenpolitik, die in Paris aus der Logik des revolutionären Kampfes gegen das Ancien Régime abgeleitet wurde, erhielt in Straßburg, vor dem Hintergrund des konfessionellen Dualismus eine andere Bedeutung.

Zweitens ist nicht von der Hand zu weisen, daß Protestantismus und Revolutionsbegeisterung in Straßburg miteinander einhergingen. Die Zugeständnisse der Nationalversammlung an ihre Kirche banden die Straßburger Lutheraner an das neue Regime. Wie die Debatte um die Zivilverfassung des protestantischen Klerus belegt, ging ihre Identifikation so weit, daß sie sogar bereit waren, ihre im August 1790 bestätigten Sonderrechte für die Ideale der Revolution aufzugeben. So erwuchs für viele Straßburger Protestanten aus konfessioneller Identität politisch-ideologische Zugehörigkeit. Es waren die stark entwickelten Gefühle des Einverständnisses mit dem neuen Regime, welche die patriotischen Protestanten - wie die überzeugten katholischen Revolutionäre auch - zum Angriff gegen die eidverweigernde Kirche bewegten. Ihre konfessionelle Gebundenheit stand ihnen bei einer solchen Initiative zumindest nicht im Wege; es kann sogar angenommen werden, daß sie förderlich war. Die Existenz einer von ihrer Sache überzeugten, darüber hinaus zahl- und einflußreichen Gruppe wie der protestantischen Patrioten trug sicherlich zur Eskalation der religionspolitischen Konflikte bei.

Deshalb kann man jedoch nicht sagen, daß der Straßburger Protestantismus insgesamt politisiert und ideologisiert wurde, daß sich die protestantischen 
Gemeinden geschlossen in eine politische Partei oder die konfessionelle Konkurrenz vollständig in eine politische verwandelt hätten ${ }^{232}$. Ebensowenig läßt sich die eidverweigernde Kirche zutreffend als konterrevolutionäre Bewegung beschreiben. Konfessionelle Interessengruppen bestimmten noch und politisch-ideologische Gruppierungen schon das politische Leben; beide gingen ineinander über und überschnitten sich, was die beteiligten Personen angeht. Politik und Gesellschaft von Straßburg befanden sich in einem Übergangsstadium, das allerdings noch lange Bestand haben sollte.

Im Rahmen unserer Fragestellung sind noch andere Schlußfolgerungen aus den religionspolitischen Geschehnissen des Jahres 1790/91 zu ziehen: Zunächst ist festzuhalten, daß die Auseinandersetzungen zwischen revolutionärer Bewegung und eidverweigernder Kirche Ideologie und politische Kultur des Clubs veränderte. Während man anfangs die leere Formel „Gegner der Revolution" benutzte, hatte man jetzt konkretere Vorstellungen von Freund und Feind. Der Kardinal de Rohan, seine Propaganda und seine Anhänger gaben reichlich Anschauungsmaterial. In der Vorstellung der Clubbisten festigten sich Bilder von Revolution und Konterrevolution, die in allem gegensätzlich waren: Hier Aufklärung, dort Fanatismus, hier Gemeingeist, dort Eigennutz, hier Blick in die Zukunft, dort Verharren in der Vergangenheit. Durch diese Art der Dialektik gelangte man auch zu einer schärferen Abgrenzung der eigenen Gruppe von der Umgebung. Während man ursprünglich von einem ,guten Volk" und einer weltweiten Verbrüderung ausgegangen war, betrachtete man die Umwelt jetzt mißtrauischer; davon zeugt die Entstehung der ersten Verschwörungstheorien und die Vorstellung vom „Volk“ als einer neutralen Masse, welche auf die eine oder andere Seite gezogen werden konnte. Dies bedeutete auch, daß sich die Legitimationsstrategien der neuen Straßburger Führung ändern mußten. Sie waren nun nicht mehr die übergeordnete Gruppierung, die alle anderen hinter sich vereinen konnte, sondern eine starke und selbstbewußt auftretende Partei, die sich zutraute, Konflikte zu führen und zu gewinnen. Dies hielt sie allerdings nicht davon ab, die Politik des Ausgleichs in den Bereichen weiterhin legitimatorisch zu nutzen, wo sie unproblematisch schien; so würde sich das Weiterbestehen des Kosmopolitismus und der liberalen Sprachpolitik auch nach dem Sommer 1790 erklären.

Das Feinbild des „Eidverweigerers“ legt nahe, daß es Überlagerungen von Kultur und Politik geben konnte, welche das Konzept der doppelten Zugehörigkeit außer Kraft setzten. Entgegen den im letzten Kapitel beschriebenen Konzepten zur Verbindung von Einheit und kultureller Vielheit, ging man jetzt mehr und mehr davon aus, daß Katholizismus und Konterrevolution Hand in Hand gingen. Daraus leitete sich bereits zu diesem frühen Zeitpunkt

${ }^{232}$ Vgl. Claude LANGLOIS, La fin des guerres de religion: La disparition de la violence religieuse en France au 19e s., in: FHS 21, 1 (1998), S. 3-26. 
der Wunsch nach hartem Durchgreifen ab; dies belegt der zu dieser Zeit noch isolierte Antrag, die Eidverweigerer zu deportieren. In der Verbindung von klarer verbaler Abgrenzung gegenüber dem Gegner, ersten Verschwörungsängsten und dem Erwägen von harten Maßnahmen zeigen sich erste Ansätze zu einer radikalen politischen Kultur. Die ,große Familie“, das Leitbild am Anfang der Clubgeschichte, war kleiner geworden; die erste Verschwörung, in die eine kulturell definierte Gruppe einbezogen war, geboren. Es hat sich gezeigt, daß Einheitskonzepte nur so lange harmonisierend wirkten, wie sich kein Widerspruch regte. $\mathrm{Da}$ Abweichler im revolutionären Einheitskonzept nicht vorgesehen waren, mußten sie ausgegrenzt und der Repression ausgesetzt werden. War Dissens entstanden, trugen Einheitskonzepte eher zur Eskalation als zur Schlichtung von Konflikten bei. So setzte sich schon in der Frühzeit der Clubgeschichte der Mechanismus der Radikalisierung in Gang. 